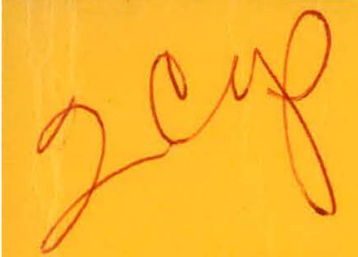

GEAP -5536

SEPTEMBER 1967

\title{
PRESSURE SUPPRESSION/GRAVITY FLOODING CONTALMENT SYSTEM FOR METROPOLITAN SITING OF LARGE POWER REACTORS
}

W.A. SUTHERLAND

J.E. HENCH

J.L. MURRAY
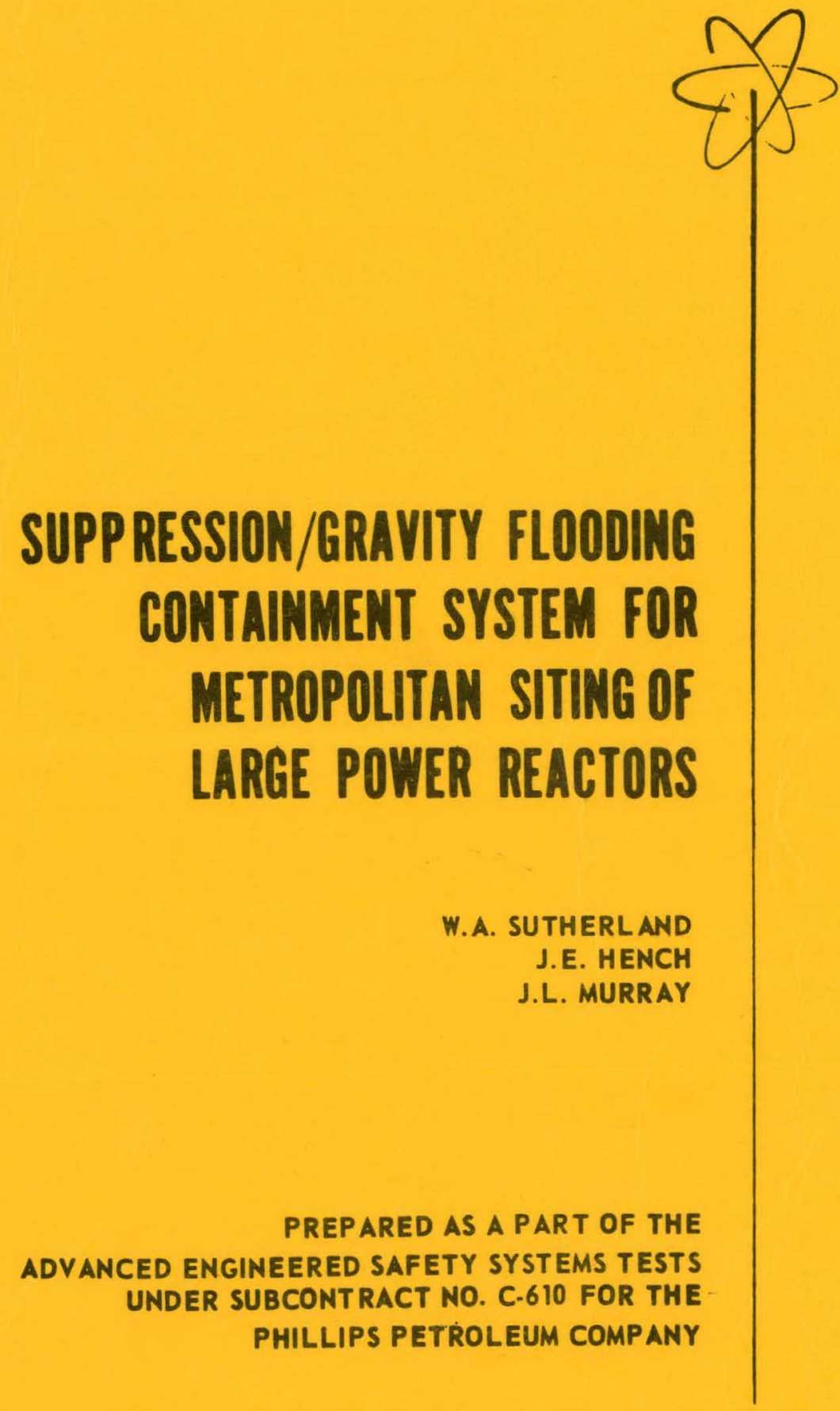


\section{DISCLAIMER}

This report was prepared as an account of work sponsored by an agency of the United States Government. Neither the United States Government nor any agency Thereof, nor any of their employees, makes any warranty, express or implied, or assumes any legal liability or responsibility for the accuracy, completeness, or usefulness of any information, apparatus, product, or process disclosed, or represents that its use would not infringe privately owned rights. Reference herein to any specific commercial product, process, or service by trade name, trademark, manufacturer, or otherwise does not necessarily constitute or imply its endorsement, recommendation, or favoring by the United States Government or any agency thereof. The views and opinions of authors expressed herein do not necessarily state or reflect those of the United States Government or any agency thereof. 


\section{DISCLAIMER}

Portions of this document may be illegible in electronic image products. Images are produced from the best available original document. 
$+$

PRESSURE SUPPRESSION/GRAVITY FLOODING

CONTAINMENT SYSTEM FOR

METROPOLITAN SITING OF LARGE POWER REACTORS

W. A. Sutherland

J. E. Hench

J. L. Murray

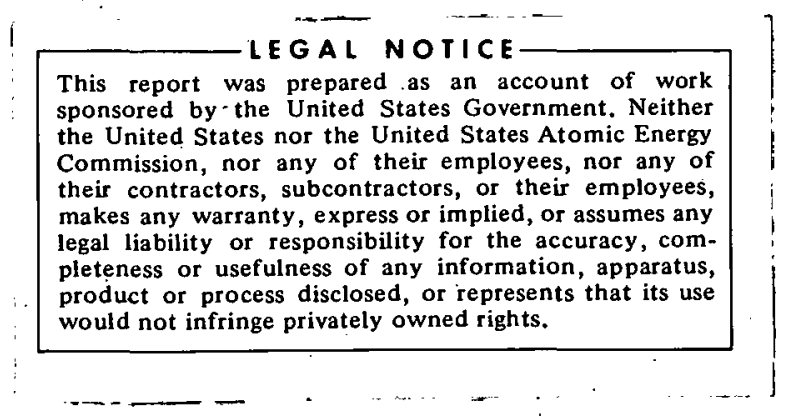

Approved:

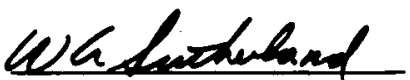

W. A. Sutherland

Project Engineer

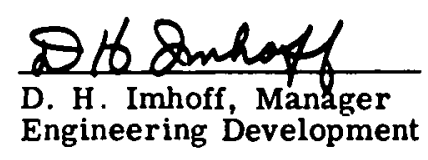

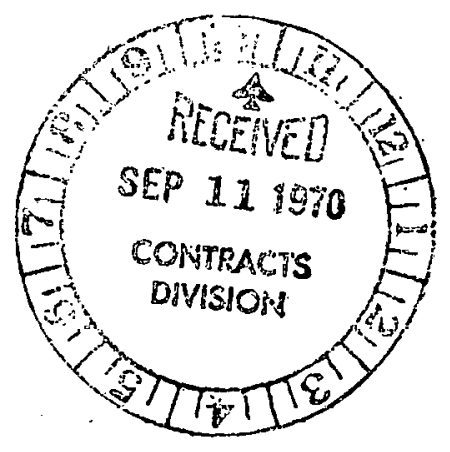




\section{LEGAL NOTICE}

This report was prepared as an account of Government sponsored work. Neither the United States, nor the Commission, nor any person acting on bebalf of the Commission:

A. Makes any warranty or representation, expressed or implied, with respect to the accuracy, completeness, or usefulness of the information contained in this report, or that the use of any information, apparatus, metbod, or process disclosed in this report may not infringe privately owned rights; or

B. Assumes any liabilities with respect to the use of, or for dam. ages resulting from the use of any information, apparatus, method, or process disclosed in this report.

As used in the above, "person acting on bebalf of the Commission" includes any employee or contractor of the Commission, or employee of such contractor, to the extent that such employee or contractor of the Commission, or employee of such contractor prepares, disseminates, or provides access to, any information pursuant to bis employment or contract witb the Commission, or his employment with such contractor. 


\section{TABLE OF CONTENTS}

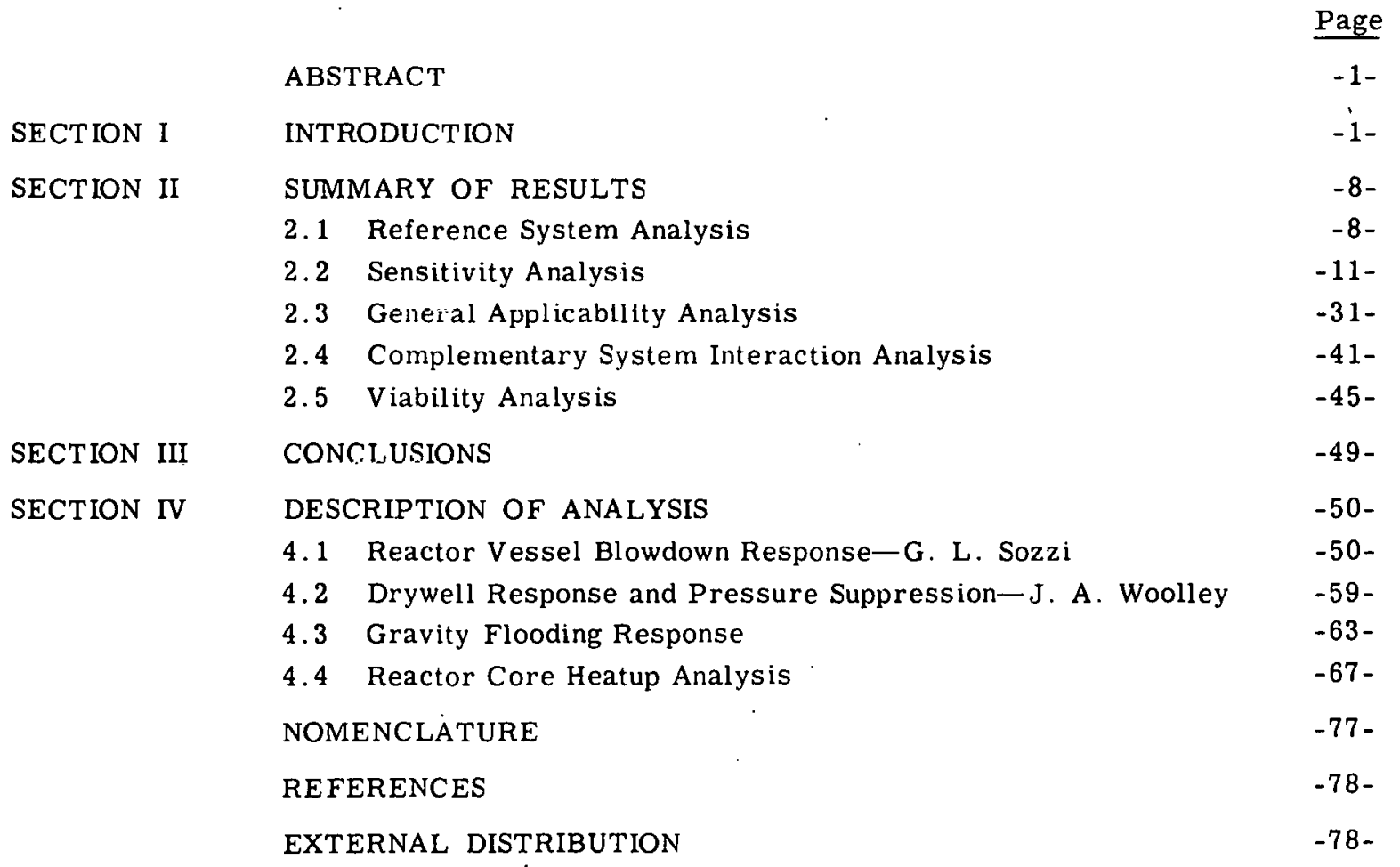




\section{LIST OF ILLUSTRATIONS}

$\underline{\text { Figure }}$

1

$2 a$

$2 \mathrm{~b}$

$2 c$

Blowdown Results for 5.5-Square-Foot Recirculation Line Break-Reference System I

Flooding Results for 5.5-Square-Foot Recirculation Line Break-Reference System I

Core Heatup Results for 5.5-Square-Foot Recirculation Line Break-Reference System I

Time to Melt Cladding versus Recirculation Line Break Area-Reference System I Time to Melt Cladding versus Steam Line Break Area-Reference System I -10Time to Begin Flooding Drywell versus Recirculation Line Break Area -Varying Floodpool Vent Flow Area, $A_{L}$ Time to Melt Cladding and Time to Flood Core versus Recirculation Line Break Area-Varying Floodpool Vent Flow Area, $A_{L}$ Time to Melt Cladding and Time to Flood Core versus Recirculation Line Break Area-Varying Liquid Flow Loss Coefficient of Floodpool Vent, $K_{L} \quad$-14Time to.Begin Flooding Drywell versus Recirculation Line Break Area - Varying Vessel Volume, $\mathrm{V}_{\mathrm{v}}$ Time to Melt Cladding and Time to Flood Core versus Recirculation Line Break Area-Varying Vessel Volume, $\mathrm{V}_{\mathrm{V}}$

' Time to Uncover Core versus Recirculation Line Break Area-Varying Loss Coefficient of Break, fL/D

Time to Melt Cladding versus Recirculation Line Break Area-Varying Loss Coefficient of Break, fL/D

Time of Peak Drywell Pressure and Time to Begin Flooding Drywell versus Recirculation Line Break Area-Varying Flood Tank Head, $\mathrm{H}_{\mathrm{L}}$

Time to Melt Cladding and Time to Flood Core versus Recirculation Line Break Area-Varying Flood Tank Head, $\mathrm{H}_{\mathrm{L}}$

Time to Begin Flooding Drywell versus Steam Line Break Area-Varying Rupturc Dick Sctting, $\Gamma_{\mathbf{R}}$

Time to Melt Cladding and Time to Flood Core versus Steam Line Break Area-Varying Rupture Disk Setting, $P_{R}$

Time to Melt Cladding and Time to Flood Core versus Recirculation Line Break Area-Varying Automatic Blowdown Vent Area, ${ }^{A} \mathrm{BV}$

'T'ime to Melt Cladding and Time to Flood Core versus Recirculation Line Break Area-Varying Auxiliary Vent Area, $\mathrm{A}_{\mathrm{S}}$ 


\section{LIST OF ILLUSTRATIONS (Continued)}

Time to Melt Cladding and Time to Flood Core versus Recirculation Line Break Area-Varying Auxiliary Vent Submergence, $\mathrm{H}_{\mathrm{S}}$

Time to Melt Cladding and Time to Flood Core versus Recirculation Line Break Area-Varying Automatic Blowdown Vent Pressure Setting, $P_{B V}$

Time to Melt Cladding and Time to Flood Core versus Recirculation Line Break Area-Reference System II

Time to Begin Flooding Drywell versus Recirculation Line Break Area - Comparison of Reference Systems I and II

Time to Melt Cladding and Time to Flood Core versus Recirculation Line Break Area-Effect of High Reactor Pressure

Time to Uncover Core versus Recirculation Line Break Area-Effect of High Reactor Pressure

Time to Melt Cladding and Time to Flood Core versus Recirculation Line Break Area-Effect of Reactor Power Density

Time to Melt Cladding and Time to Flood Core versus Recirculation Line Break Area-PWR System

Reference System III

Time to Melt Cladding and Time to Flood Core versus Recirculation Line Break Area-Reference System III

Net Time.Core is Uncovered versus Recirculation Line Break Area - Comparison of Reference Systems I, II, and III

Time to Melt Cladding and Time to Flood Core versus Recirculation Line Break Area-Effect of HPCI System

Redundant Double Rupture Disk System

Pipe Maximum Steam/Water Discharge Rate

Pipe Maximum Steam/Water Discharge Rate

Cladding Temperature versus Time-Comparison of GE Analysis with 


\section{LIST OF ILLUSTRATIONS (Continued)}

Figure

44
Title

Page

Pounds of Zirconium Reacted versus Time-Comparison of GE Analysis with NURLOC $\Lambda$ nalysis

$-73-$

Cladding Temperature versus Time-Comparison of GE Analysis with CHEMLOC Analysis

$-75-$

Pounds of Zirconium Reacted versus Time-Comparison of GE Analysis with CHEMLOC Analysis 


\section{ABSTRACT}

This report is a description and an analysis of a new containment system concept which provides a passive means for cooling the reactor core following a loss-of-coolant accident. This concept utilizes pressure suppression for quickly reducing drywell pressure and, in addition, incorporates a gravity flooding technique for automatically cooling the core. Pressure suppression: gravity flooding is a natural extension of existing technology to meet the need for improved containment systems for metropolitan siting of large power reactors. The study reflects a systems approach to nuclear reactor c ontainment and a safety design philosophy of prompt, aggressive action to arrest and contain an accident early in the transient.

The pressure suppression/gravity flooding containment system is found to be a technically feasible system which can handle, with substantial margin, the loss-of-coolant accident for a wide range of break a reas without assistance from any other engineered safety system. The system is very flexible in its application and is not sensitive to tolerance variations in system parameters. The minimum break aiea which can be handled is determined by appropriate combinations of system parameters. Therefore, the designer is free to provide other emergency core cooling systems for small breaks, if desired, and then specify the size break above which gravity flooding will be relied upon. There are many avenues for further refinement and optimization open to the designer, and the concept $\mathrm{c}$ a n be applied to other system configurations. However, to reduce this concept to practice, the need remains to extend the range of experimental information on the performance of condens ing, flooding, and venting systems.

SECTION I

\section{INTRODUCTION}

The outstanding safety record of the nuclear power industry is the result of a general recognition by the U.S. Atomic Energy Commission and the nuclear power industry of the problems of potential accidents and of the safeguards which have been implemented through aggressive $\varepsilon$ cicntific investigations to expand the knowledge and understanding of the basic phenomena involved. This understanding has been the key to the application of sound engineering principles in the design of reactor systems. The Commission and nuclear power industry recognize their common missions to extend and expand research. development, and test activities to provide a continued and increased focus on safety matters. This is reflected in the Advanced Engineered Safety Systems Tests (AESST) program, which is directed toward developing the advanced concepts for reactor containment systems which are suitable for metropolitan siting of large water reactors.
The study reported herein was undertaken as a part of the Phase I work of the AESST program to evaluate the feasibility and practicality of the pressure suppression/ gravity flooding concept as the major safeguard to mitigate the loss-of-coolant accideill. The methods, techniques, and assumptions used in the analysis reflect the state of the art at the start of the program; although it is recognized that improvements in these analytical methods have been developed in the interim, credit was not taken for them in this study because it was desired to maintain a constant basis for comparison of results: for example, the substantially greater marrin which is shown for this system by more recent information is discussed in Section IV.

The pressure suppression; gravity floodiny containment system concept is basically an extension of the established pressure 
suppression containment system currently in use. In this extended application, however, a portion of the pressure suppression pool is located above the drywell, and is used to flood the entire drywell and reactor vessel in the event of a loss-of-coolant accident (see Figure 1). The sequence of events which occurs during a loss-of-coolant accident in a suppression/flooding system is:

1. A pipe break initiates the accident.

2. The coolant leaves the primary system and pressurizes the drywell.

3. Air and steam flow from the drywell through the auxiliary pool vents into the auxiliary pool.

4. Rupture disks burst, relieving the drywell pressure.

5. Air and steam flow from the drywell into the floodpool.

6. Water flows from the floodpool into the drywell.

7. Reactor vessel vents open for venting and reflooding the vessel.

8. Water flows from the drywell into the reactor vessel, reflonding the reactor core.

An example of the reactor system and containment system response to the loss-of coolant accident is shown in Figures $2 a, 2 b$, and $2 \mathrm{c}$ for a 5.5-sq-ft break in the recirculation line. Figure 2 a shows the primary system pressure dropping rapidly as the coolant flows into the drywell. The drywell pressure rises rapidly unt il the rupture disks burst, continues to rise until the flow through the vent exceeds the flow from the reactor, and then decreases to a value slightly above atmospheric pressure. Figure $2 \mathrm{~b}$ slows the water level in the drywell and the corresponding level in the reactor vessel during the blowdown and subsequent reflooding. Figure $2 c$ shows a summary plot of the cladding temperature in the core during a loss-ofcoolant transient without any subsequent cooling: The top curve in this figure represents the hottest point in the core as a function of time. The effectiveness of the gravity flooding system is demonstrated by the margin between the time to reflood the core and the time for the hottest point in the core to reach the cladding melting point.

This report presents the results of a study to determine the capabilities of the suppression/flooding containment concept. The analysis is primarily concerned with studying the thermodynamic, hydrodynamic, and mechanical performance of the system as a passive means for absorbing the energy released because coolant is lost from the reactor and for removing the heat from the reactor core. As such, the functioning of other safeguard systems is not fundamental to this investigation, other than evaluation of how simultaneous operation of these other systems would affect the performance of the suppression/flooding system.

To evaluate the feasibility of the system the analysis was divided into five parts:

1. Reference System Analysis. The purpose of this analysis was to study the effectiveness of a reference reactor containment design which is based upon a standard BWR and a proposed suppression/flooding containment system. This system was not necessarily optimized with regard to its effectiveness as a post-accident core cooling system. Rather the reference system analysis evaluated the performance of one containment configuration and established which parameters should be investigated in the sensitivity analysis. 


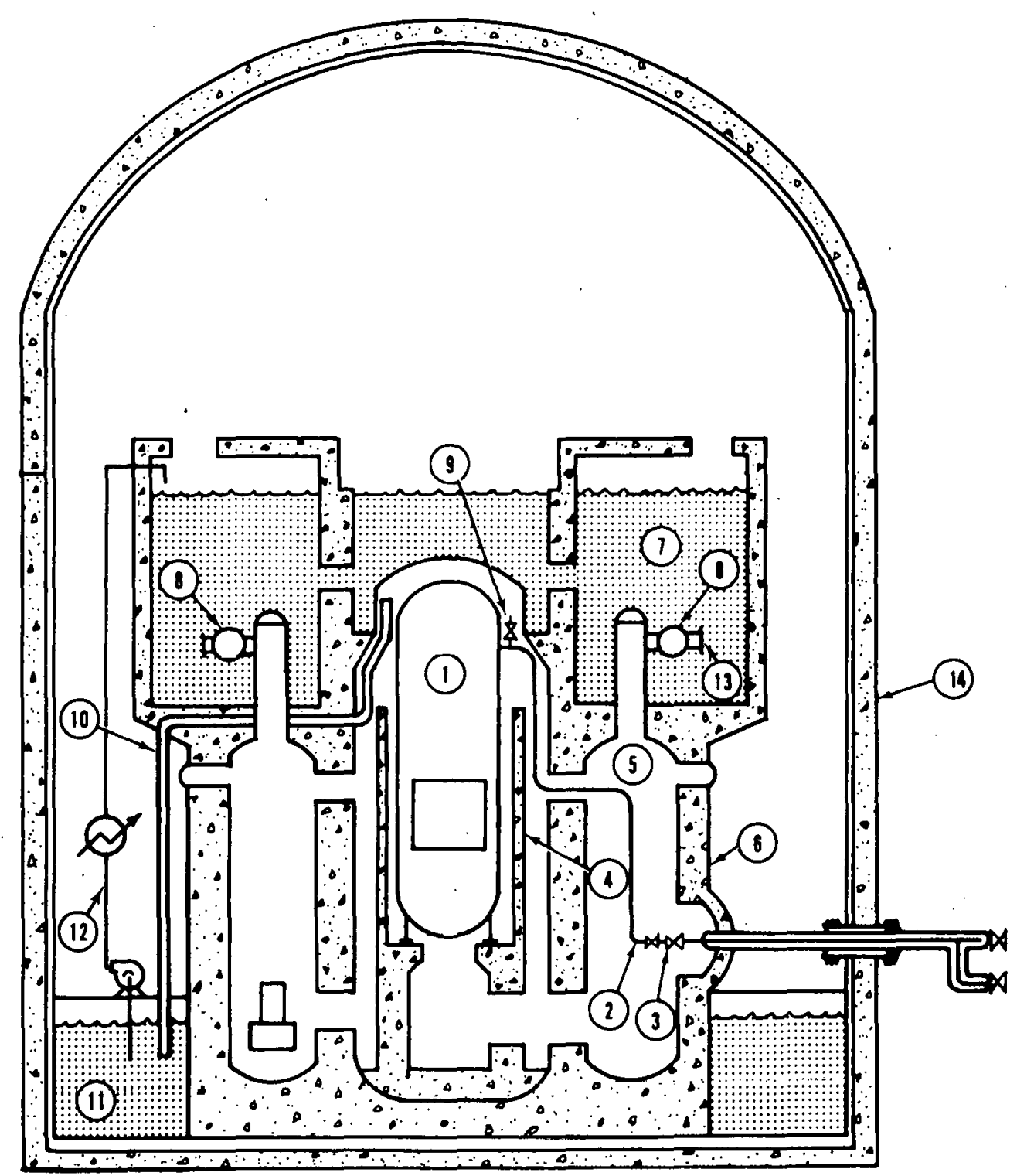

1. REACTOR VESSEL

2. MAIN STEAM LINES

3. MAIN STEAM ISOLATION VALVES

4. REACTOR COMPARTMENT

5. EQUIPMENT COMPARTMENTS

6. INNEK CONTAINMENT STRUCTURE

7. FLOOD P.OOL
8. DRYWELL VENTS

9. REACTOR VESSEL VENT

10. AUXILIARY PRESSURE SUPPRESSION VENT

11. AUXILIARY SUPPRESSION POOL

12. POST-ACCIDENT COOLING SYSTEM

13. RUPTURE DISKS

14. SECONDARY CONTAINMENT BUILDING 


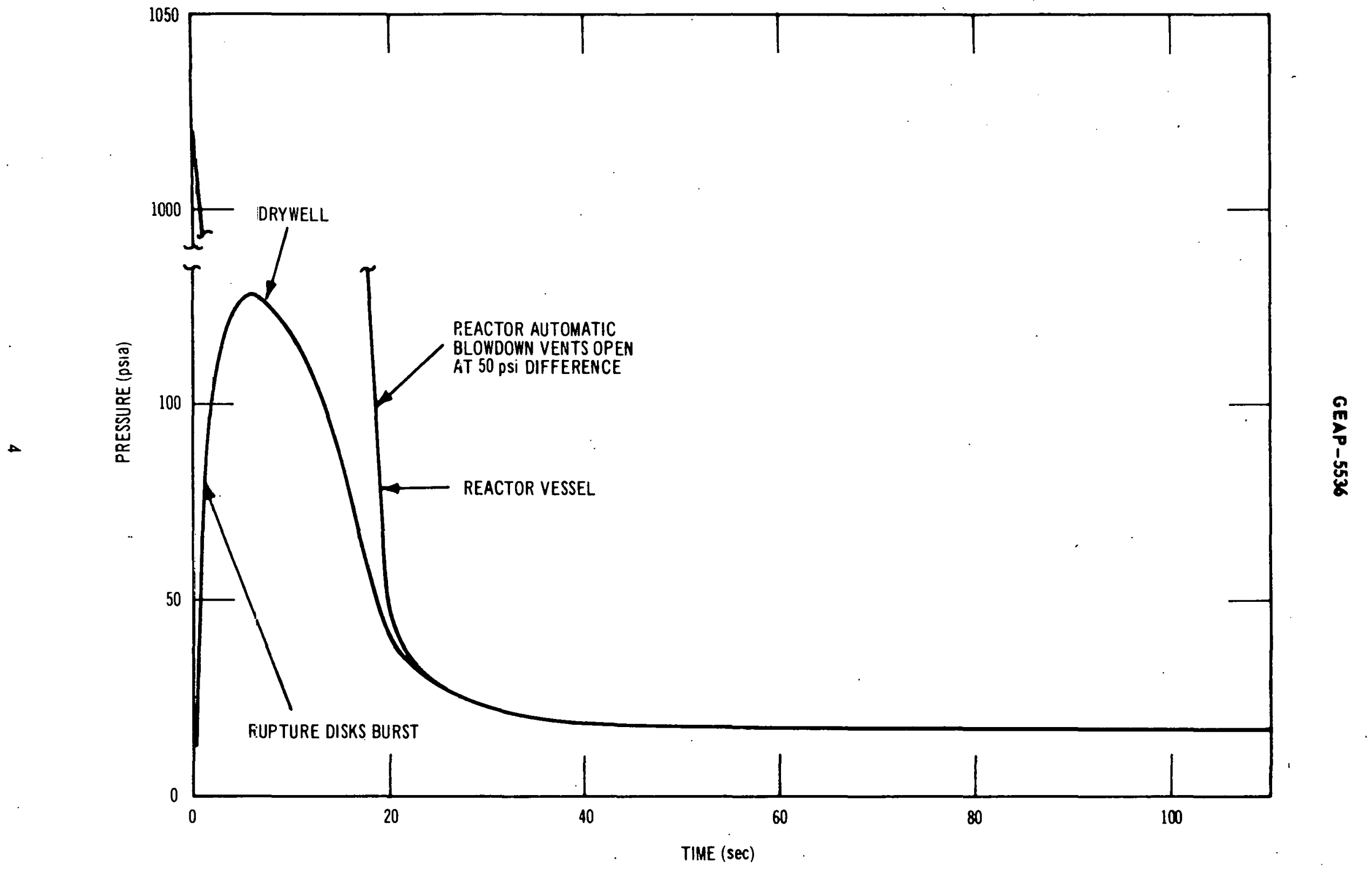

FIGURE 20. BLLWDOWN RESULTS FOR 5.5-SOUARE-FOOT RECIRCULATION

LINE BREAK-REFERENCE SYSTEM I 


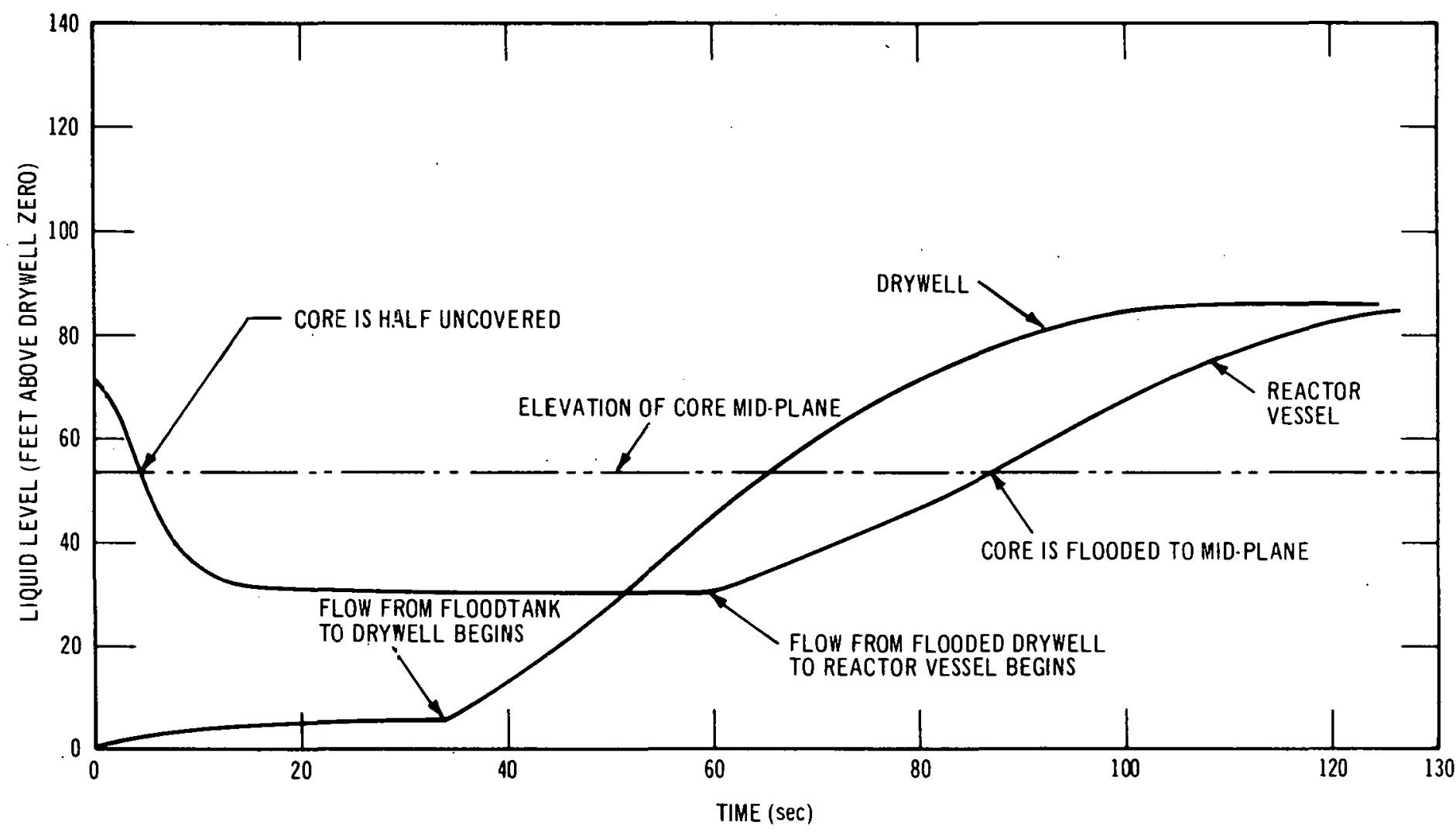




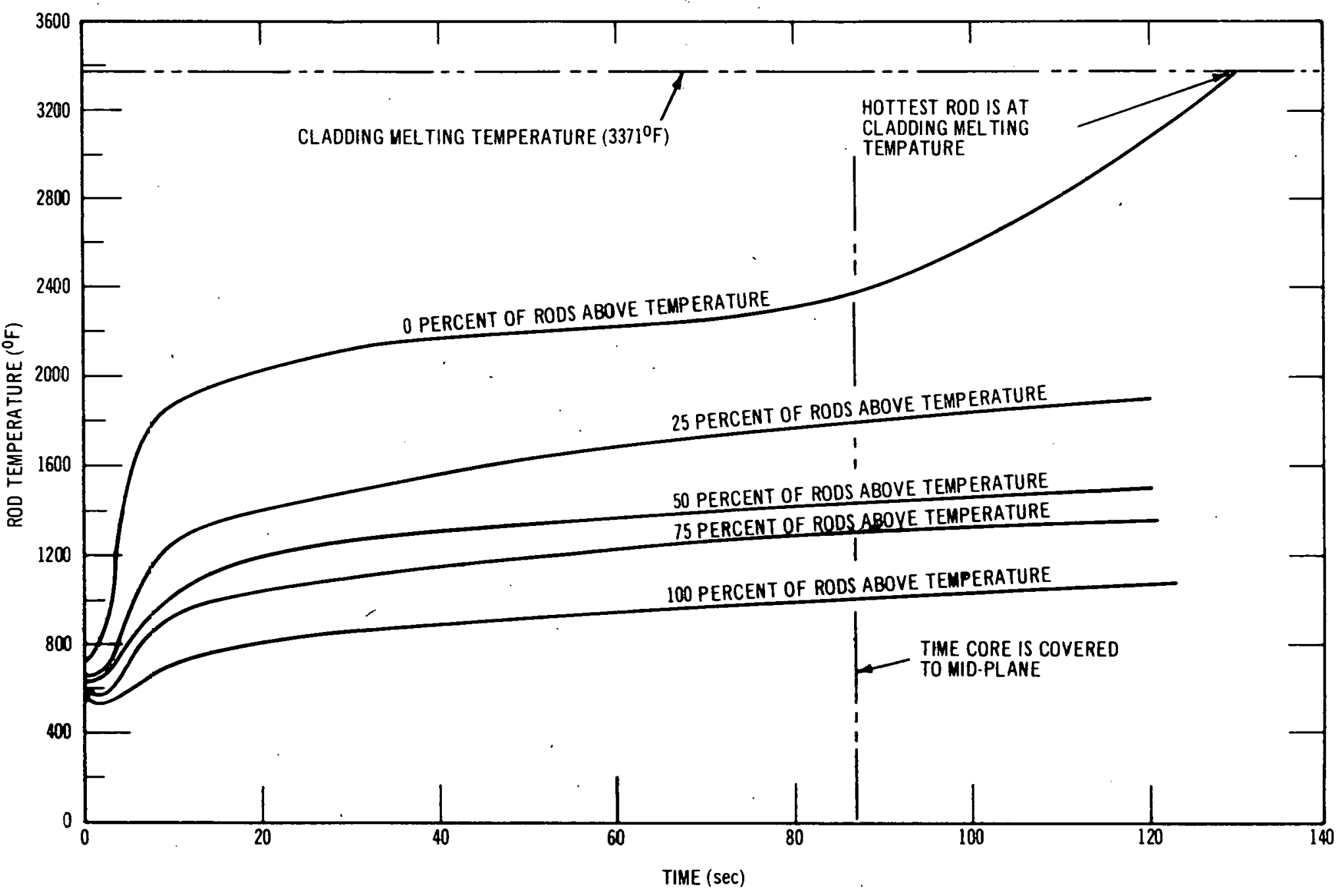


2. Sensitivity Analysis. The purpose of this analysis was to determine the sensitivity of the suppressiun. lluoding system to various system parameters and to ensure that the response of the system was not critically sensitive to any of these parameters. The sensitivity analysis also provided further understanding of, and insight into. the system performance, contributing to system improvements and optimization.

3. General Applicability Analysis. Tile purpose of this analysis was to demonstrate how the suppression floodingr concept may be applied to a bruad spectrum of reactor sizes and types. The reactor containment system design used in this part of the study incorporated the improvements and optimization developed in the Sensitivity Analysis. System performance was then investigated for reactors with higher power densities, operating pressures, etc. This study examined the suitability of the suppression; flooding concept for both BWR and PWR applications.

4. Complementary Systems Interaction Analysis. The purpose of this analysis was to determine interaction effects from operation of other emergency cooling systems (e.g., core spray) simultaneously with the suppression/ flooding system.

5. Cuniponent Viability Analysis. The purpose of this analysis was to demonstrate the viability of the suppression/ flooding concept by examining those parts of the system which are critical to its successful operation and are not already proven components in existing reactor containment concepts.
Finure 1 shows schematically the suppression; flooding containment concept. For a BWR system. the reactor vessel, all high-pressure reactor equipment, and the steam lines up to the isolation valves are housed within interconnected prestressed concrete shafts. or silos. which constitute the primary containment envelope. For a PWR system, the primary system equipment. including reactor vessel. primary pumps. steam generators, and primary system piping are housed in the interconnected shafts of the primary containment. The sequence of events following rupture of either the BWR or PWR primary system would be essentially the same. However, the functional description which follows is based on the BWR system.

The prestressed concrete primary containment envelope envisioned in the reference concept is capable of containing the initial peak pressure from a rupture of the reactor primary system without dependence on pressure suppression. This feature makes the primary containment design pressure insensitive to reactor system break size (i.e., vessel blowdown rates) and provides greater flexibility in the selection of pressure suppression vent area. For any reasonable break size the drywell pressure capability will not be approached by the actual peak pressure since the drywell will be venting into the auxiliary suppression pool, and high drywell pressure will rupture the disks which also vent the drywell to the flood tanks. At the end of the blowdown/pressure-suppression transient the water in the flood tank will llow hy gravity through the drywell vents into the drywell and inundate the reactor compartment, equipment compartments, pressure vessel, and reactor core. The reactor vessel is flooded through the break and through the two reactor vessel vents located on the side of the reactor vessel below the final flooded water level. 
The final flood tank water level, as well as the auxiliary pool water level, will remain above the vents 10 ensure condensing of any steam generated within the primary containment subsequent to the flooding action. Vents to the auxiliary suppression pool perform a pressure suppression role as well as providing the venting necessary for proper flooding of the drywell. Sizing of these auxiliary vents, together with the burst pressure selected for the rupture disks, determine the ninimum break size for which gravity flooding will occur. To ensure that a back pressure would not build up within the reactor vessel itself, and thereby prevent flooding from the primary containment into the reactor vessel, the top of the reactor is vented to the drywell by two reactor vents which are located on the reactor head. Hence, there are two types of reactor vessel vents: those located at the top of the vessel for venting of the vessel during reflooding, and those located on the side of the vessel just above the reactor core which promote faster vessel reflooding.

The gravity flooding feature, which provides a passive method for automatic core cooling, also provides additional shielding of the reactor core and an additional barrier for fission product retention after a loss-ofcoolant accident. In addition to the primary containment envelope there is a secondary envelope which encompasses the primary containment and provides a fission product barrier which prevents leakage to the environs. The design of this latter envelope is based on leaktightness requirements and is relatively independent of the details of operation of the primary containment pressure-suppression and gravity-flooding system.

\section{SUMMARY OF RESULTS}

\subsection{REFERENCE SYSTEM ANALYSIS}

The pressure suppression/gravity flooding containment system designated as Reference System I is based on a conceptual design suggested for use with a standard boiling water reactor system. As such, detailed performance calculations had not previously been made for system optimization. This investigation makes use of Reference System I as a means for initiating the investigation of system performance and for determining the important parameters for investigation in the Sensitivity Analysis. The results of the Reference System Analysis are very encouraging. The Reference System I suppression/flooding system refloods the reactor core in about $2 / 3$ of the time required for the fuel cladding to rcach the melting temperature following a recirculation line break and in about $1 / 2$ the time required for the fuel cladding to reach the melting temperature following a steam line break.

This analysis covers a range of break areas up to $10 \mathrm{sq} \mathrm{ft}$ (see Figures 3 and 4 ). For break areas of about $0.3 \mathrm{sq} \mathrm{ft}$ and smaller, the blowdown from the reactor vessel into the drywell will not burst the rupture disks, and other cooling systems are provided to cool the reactor core. Thus, compared with present-day low pressure emergency coolant injection systems, the reference flooding system offers substantially equivalent performance against small breaks (i.e., core spray typically provides protection down to the range of 0.1 to $0.2 \mathrm{sq} \mathrm{ft}$ break area) and has the usual dependence on other special systems to round out the protection against very small breaks. It should be noted that for all suppression/flooding designs there is a minimum break area below which the 


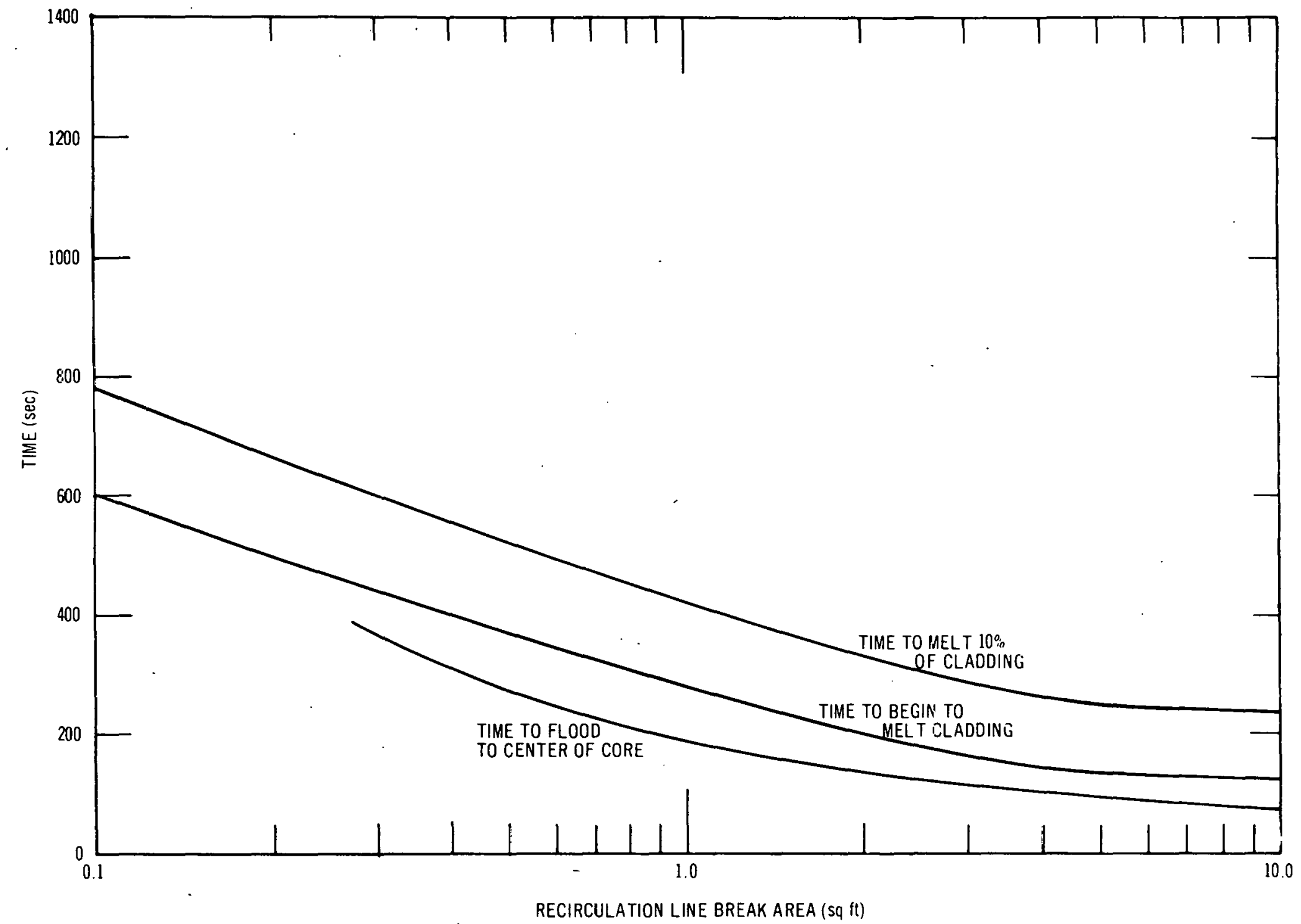




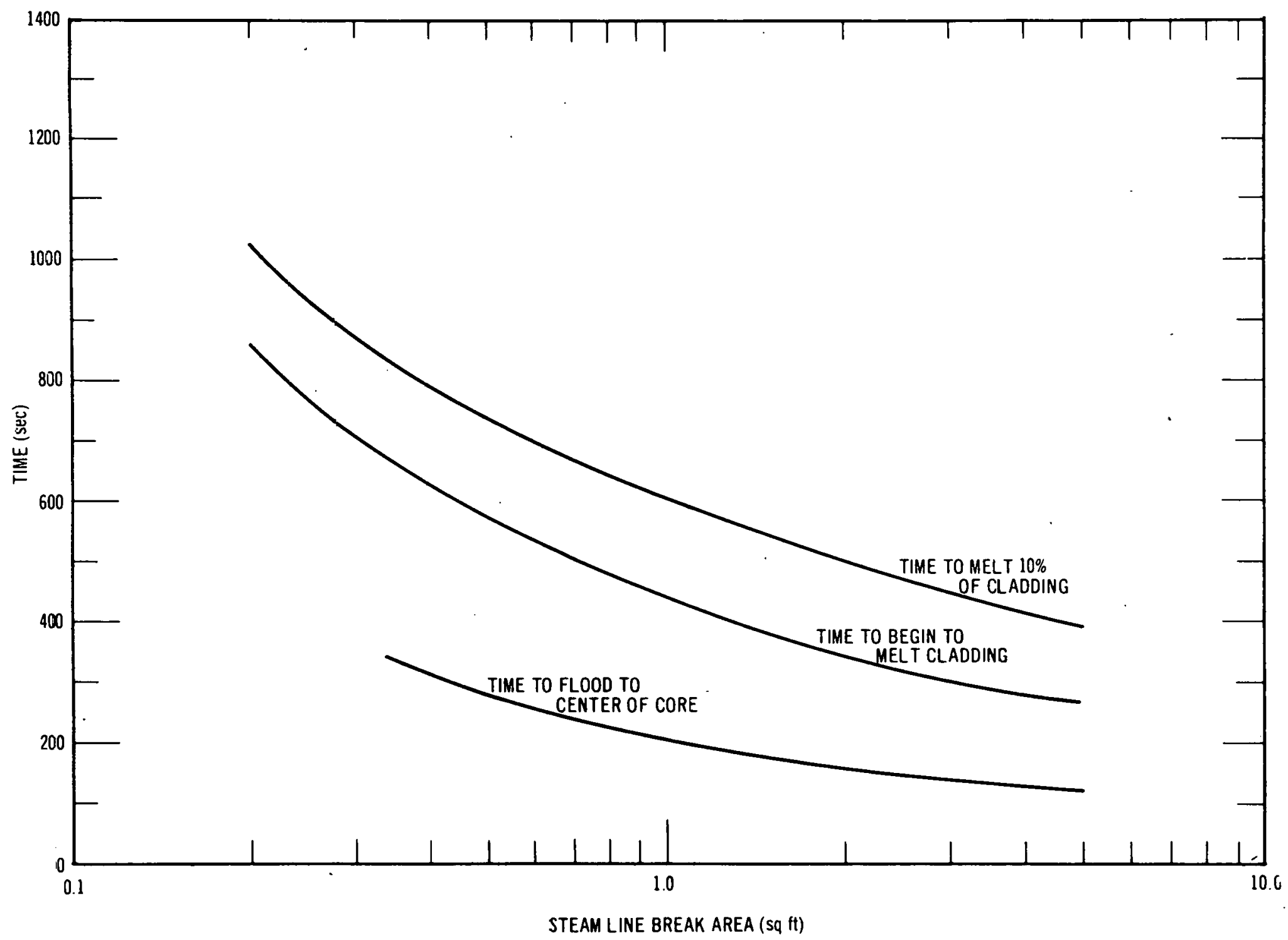


rupture disks do not burst, and that this break area is chosen by adjustimy the vent area, drywell volume, etc. The choice of the minimum break area to be cuvered by gravity flooding depends on the over-all system requirements, which include. among other things, the desirability of inundating the drywell when a small leak occurs somewhere in the system. It is entirely possible that the designer will choose not to utilize the full range of capability of the gravity flooding system. However, at this stage of development it is desirable to investigate the system's small-break capability and defer judgment on the minimum break size to be covered.

\subsection{SENSITIVITY ANALYSIS}

\subsubsection{General}

The primary function of the sensitivity analysis is to investigate the suppression. flooding system performance over a wide range of system design parameters in order to ascertain whether it is critically sensitive to variation of any one of these parameters. This analysis also provides the basis upon which parameters may be changed to improve the system performance for design optimization. The results of the sensitivity analysis showed that the suppression/flooding system is not overly sensitive to any of the design parameters studied, that there is considerable margin available for improving Reference System I, and that the suppression/ flooding system is capable of handling a wide range of loss-of-coolant accidents without additional cooling systems. An improved system, designated Reference System II, was designed using the Sensitivity Analysis results. This improved system was then studied in the General Applicability Analysis

\subsubsection{Drywell Vent Area}

The sensitivity of the system performance to changing the drywell vent area was studied by analyzing the Reference System I with vent areas of 50 and $100 \mathrm{sq} \mathrm{ft}$. (The flow area of the drywell vents for Reference System I is $75 \mathrm{sq} \mathrm{ft}$.) The effect of increasing the vent flow area is to blow down the drywell more quickly and also to flood the drywell more quickly. As shown in Figure 5, there is about 5 seconds difference in the time to blow down the drywell and begin flooding between the 50-, 75-, and 100-sq-ft cases. Figure 6 shows the cumulative effect on the time to reflood the reactor core. The $75-\mathrm{sq}-\mathrm{ft}$ vent refloods the core about 40 seconds faster than the 50-sq-ft vent, and the $100-\mathrm{sq}-\mathrm{ft}$ vent refloods about 20 seconds faster than the 75-sq-ft vent. Hence, the major gain in increasing the drywell vent area is to increase the flow rate of water from the floodpool into the drywell.

\subsubsection{Drywell Vent Loss Coefficient}

The effect of variation in the vent loss coefficient on the system performance is essentially the same as the effect of variation in vent flow area, i.e.. an increase in vent loss coefficient has the same effect as a decrease in vent flow area. Figure 7 shows the effect of changing the vent loss coefficient on the time to reflood to the midpoint of the reactor core. Reducing the loss coefficient $(k=1.51)$ results in a gain of approximately 20 seconds over the Reference System I performance. Thus, it can be seen that the reactor designer can improve the flooding time of a suppression/flooding system by reducing the losses in the drywell vent header or by increasing the vent area. 


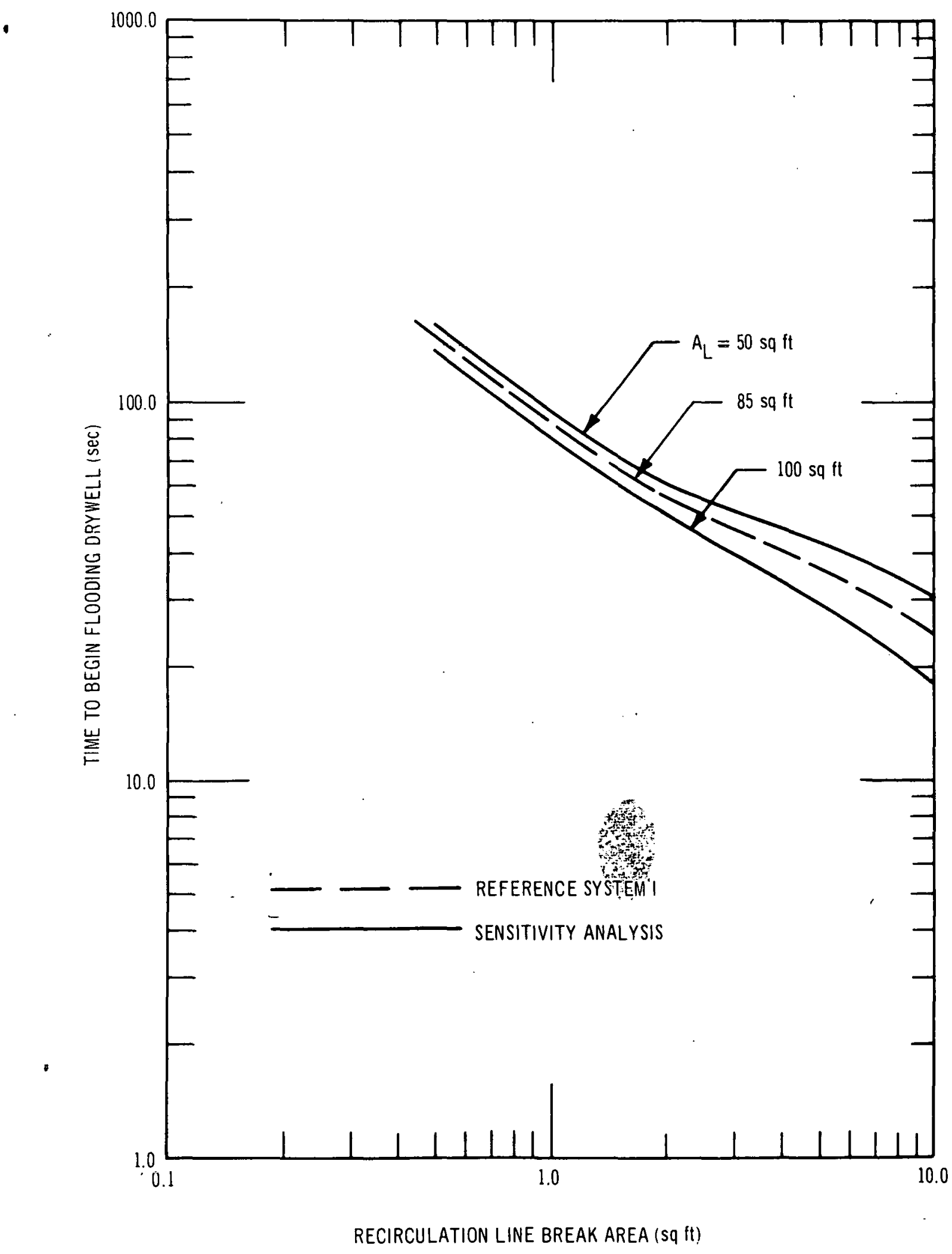

FIGURE 5. TIME TO BEGIN FLOODING DRYWELL VERSUS RECIRCULATION LINE RREAK AREA-YARYING FLOODPOOL VENT FLOW AREA, AL 


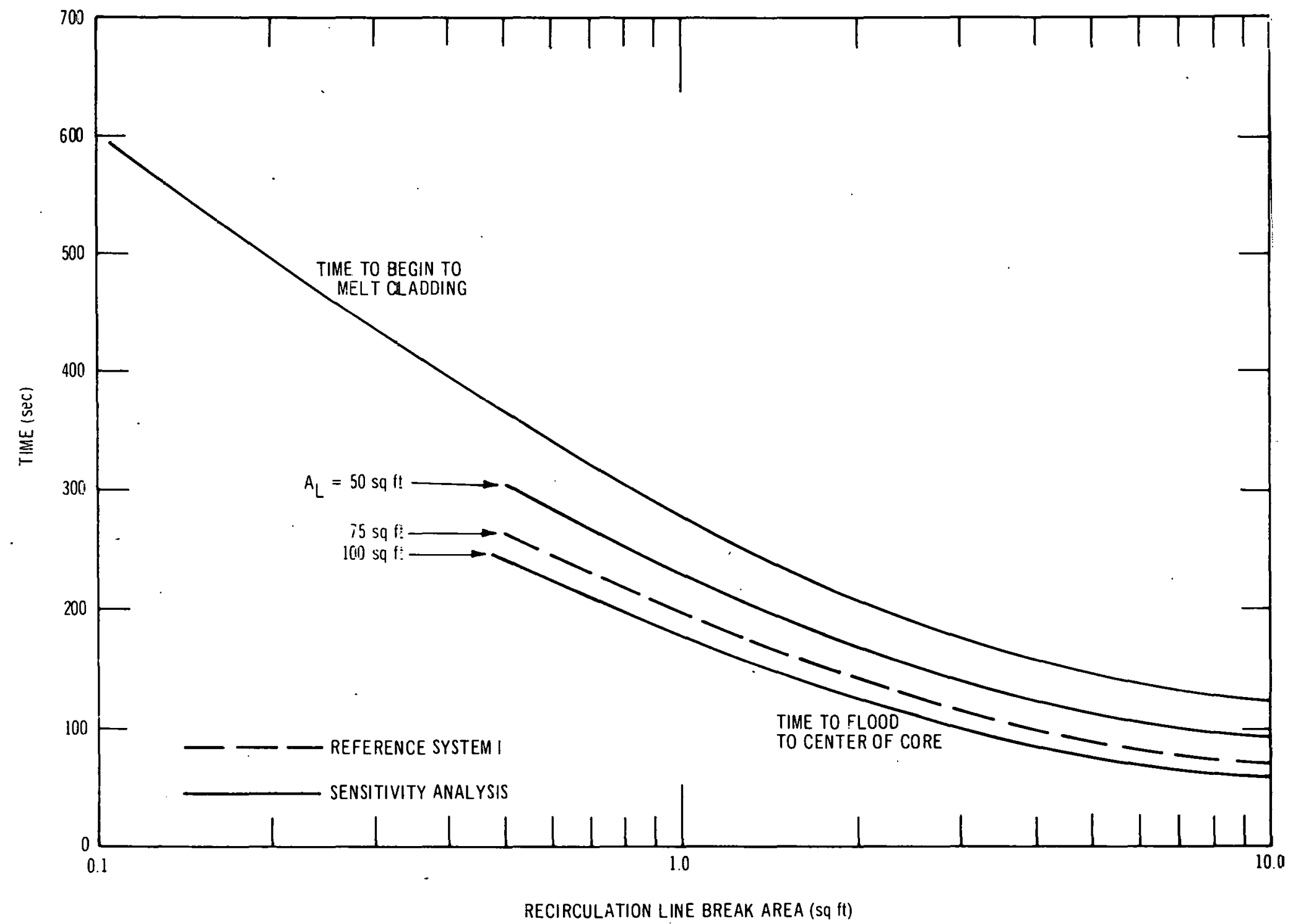

FIGURE 6. TIME TO MELT CLAODING AND TIME TO FLOOD CORE VERSUS RECIRCULATION LINE BREAK AREA-VARYING FLOODPOOL VENT FLOW AREA, $A_{L}$ 


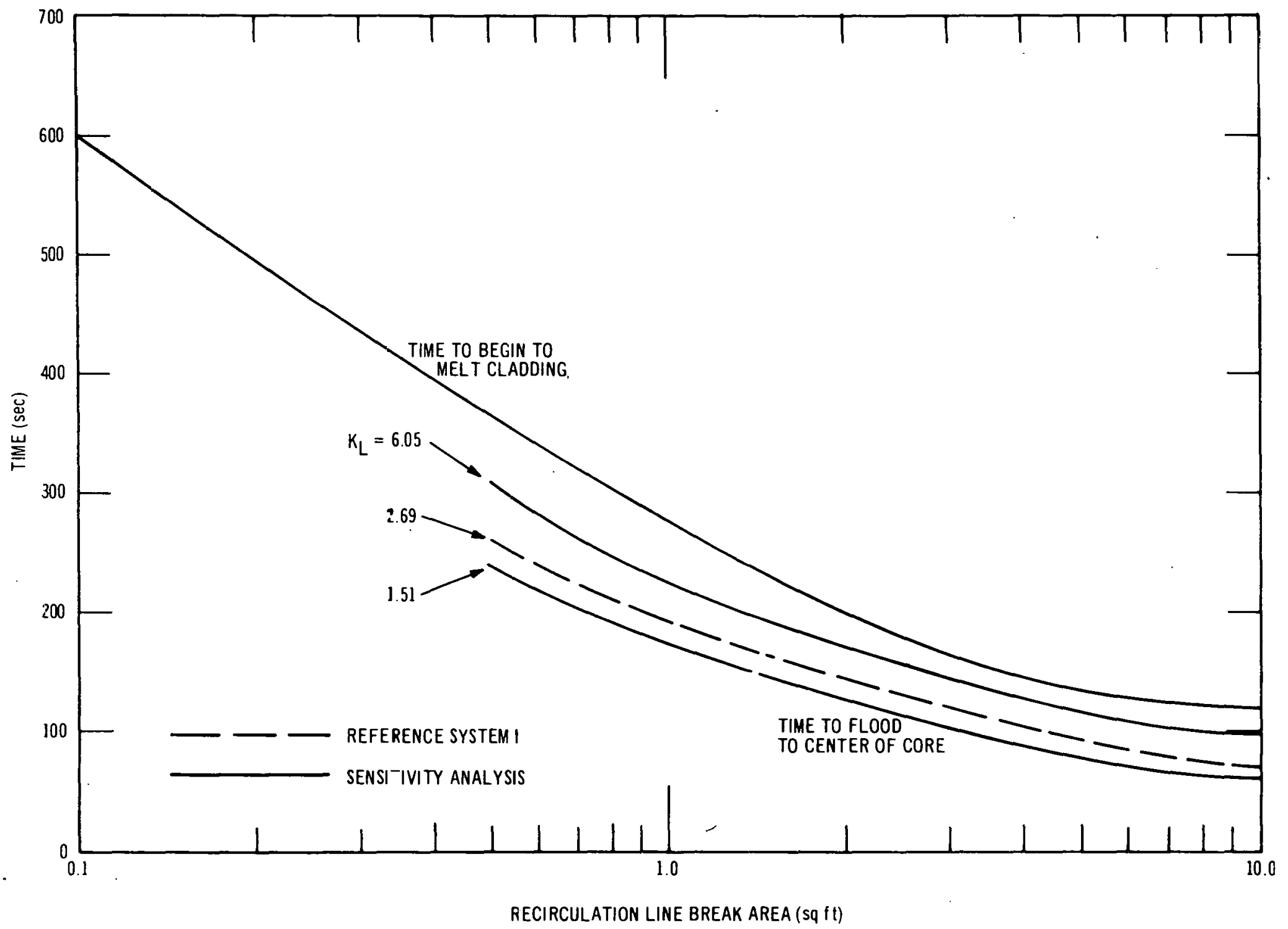

FIGURE 7. TIME TO MELT CLADDING AND TIME TO FLOOD CORE VERSUS RECIRCULATION LINE BREAR AREA -VARYING LIQUID FLOW LOSS COEFFICIENT OF FLOODPOOL VENT, $K_{L}$ 


\subsubsection{Reactor Vessel Volume}

The effect of varying the reactor vessel volume was determined by analyzing Reference System I with the reactor vessel volume changed \pm 25 percent. One effect of increasing the reactor vessel volume is to increase the stored mass and energy which will be blown down into the drywell, thereby prolonging the blowdown of the drywell and extending the time to begin flooding the drywell. Another effect of a larger vessel is the increased time required to fill the vessel to the core midpoint for a given flow rate into the vessel. Figure 8 shows the effect of vessel size on time to blow down the drywell (i.e., time to begin flooding), and Figure 9 shows the cumulative effect of drywell blowdown and the reactor vessel reflooding time on the time to reflood to the core midpoint. Comparison of these two figures indicates that a greater fill time is roughly balanced by a greater blowdown time.

\subsubsection{Hydraulic Resistance in the Blowdown $\underline{\text { Line }}$}

The effect of hydraulic losses on the pipe from the reactor vessel to the break location was studied by varying the $\mathrm{fL} / \mathrm{D}$ parameter. This parameter incorporates both flow friction and local flow losses such as valves, fittings, etc. An $\mathrm{fL} / \mathrm{D}$ ratio of zero represents a break at the vessel, while an $\mathrm{fL} / \mathrm{D}$ ratio of 20 represents an exceptionally large amount of flow resistance due to restrictions in a long run of pipe.

Because two of the reactor vessel vent valves provide unrestricted additional openings for flooding, the time required to reflood the vessel is not too sensitive to flow resistance through the break. However, as shown in Figure 10, hydraulic resistance in the ruptured pipe significantly increases the duration of the blowdown, and correspondingly delays the time when flooding can start. Figure 11 shows the cumulative effect of hydraulic resistance on increasing the time to reflood to the core midpoint. It should be noted, however, that the time to initiate cladding melting is also increased since, during the longer blowdown, the core remains covered for a greater length of time.

\subsubsection{Floodpool Water Depth}

The effect of the water depth in the floodpool was examined by analyzing Reference System I with the drywell vent raised and lowered 5 feet in the pool without otherwise changing the system. One effect of decreasing the depth of water in the floodpool over the vent is to decrease the backpressure against which the drywell must exhaust, thereby increasing the blowdown flow rates from the drywell to the floodpool and tending to decrease the time required to blow down the drywell. However, the lower back pressure associated with lower submergence depth, $\mathrm{H}_{\mathrm{L}}$, requires the drywell to blowdown to a lower absolute pressure, thereby prolonging the time to begin flooding the drywell. The latter phenomenon dominates the time to begin flooding, as can be seen in Figure 12. The system with the lowest floodpool vent submergence depth $\left(\mathrm{H}_{\mathrm{L}}=30 \mathrm{ft}\right)$ reaches peak pressure first, but is the last to begin flooding. Another effect of decreasing the water depth over the vent is to reduce the water flow rate into the drywell during flooding. Figure 13 illustrates the cumulative effect of these factors: the system with a $30-\mathrm{ft}$ vent submergence is about 10 seconds slower to reflood to the core midpoint than the system with a 35-ft vent submergence, while the time to begin flooding is only about $5 \mathrm{sec}-$ onds longer for the $\mathrm{H}_{\mathrm{L}}=30 \mathrm{ft}$ case than for the $\mathrm{H}_{\mathrm{L}}=35 \mathrm{ft}$ case. Therefore, the net effect of decreasing the water depth over the floodpool vents is to increase the time to reflood the core. 


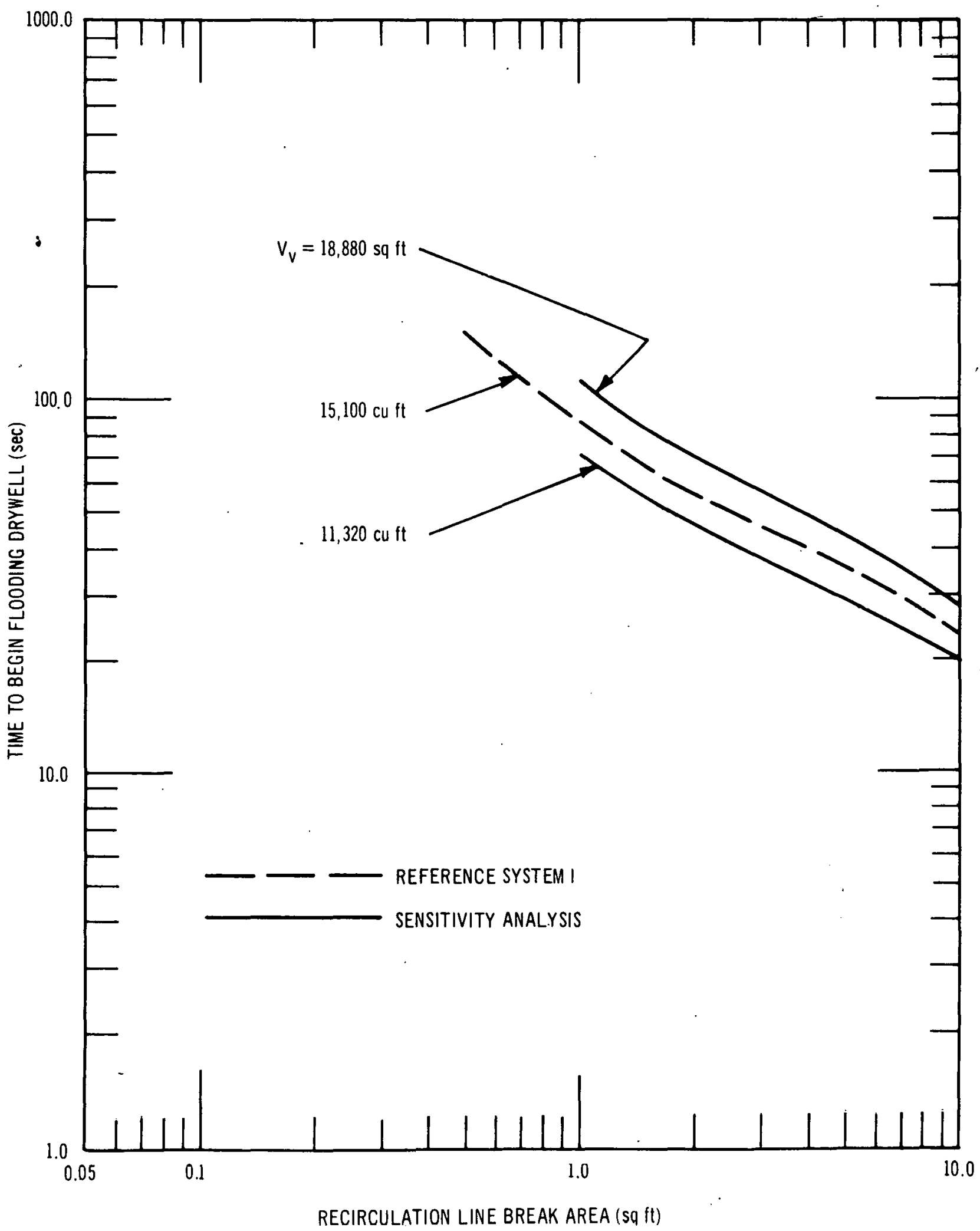

FIGURE 8. TIME TO BEGIN FLOODING DRYWELL VERSUS RECIRCULATION LINE BREAK AREA-VARYING VESSEL VOLUME, $v_{v}$ 


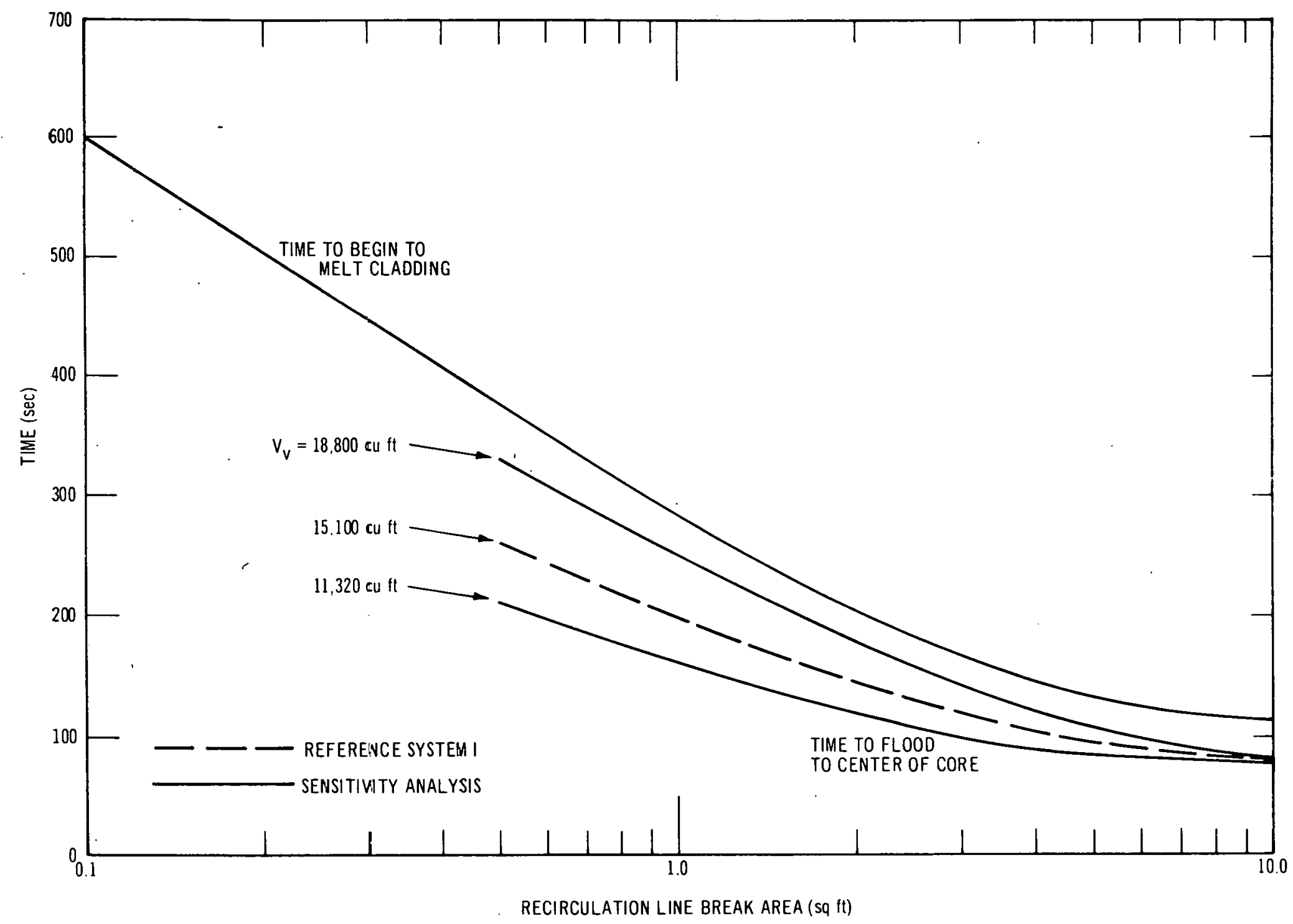

FIGURE 9. TIME TO MELT CLADDING AND TIME TO FLOOD CORE VERSUS RECIRCULATION LINE BREAK AREA-VARYING VESSEL VOLUME, $V_{v}$ 


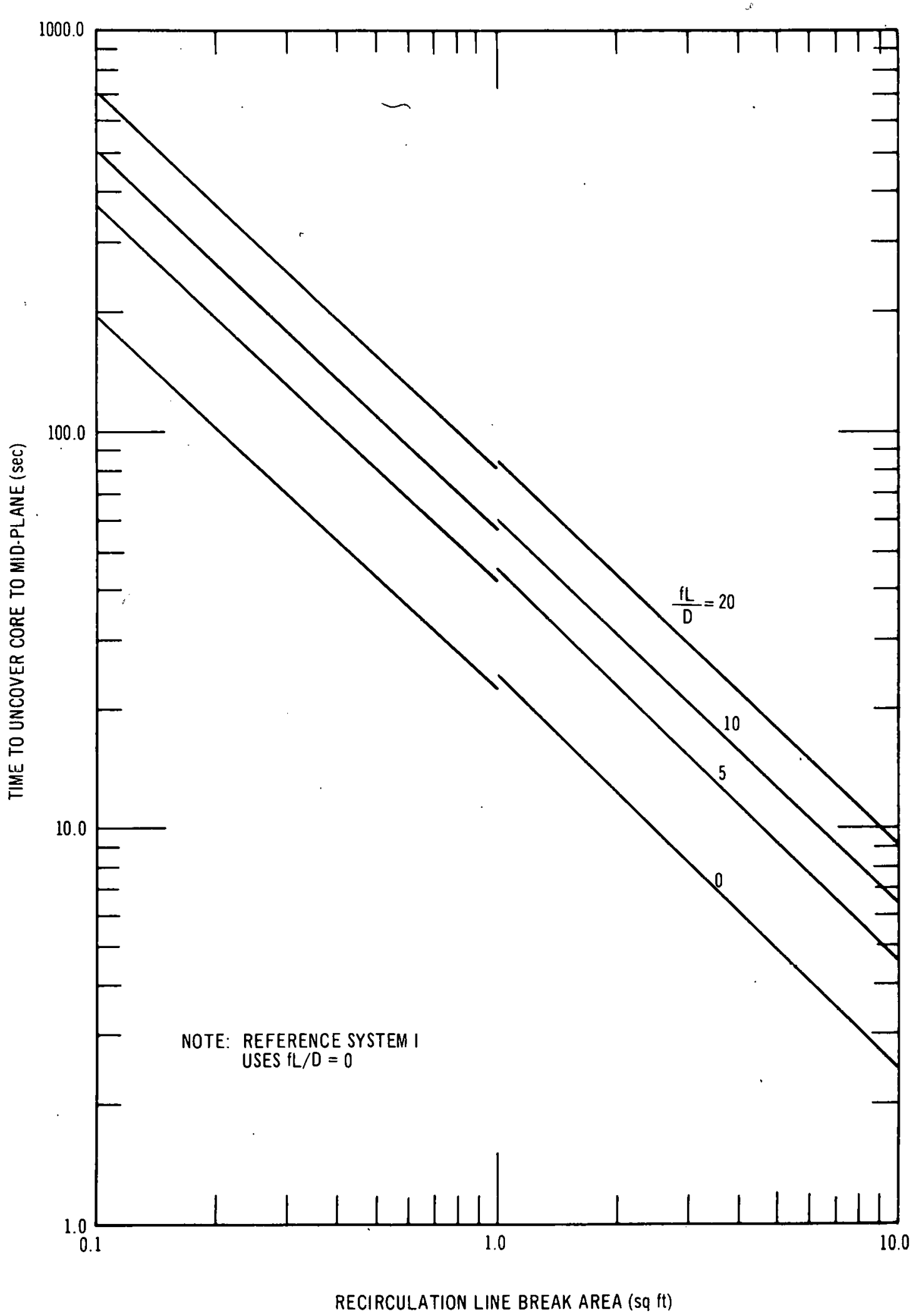

FIGURE 10. TIME TO UNCOVER CORE VERSUS RECIRCULATION LINE BREAK AREAVARYING LOSS COEFFICIENT OF BREAK, RL:D 


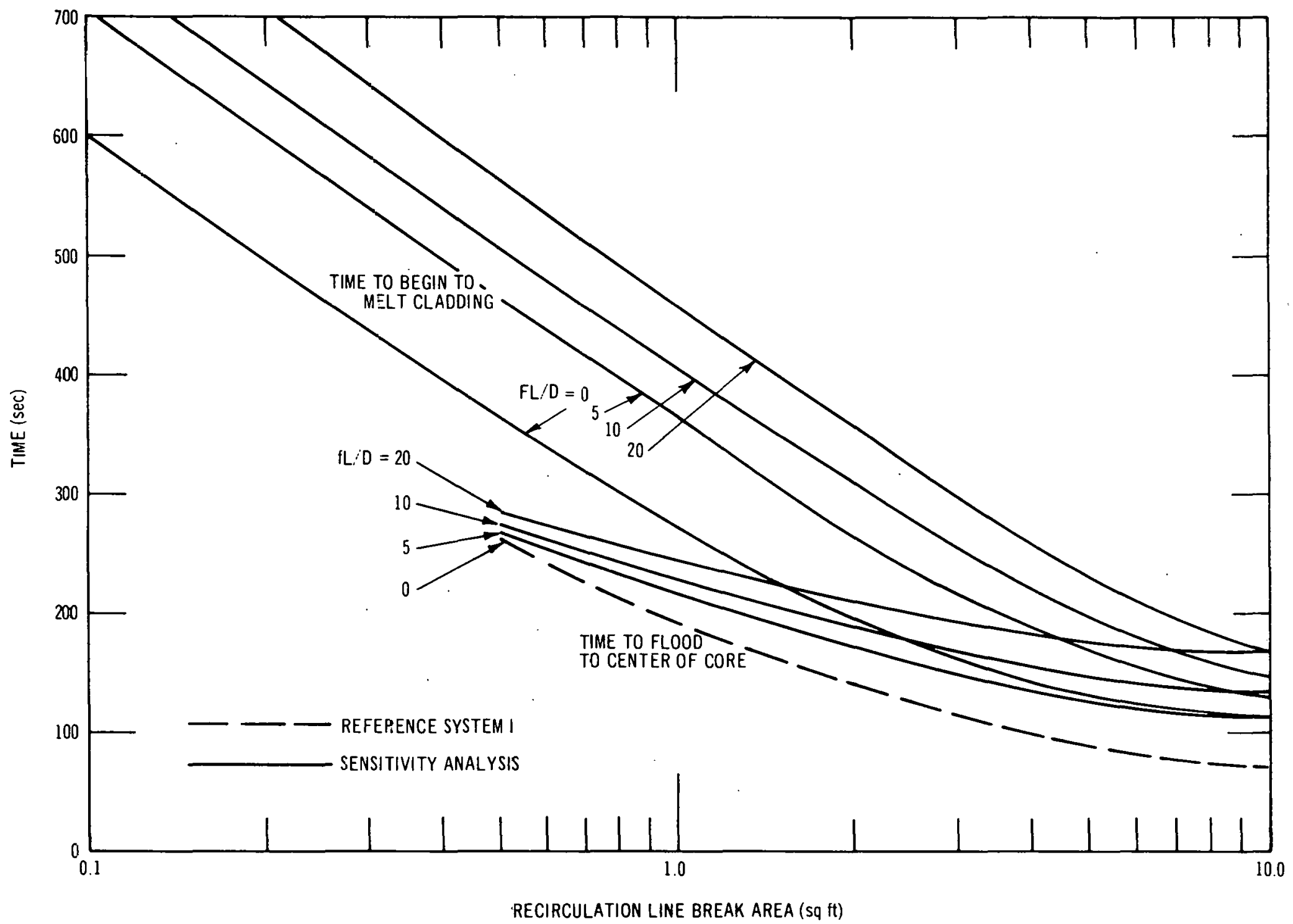




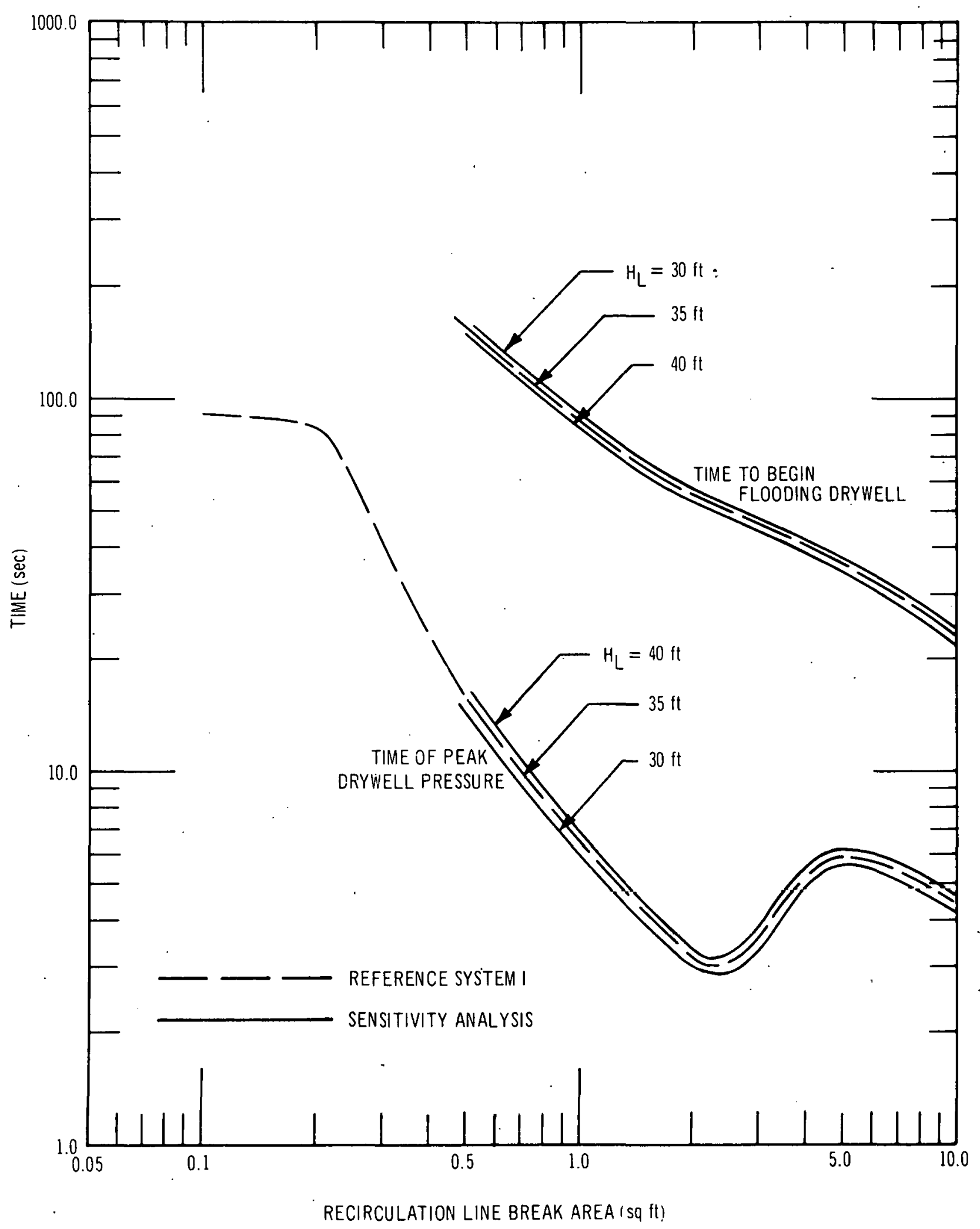

FIGURE 12. TIME OF PEAK DRYWELL PRESSURE AND TIME TO BEGIN FLOOUING URYWELL VERSUS RECIRCULATION LINE BREAK AREA-VARYING FLOOD TANK HEAD, $H_{L}$ 


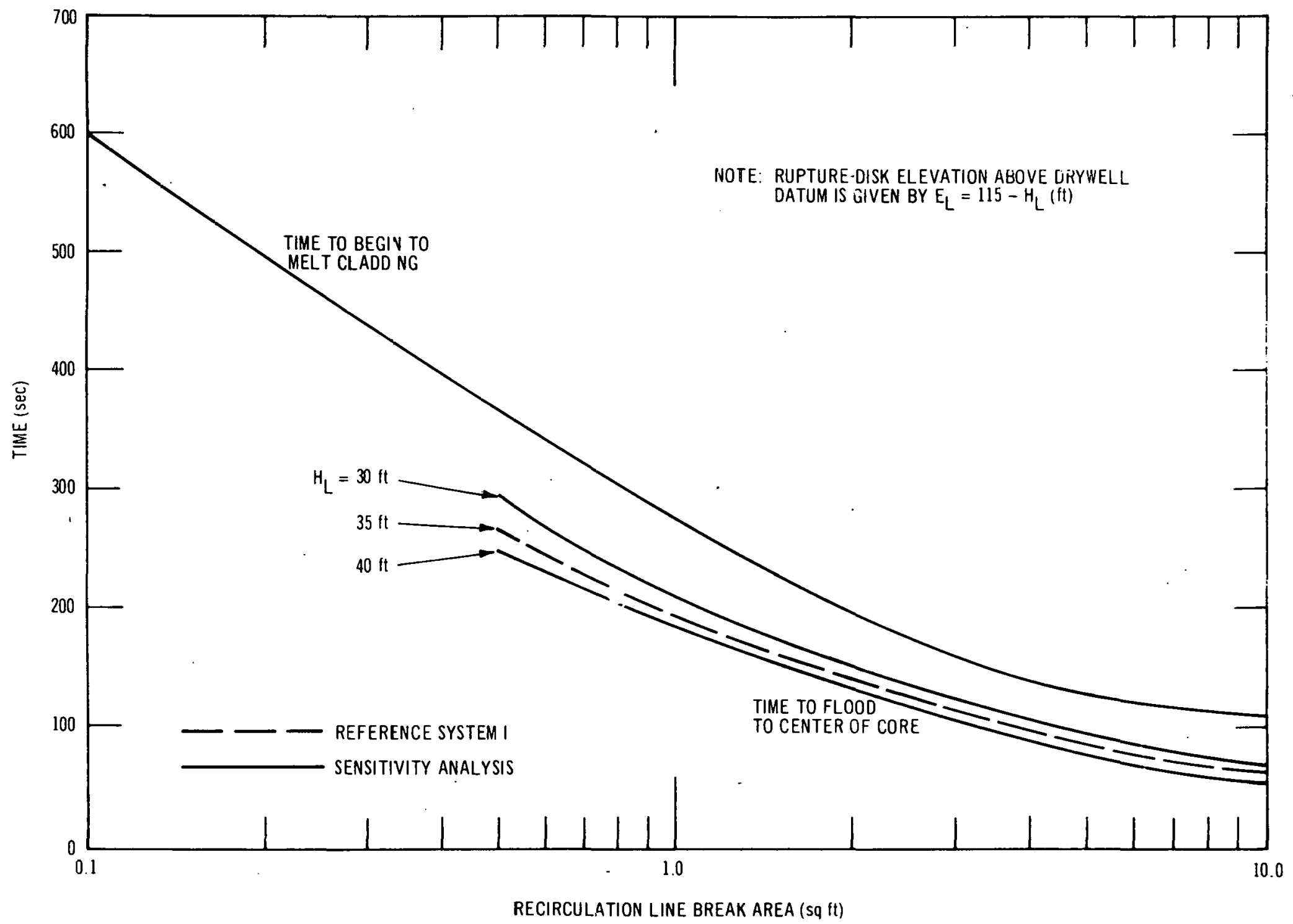

FIGURE 13. TIME TO MELT CLADDING AND TIME TO FLOOD CORE VERSUS RECIRCULATION LINE BREAK AREA-VARYING FLOOD TANK HEAD, HL 


\subsubsection{Rupture Disk Burst Pressure}

The sensitivity of Reference System I to the burst pressure of the drywell vent rupture disks was analyzed for burst pressures of $8 \mathrm{psid}, 30 \mathrm{psid}$, and $70 \mathrm{psid}$. (Reference System I pressure setting is 50 psid.) The primary effects of increasing the rupture disk pressure setting are: (1) an increased time to rupture the disks because of the higher presslire level which must be reached, and (2) a larger minimum break area is required to rupture the disks. Both of these effects are illustrated in Figure 14. Note that it takes longer to begin flooding the drywell for the higher-pressure rupture disks, and that the 8 psid and 30 psid rupture disks are the only ones to burst for a break area of $0.2 \mathrm{ft}^{2}$. This graph illustrates the considerable flexibility which the designer has in the choice of the lower limit to be set on break size which will activate gravity flooding, inundate the drywell, and flood the core. By simply varying the rupture disk pressure setting, with proper attention to the other parameters (e.g. , auxiliary vent size, loss coefficient, etc.), the desired lower limit may be obtained.

Figure 15 compares the core flooding time to the time to melt cladding for Reference System I. Additional margin is gained for small breaks by decreasing the rupture disk pressure setting.

\subsubsection{Reactor Vessel Vent Area}

The reactor vessel vents contribute to the performance of the gravity flooding system hy venting stea $m$ from the vessel. Two of the four vents are located such that they also provide additional flooding area into the vessel when the drywell is flooded. This feature improves the reflooding time for small breaks where backflow through the break is slow. The effectiveness of this feature was investigated by analyzing Reference Systcm I with flooding vent areas of 0 and $10 \mathrm{sq} \mathrm{ft}$ (Reference System I area $=3.54 \mathrm{sq} \mathrm{ft}$ ). If neither of the two reactor flooding vent valves open, all reactor vessel reflooding must take place through the break itself. This will of course penalize the small break the most. since for these breaks the flooding vent area provides most of the area for vessel reflooding. However, Figure 16 shows that for breaks as small as $0.7 \mathrm{sq} \mathrm{ft}$ the suppression/flooding system prevents core melting without any assistance from other emergency core cooling systems, even with the two flooding vents closed.

\subsubsection{Auxiliary Vent, Reactor Vessel Vent Set Pressure, and Drywell Volume}

The sensitivity of the suppression/ flooding system to variation of the auxiliary vent loss coefficient, flow area, and depth of submergence, was investigated, and it was found that the system performance is relatively insensitive to changes of these parameters. Figures 17, 18 and 19 show the results obtained. Also, the effect of varying the reactor vessel vent set pressure was investigated and found to be very slight for set pressures less than 200 psi (see Figure 20). Finally, the effect of changing the drywell volume $\dot{x} 25 \%$ was found to be practically nil.

\subsubsection{Reference System II}

Reference System II is an improvement of Reference System I, based upon the knowledge and insight gained from the Sensitivity Analysis. The changes made to Reference System I for Reference System II (Figure 21) were:

1. Reshape the drywell so that the central drywell silo (reactor room) is filled to a level above the refill vents before filling the side (equipment) silos, and locate the communication ports to the side silos 5 feet above the reactor vessel refill vents. The purpose of this modification is to accelerate the rise of the water level around the vessel by filling the central silo over the 
0

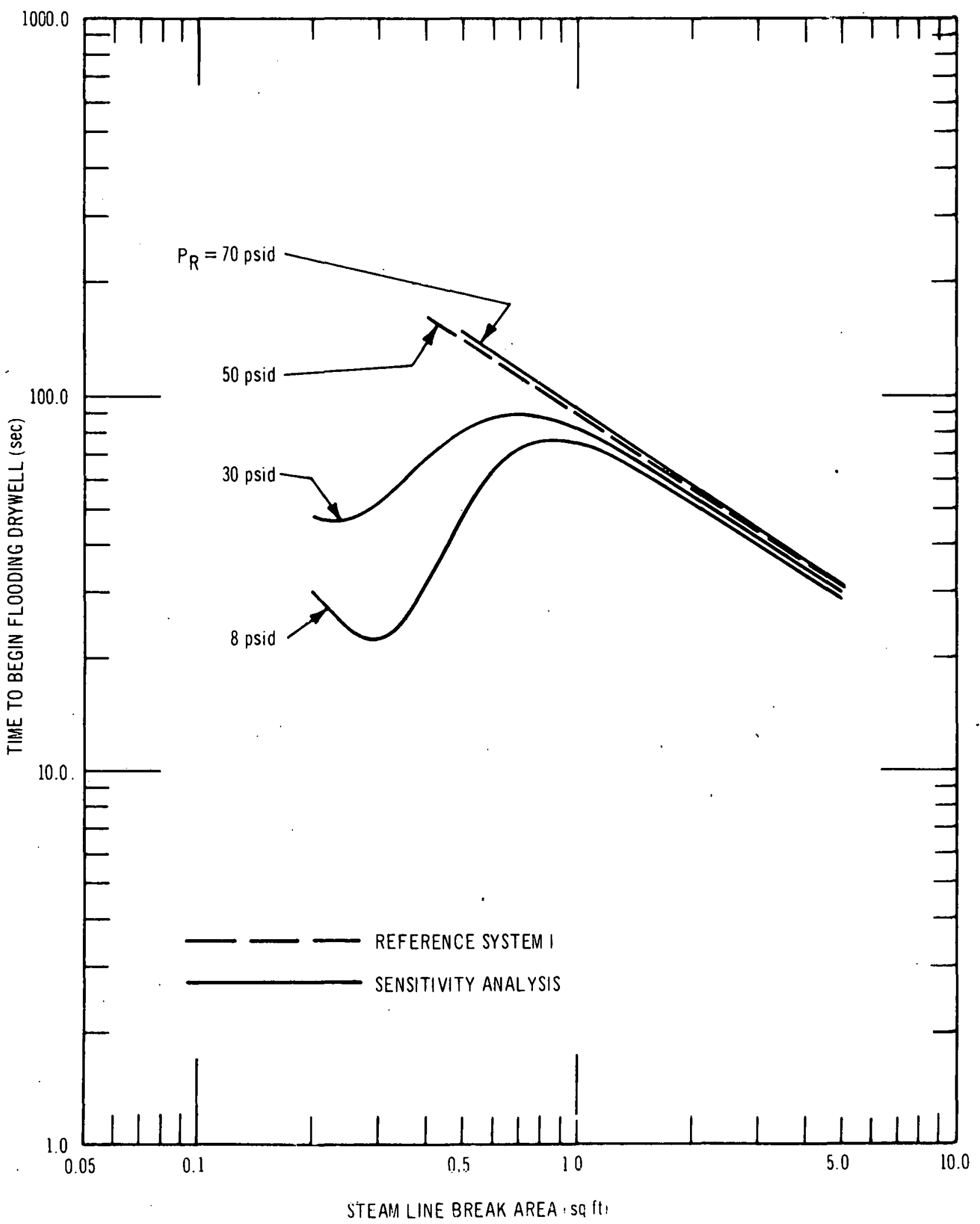




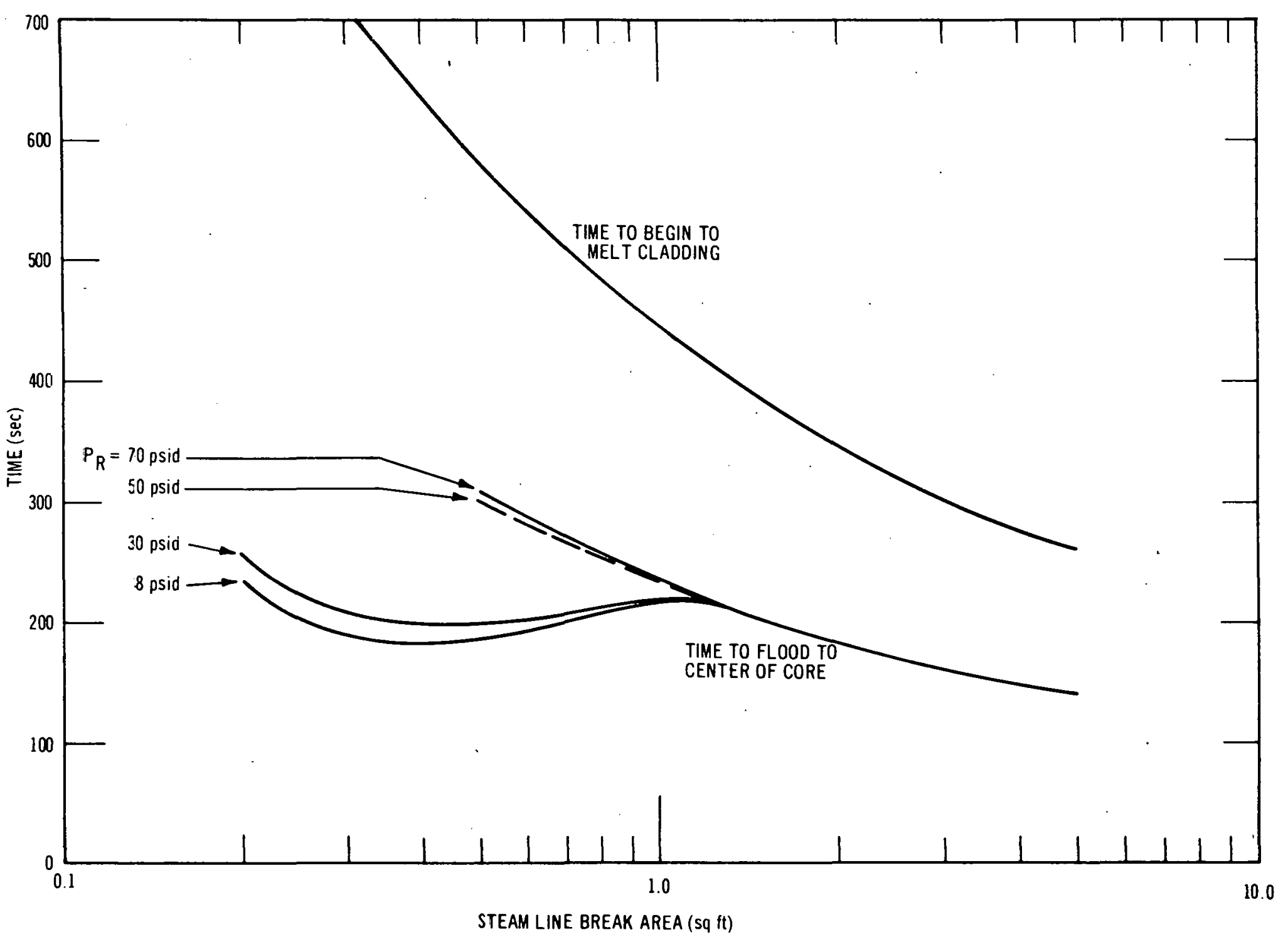

FIGURE 15. TIME TO MELT CLADDING AND TIME TO FLOOD CORE VERSUS STEAM LINE BREAK AREA - VARYING RUPTURE DISK SETTING, $P_{R}$ 


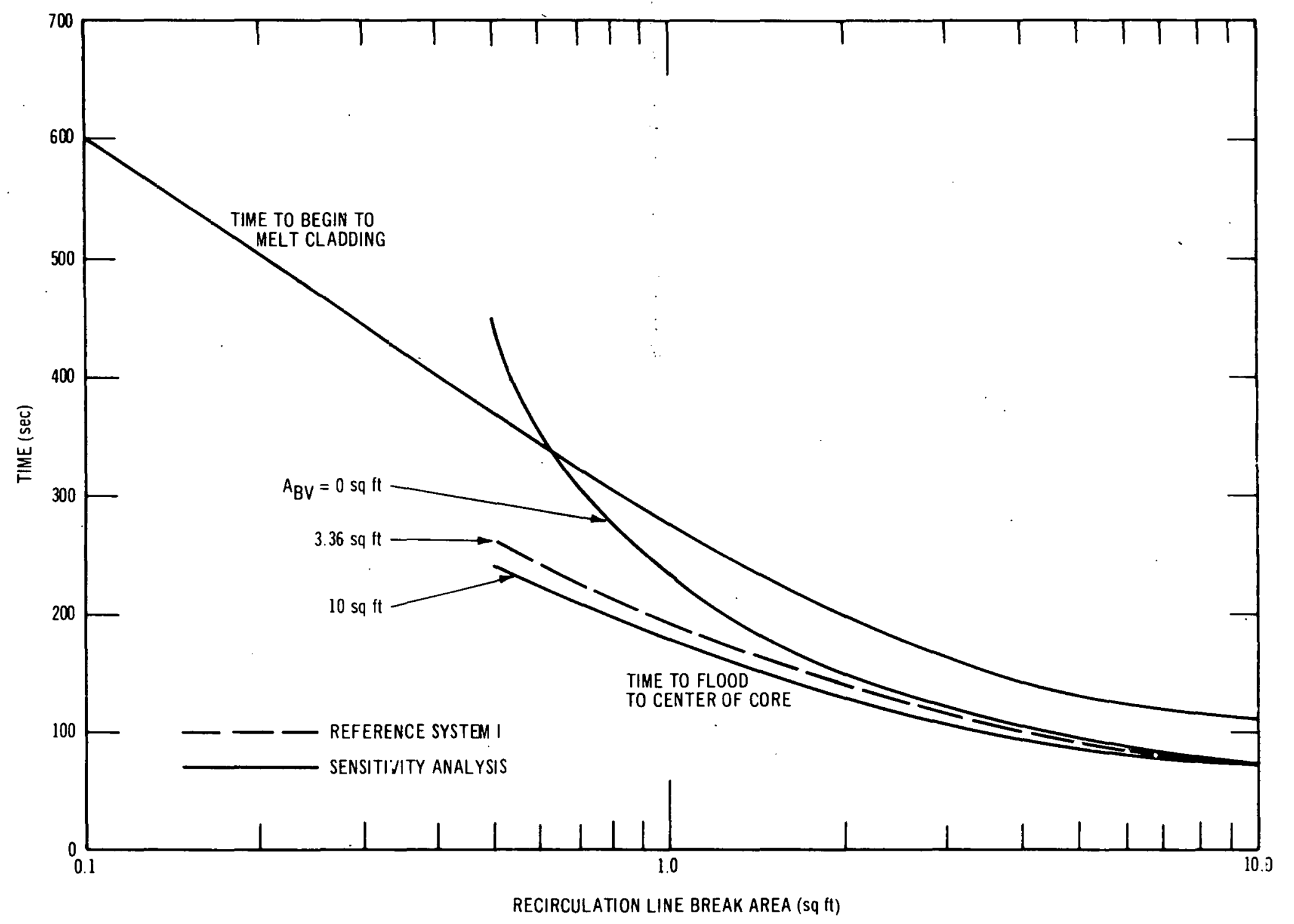

FIGURE 16. TIME TO MELT CLADDING AND TIME TO FLOOD CORE VERSUS RECIRCULATION LINE BREAK AREA - VARYING AUTOMATIC BLOWDOWN VENT AREA, A $B V$ 


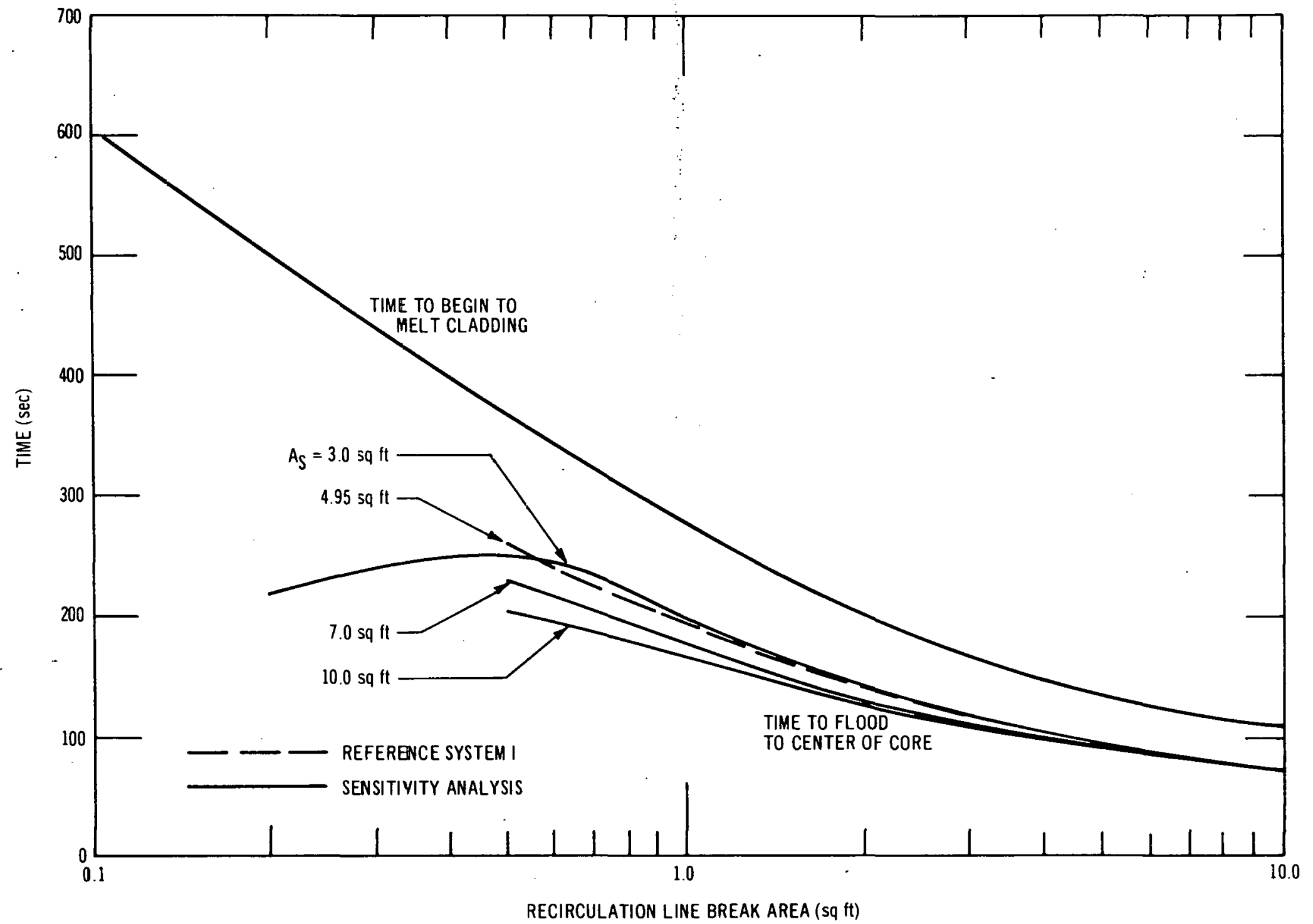

FIGURE 17. TIME TO MELT CLADDING AND TIME TO FLOOD CORE VERSUS RECIRCULATION LINE BREAK AREA-VARYING AUXILIARY VENT AREA, AS 


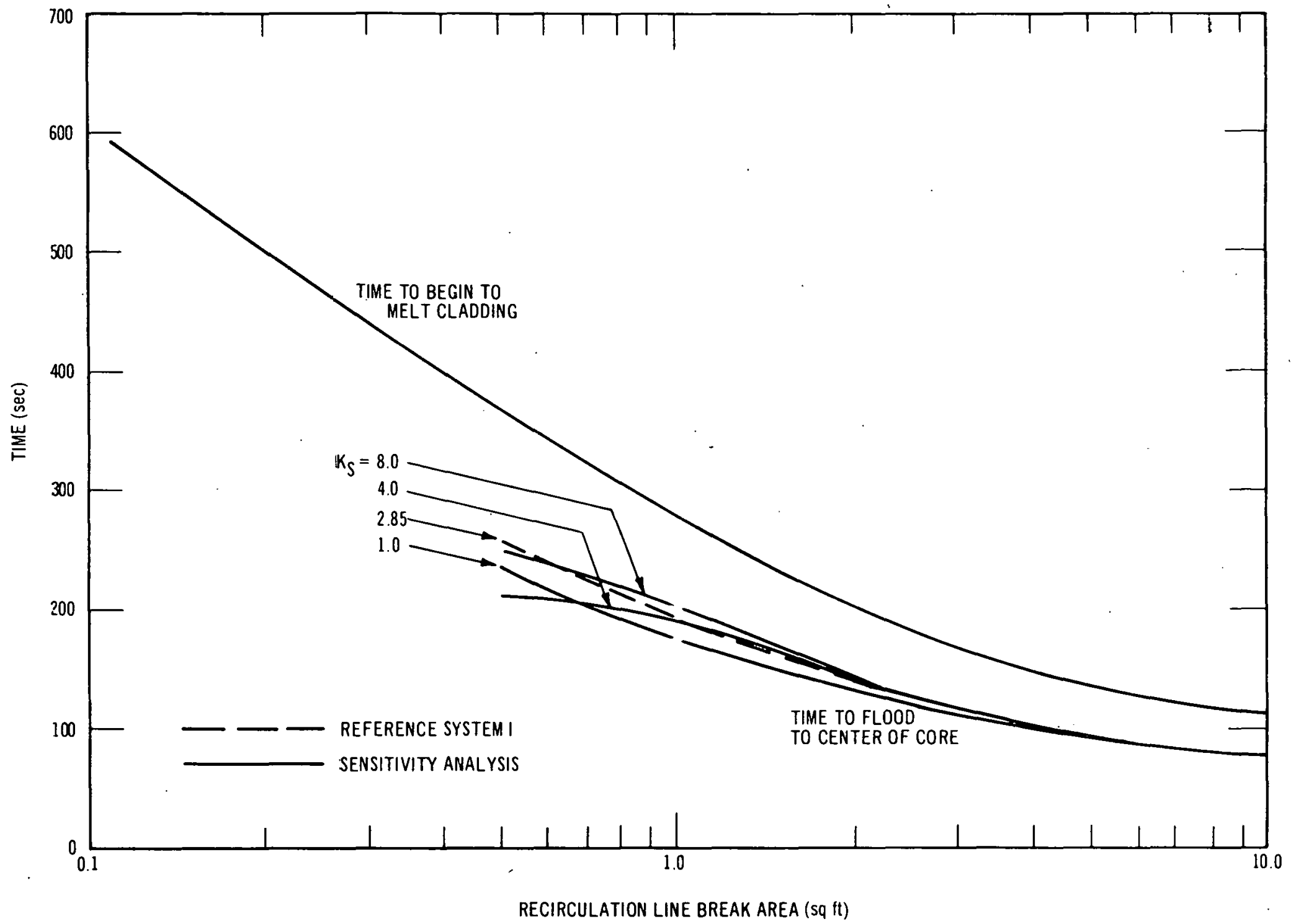




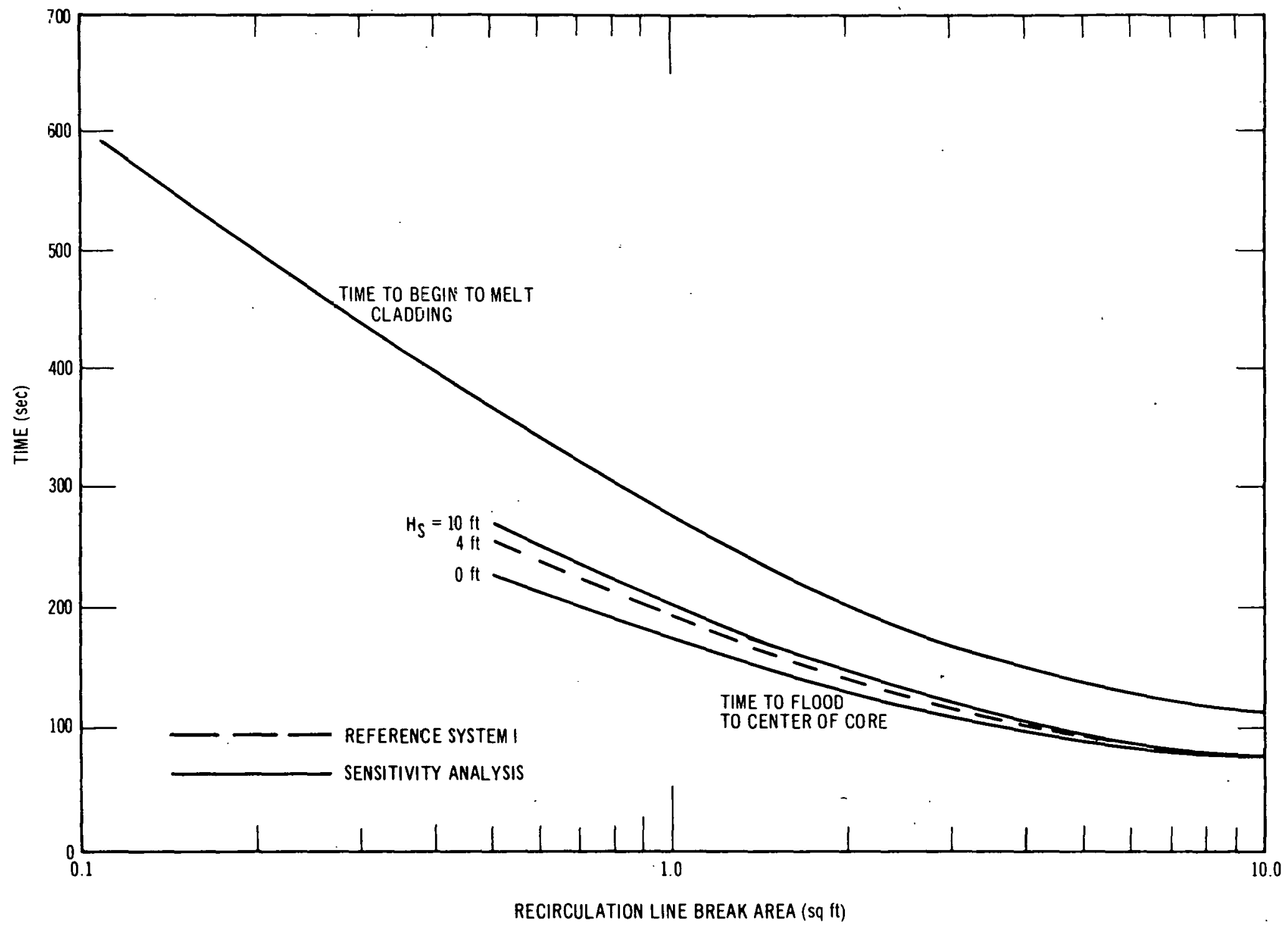

FIGURE 19. TIME TO MELT CLADDING AND TIME TO FLOOD CORE VERSUS RECIRCULATION LINE BREAK AREA-VARYING AUXILIARY VENT SUBMERGENCE, HS 


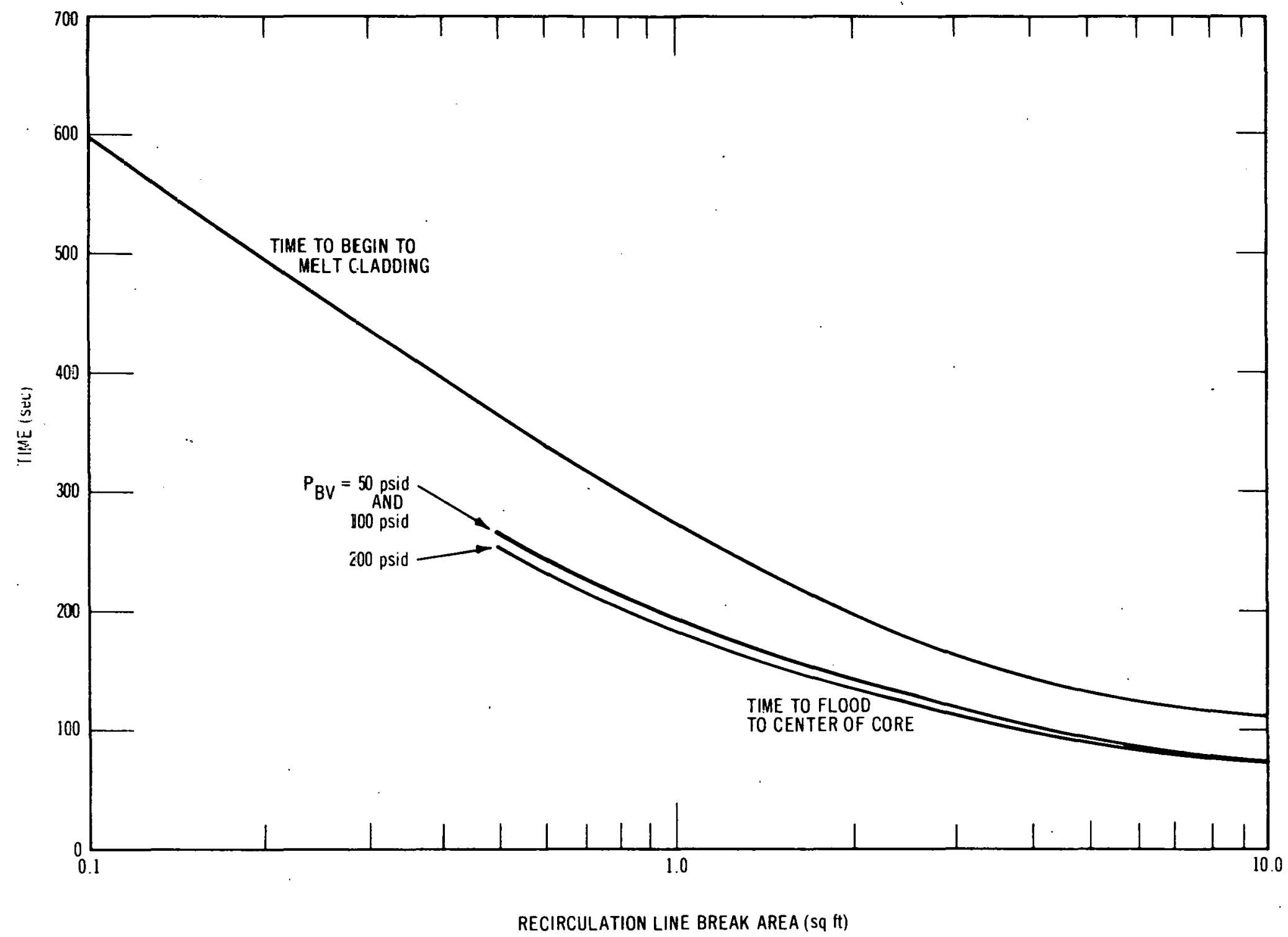




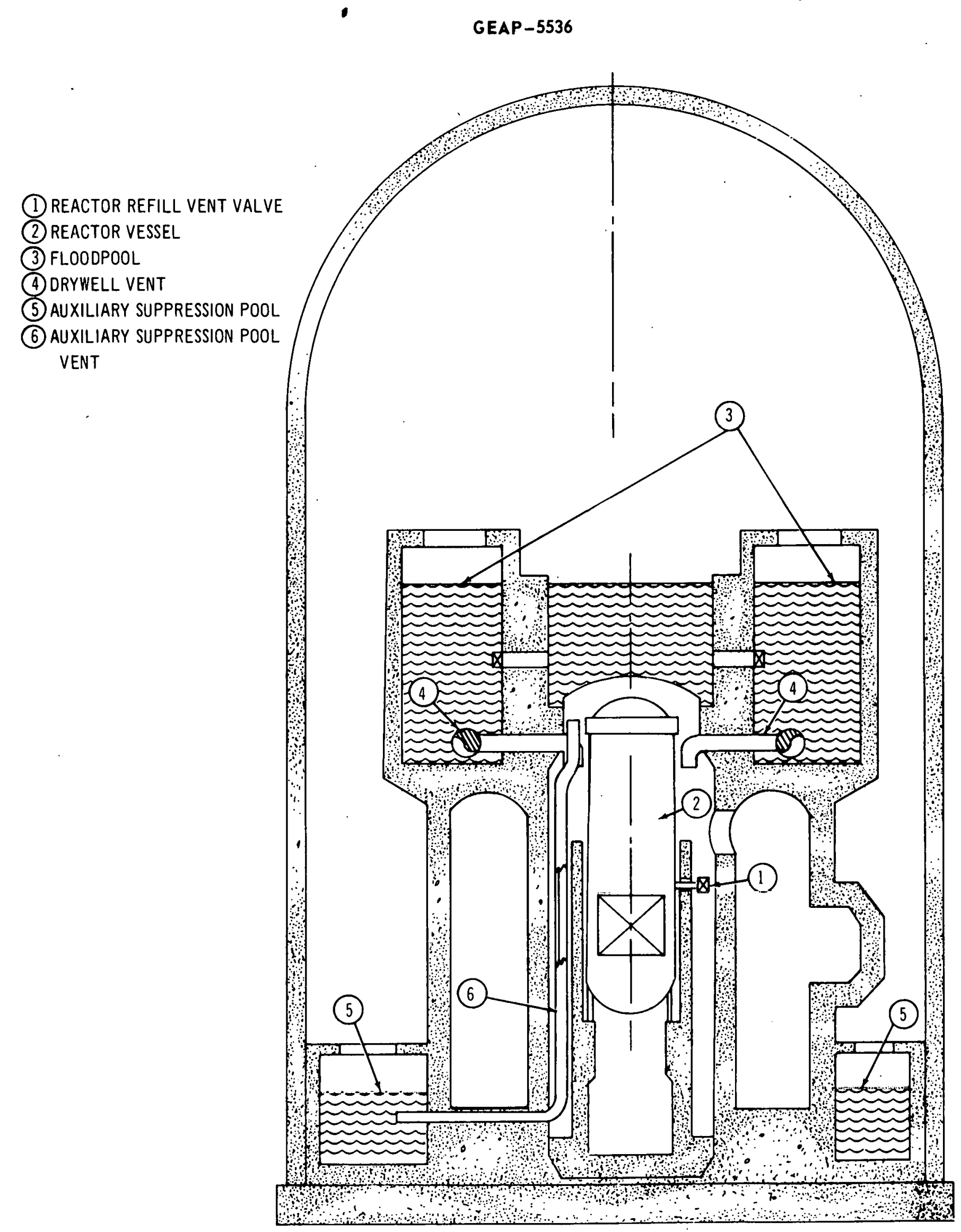

FIGURE 21. REFERENCE SYSTEM II 
reactor vessel refill vents before flooding the side silus.

2. Lower the two reactor reflood vents to a level 1 fout above the top of the core. The purpose of this modification is to reduce the time to berin fluoding the reactor vessel through the vessel vents.

3. Set two of the reactor vessel vent valves to open when the liquid level reaches the core midpoint during a blowdown. There are two reasons for doing this. First, after the water level has fallen to where the core is one-half to one-quarter covered, the core is no longer being effectively cooled, at which point it is desirable to accelerate the vessel blowdown to reduce the time that the core is uncovered. Opening the reactor vessel vents provides an additional $3.54 \mathrm{sq} \mathrm{ft}$ of blowdown flow area from the steam dome, which effectively reduces reactor vessel pressure with a minimum loss of water from the vessel. This is particularly efficacious for the small break cases. Second. opening the reactor vessel vents when the liquid level falls to the core midpoint increases the blowdown rate, which bursts the rupture disks, which would otherwise not burst for small breaks. The reactor vent valve low water level trip could be actuated from the reactor water level instrumentation in the same manner as the standard Automatic Blowdown System which is part of the current emergenry core cooling systems. Alternately, since water level is roughly proportional to pressure during a blowdown, the automatic blowdown system described in Section 2.5 could be used.

4. Increase the auxiliary vent flow area from $4.95 \mathrm{sq} \mathrm{ft}$ to $50 \mathrm{sq} \mathrm{ft}$. The pur pose of this change is to accelerate the drywell blowdown by providing addi tional pressure suppression flow area. This contributes to reducing the time for the drywell to blow down to the level of the flood pool back pressure. thereby reducing the time for drywell flooding to berin. In addition, a large vent to a low-backpressure pool permits faster drywell depressurization at the stage when the drywell pressure is approaching the floodpool back pressure. Since the auxiliary pool vent submergence depth is only $4 \mathrm{ft}$ (drywell vent depth is $35 \mathrm{ft}$ ), the back pressure against which the drywell must blow down through the auxiliary vent is lower.

5. Lower the rupture disk set pressure from 50 psid to 10 psid. Because of the greatly increased auxiliary vent flow area of Reference System II the maximum drywell pressure at all break areas is lower. This rupture disk set pressure will allow the gravity flooding system to handle the reactor core cooling for break sizes down to $0.1 \mathrm{sq} \mathrm{ft}$ without assistance from any other emergency core cooling system.

Reference System II is the basic system used in the General Applicability Analyses.

\subsection{GENERAL APPLICABILITYY ANALYSIS}

\subsubsection{Reference System II}

The insight into pressure suppression/ gravity flooding containment systems provided by the sensitivity analysis allowed a first step toward optimization of the concept, designated as Reference System $\Pi$. (Details of this system may be found in Section 2.2.) This system was used as the basis for all investigation in the General Applicability Analysis. Of the five changes which were made to Reference System I to make Reference System II, the 
most significant is the change in the criterion fur (n)ening l!ic reactor vessel vent. This change from a pressure to a water level criterion was incorporated because of the long periuds during which the core is otherwise uncovereci during bluwdown lur small break areas. Firrure 22 is a comparison of the time to melt and time to uncover the core for Reference System II. The margin between these two curves is increased considerably over the margin which existed for Reference System I, especially at the smaller break areas (see Figure 3 ).

For a recirculation line break, the margin between the two curves is increased partly because of the faster core reflooding time of Reference System II. and partly because the time to initiate melting with Reference System II is slightly increased. The reason for the difference in the time-to-melt curves between Reference System I and II is that convective heat transfer takes place during blowdown of the reactor vessel with Reference System II after the core is uncovered. The reason for the convective heat transfer during blowdown is that the vents on top of the vessel have opened, and some of the steam which blows out these vents must pass through the core. On the contrary, with Reference System I, there is no convection of fluid past the core during a recirculation line break, and consequently no convective heat transfer after the core is uncovered.

The second most significant improvement incorporated in Reference System II is the increased auxiliary vent area. This allows the drywell to blow down much more rapidly, thereby allowing the drywell to flood more quickly. Figure 23 compares the drywell flooding time of Reference Systems I and II, illustrating the effect of the larger auxiliary vents in Reference System II. Clearly, Reference System II represents considerable improvement over Reference System I, and illustrates the flexibility and adaptability of the pressure suppression, gravity flooding concept.

\subsubsection{Reactor Pressure}

The effect of increasing the reactor operating pressure is to decrease both the time to initiate core melting and the time to flood, primarily because of the accelerated blowdown rates which are associated with the higher pressure. The core is uncovered sooner, and the vessel is blow down sooner. This fact is illustrated in Figure 24 which shows the shorter times associated with the 1500 psia system compared with the 1015 psia system. The 1500 psia system is simply Reference System II, except that the operating pressure is 1500 psia instead of 1015 psia. Figure 25 compares the core uncovery times for the two systems, and shows a decrease in blowdown time of about 12 percent over the entire range of break areas. A second order effect of increasing the reactor system pressure is to increase the saturation temperature, raising the temperature levels and reducing the time to initiate cladding melting. The pressure suppression/gravity flooding system appears to be completely adequate to handle the core cooling problem even at much higher operating pressures.

\subsubsection{Power Density}

The effect of power density was studied by simply increasing the power density of Reference System II without changing any other parameter. The results obtained from this analysis are, therefore, conservative, since increasing the power density in a real plant generally involves other changes, in addition to increasing the specific power in the fuel. Specifically, these changes ordinarily involve increasing the heat transfer area by increasing the number of fuel rods and decreasing the rod diameter. Smaller rods help in two ways in a loss-of-coolant 


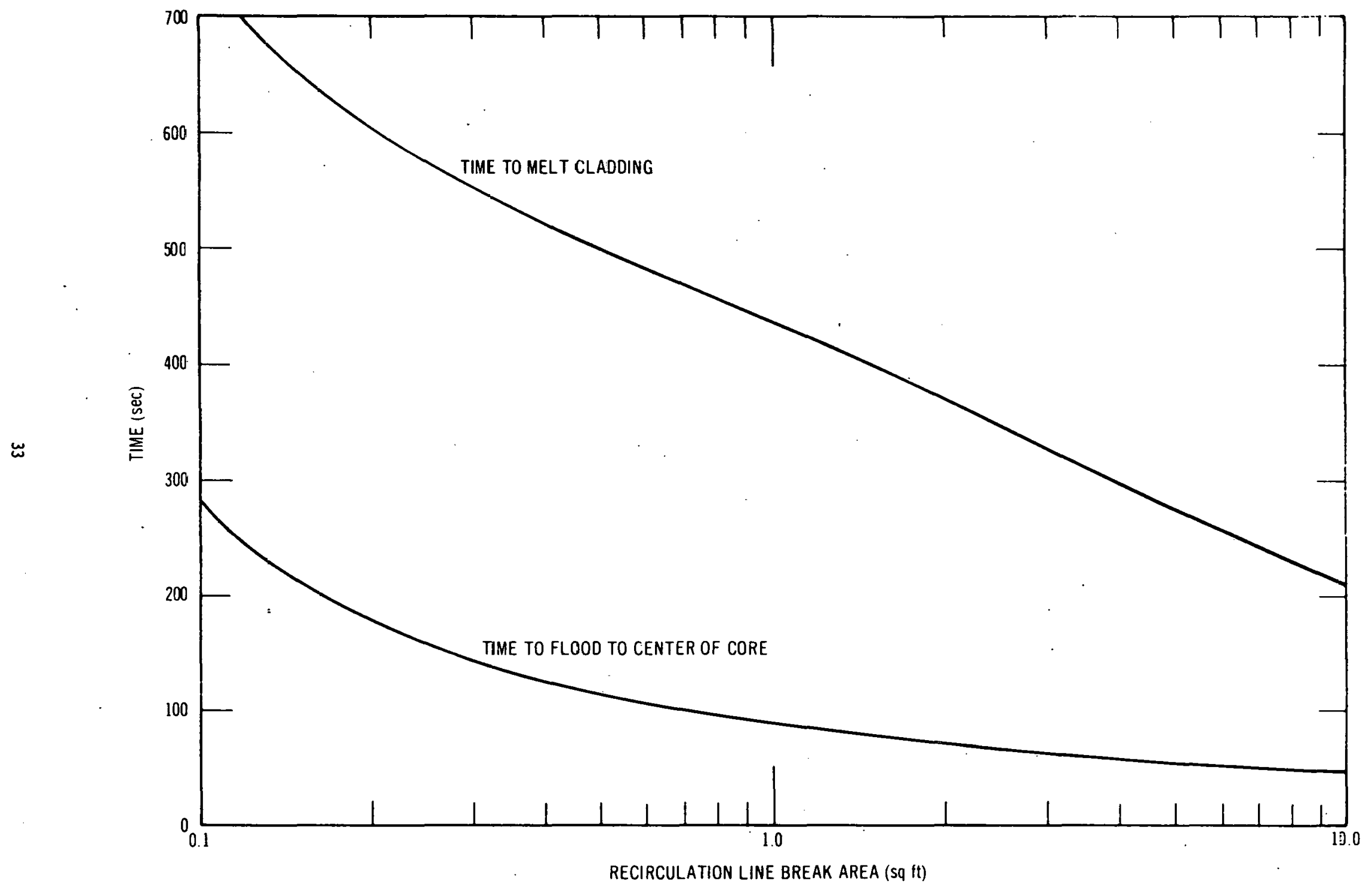




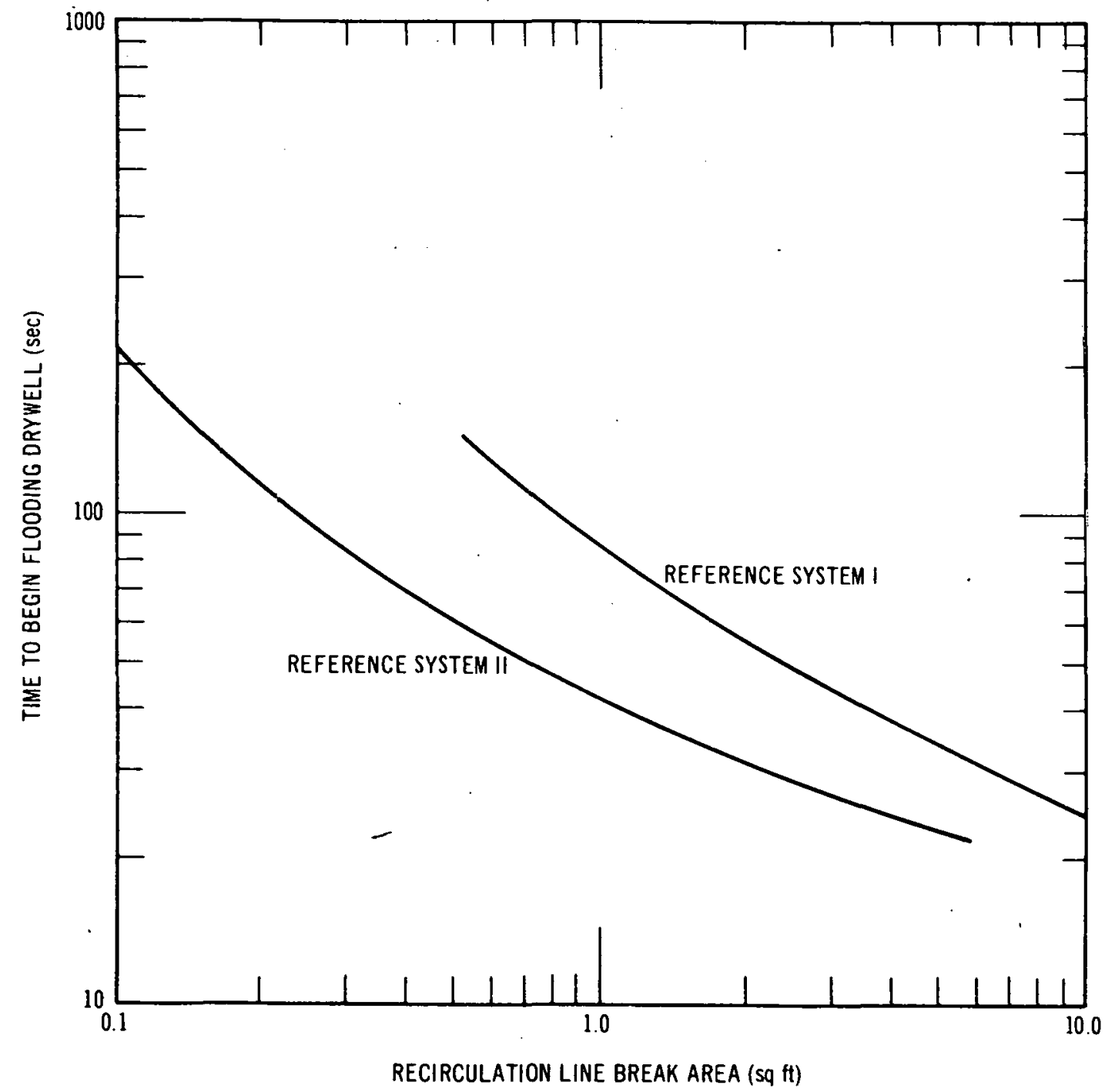

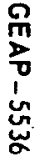

FIGURE 23. TIME TO BEGIN FLOODING DRYWELL VERSUS RECIRCULATION LINE BREAK AREA-COMPARISON OF REFERENCE SYSTEMS I ANC II 


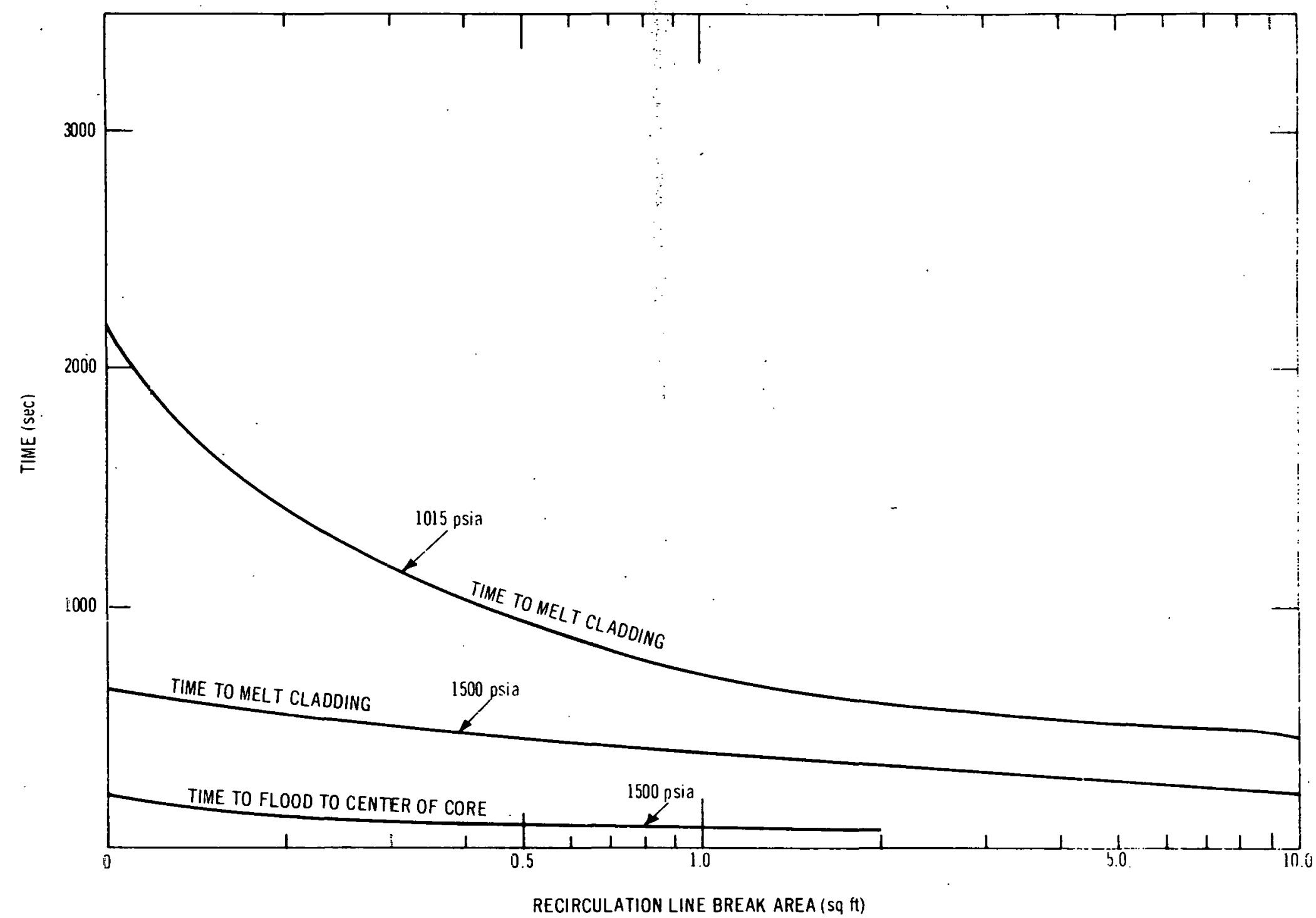

FIGURE 24. TIME TO MELT CLACDING AND TIME TO FLOOD CORE VERSUS RECIRCULATION LINE BREAK AREA-EFFECT OF HIGH REACTOR PRESSURE 


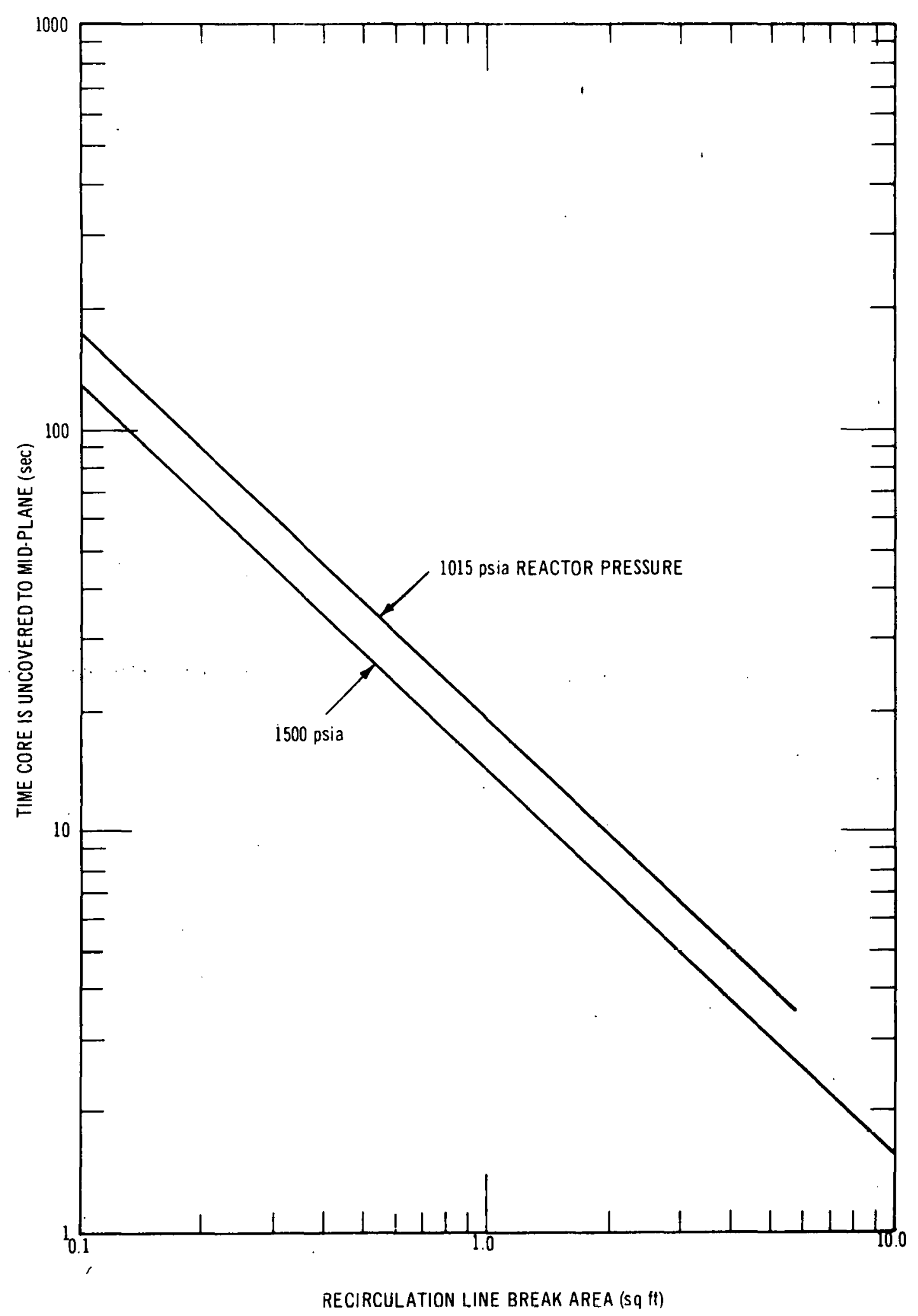

FIGURE 25. TIME TO UNCOVER CORE VERSUS RECIRCULATION LINE BREAK AREA-EFFECT OF HIGH PEACTOR PRESSURE 
transient. First, the increased heat transfer area helps to remove the heat faster, and second, there is less stored heat in a fuel bundle with smaller rods because the center temperatures will be lower. However, the analysis of the effect of power density was conducted by simply increasing the power levels of a specific plant so that comparison between the different power densities may be made without involving other complicating factors. The primary effect of increasing the power density is to increase the temperature rise rate in the core after it becomes uncovered. This effect can be seen in Figure 26 , in which the time to initiate cladding melting is shown decreasing monotonically with increasing power density at all break areas. From this figure it can be seen that the pressure suppression/gravity flooding system is adequate to handle power densities considerably higher than the reference power density of $40 \mathrm{~kW} / \mathrm{l}$.

\subsubsection{Pressurized Water Reactor}

Application of the pressure suppression/ gravity flooding concept was studied by using the 1300 MWt Brookwood PWR Plant (Rochester Gas \& Electric). This plant has a power density of about $75 \mathrm{~kW} / 1$, operates at $2300 \mathrm{psia}$, and $575^{\circ} \mathrm{F}$. The enclosed volume of a PWR primary system is less than that of an equal size BWR plant: Thus, there is less stored energy in a PWR and the blowdown time will be less. Because the reactor vessel for a PWR is smaller, and the core is closer to the bottom of the vessel. the time to reflood the core will be less than for an equivalent BWR. Also, because the PWR has top-entry control rods, the reactor vessel sits lower in the drywell, accelerating the time for reactor vessel hooding to begin. 'The Brookwood PWR system was thus fitted into the Reference System II design, with the above-noted changes. and the applicability of the suppression flooding system toward use with a PWR was analyzed. The results indicate that the two sys- systems are entirely compatible. Figure 27 compares the time to melt and time to flood for the PWR system which was analyzed. The margin between these two curves is great enough to be able to conclude that the suppression/flooding system can handle a PWR system without the aid of other supplementary cooling systems. Because the siured energy in a PWR system is less than that in a BWR system, the blowdown of the primary system is in general faster for PWR systems. Also, the PWR cores have higher power densities, resulting in faster core heatup rates than for BWR plants. The net result is that a PWR system blows down and refloods faster, but because of its higher core power density, it also tends to begin cladding melting sooner.

\subsubsection{Reference System III}

Another step toward optimization of the pressure suppression/gravity flooding system was taken by incorporating direct reflooding of the reactor vessel into the Reference System II design. This new system, shown in Figure 28, is designated Reference System III, and is identical with Reference System II except that the two reactor vessel refill vents are connected directly with the floodpool. Thus, when the water level reaches the core midpoint and the two reactor vessel reflood vent valves open, the vessel is blowing down directly into the floodpool. This is very similar to the Automatic Blowein Vents in existing pressure stinpression systems which vent the reactor vessel directly to the suppression pool in order to speed up the vessel blowdown. However. in Reference System III. the pipes which con:ect the vessel to the floodpool are used for clirect llooding of the vessel after blowdown is completed, thereby accelcrating the time to reflood the reactor core.

A second advantage of this arrangement is that the drywell is not inundated for smaller pipe breaks, since the rupture ciisks do not hurst. Furthermore, the minimum break for 


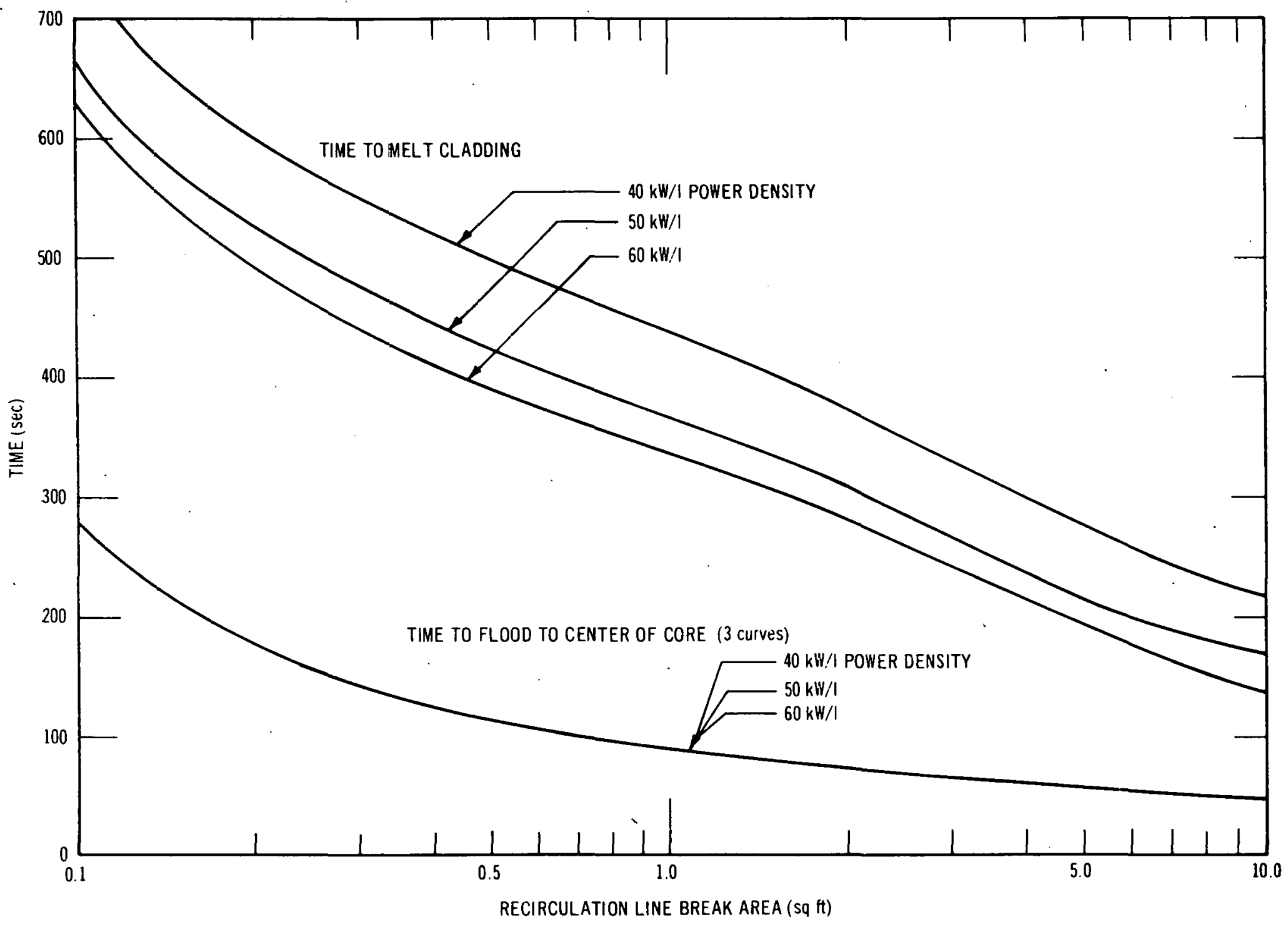

FIGURE 26. TIME TO MELT CLADDING AND TIME TO FLOOD CORE VERSUS RECIRCULATION LINE BREAK AREA-EFFECT OF REACTOR POWER DENSITY 


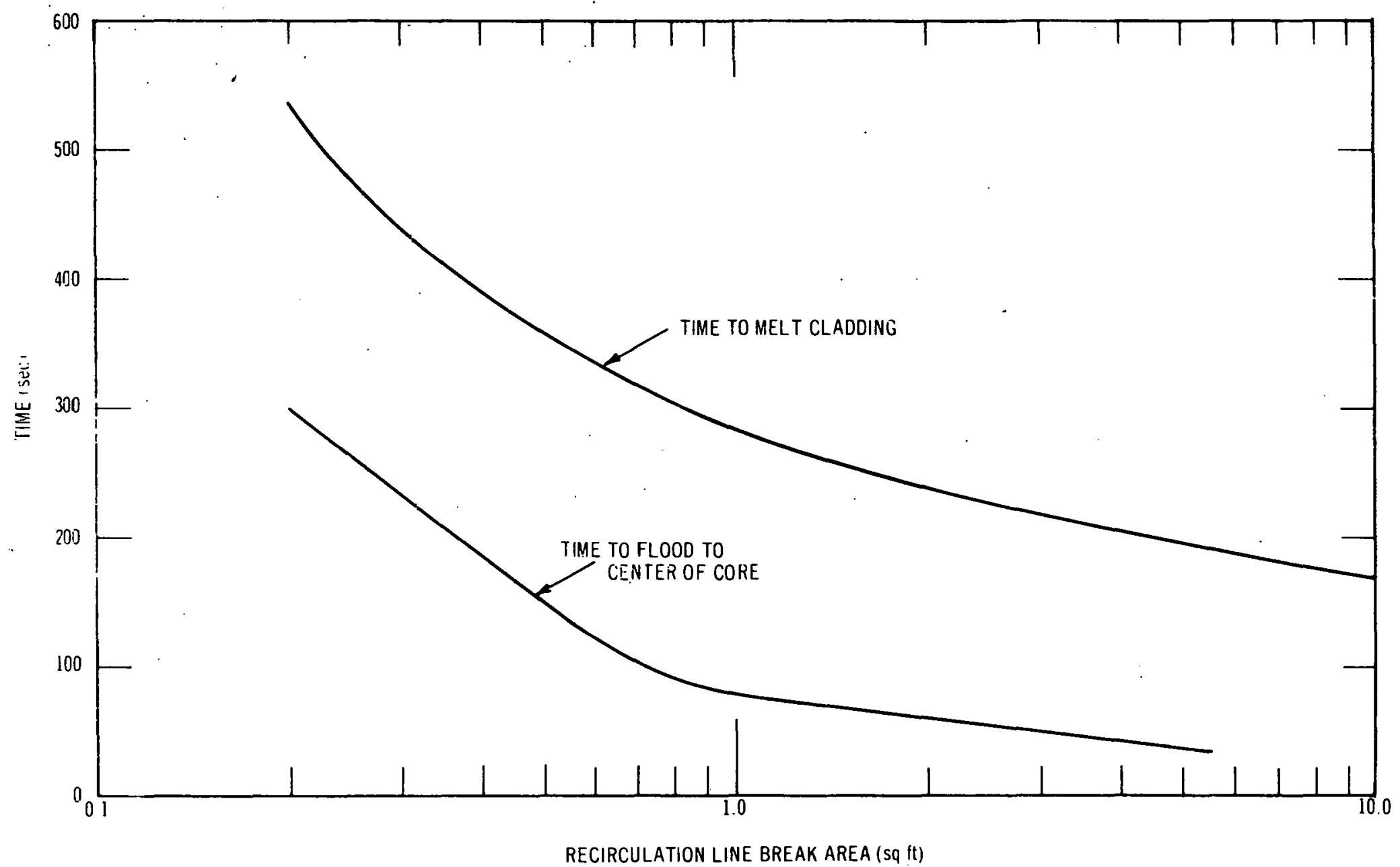




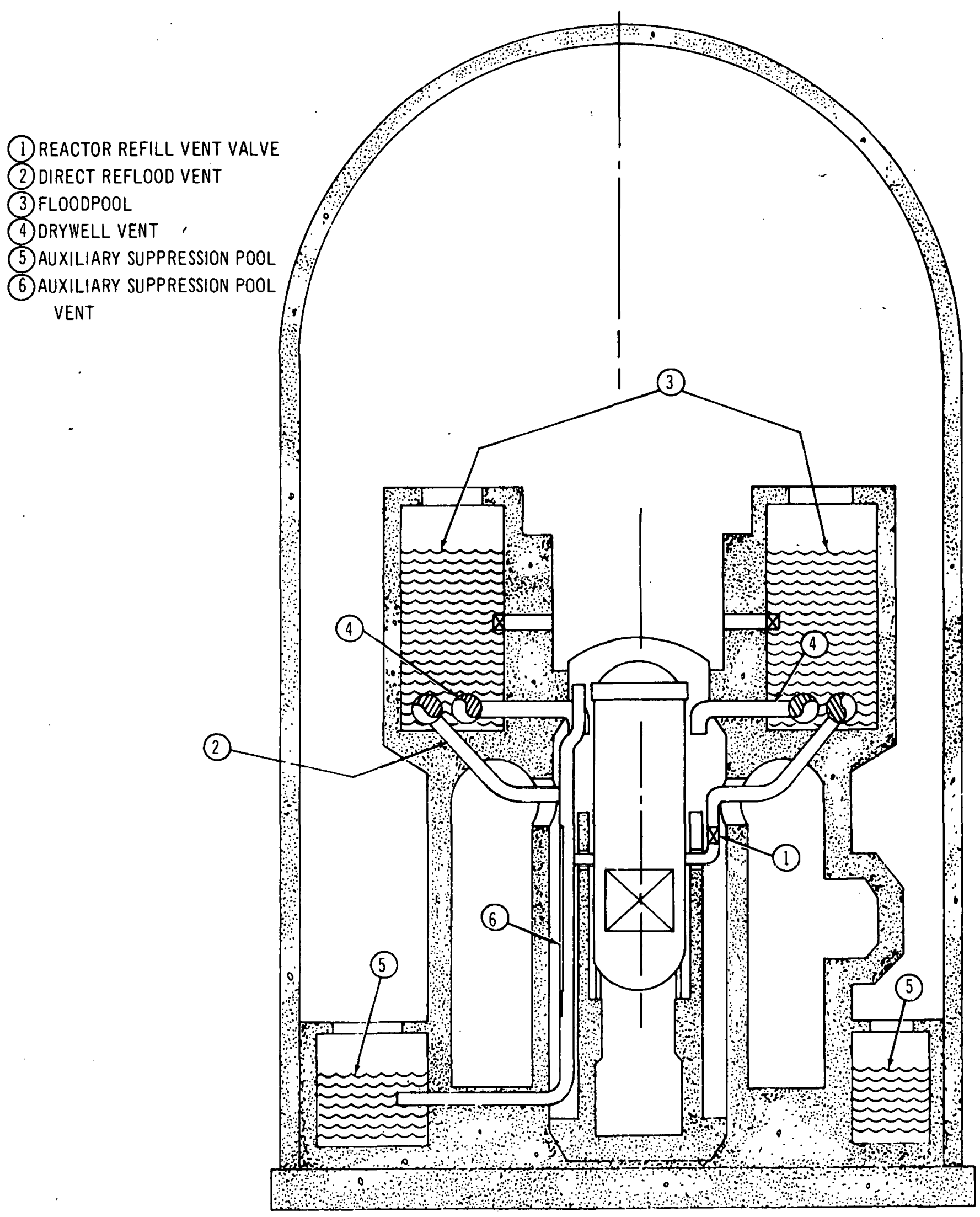

FIGURE 28. REF ¿RENCE SYSTEM III 
which drywell flooding occurs can easily be set by adjustuent of appropriate system parameters. The drywell is not flooded for smaller. breaks because the vessel blowdown vents do not discharge into the drywell, resulting in a lower drywell pressure which does not burst the rupture disks, and the drywell is not flooded. Figure 29 compares the time to ini tiate cladding melting and the time to reflood the reactor core. This graph shows the large margin between time to reflood and time to initiate melting for Reference System III, illustrating the ability of pressure suppression/gravity flooding to adequately handle the loss-of-coolant accident without the assistance of supplementary cooling systems.

The most important variable with regard to the temperature rise in the reactor core is the length of time which it is uncovered, since this is primarily what determines the maximum core temperature for a given reactor core. Figure 30 compares the core uncover time for Reference Systems I, II, and III, showing the improvement which was made in Reference Systems II and III. Since the ultimate system would have no time during which the core is uncovered, this graph illustrates very clearly the real margin between the systems, and how much margin remains for future development.

\subsection{COMPLEMENTARY SYSTEM INTERACTION ANALYSIS}

Containment systems currently in use rely on a number of active emergency core cooling systems to prevent core melt as a consequence of a loss-of-coolant accident. In the BWR system the core spray cystem and low pressure coolant injection system are two independent means for delivering cooling water to the reactor core after the reactor vessel is depressurized. However, small breaks in the primary system of both a PWR and a BWR present a problem for emergency core cooling because the pressure in the vessel can remain high for an appreciable time after the water level has dropped beluw the core. To cover this contingency. the high pressure coolant injection system (HPCI) uses the pressure in the vessel to drive a steam-turbine, pump to pump coolant into the vessel. The net effect is to maintain water level and reduce vessel pressure until the core spray or low pressure coolant injection systems (LPCI) can be used. In addition, an automatic blowdown system is provided which detects critically low water level in the reactor vessel and opens the relief valves to reduce vessel pressure and thereby permit the core spray or LPCI to come on. The automatic blowdown provides the same effect as discussed above for Reference System II where the reactor vessel vent valves are opened to accelerate the blowdown for the small break case.

Which of these systems would be used with the pressure suppression/gravity flooding system, and over what range of break sizes, is determined by the system designer. In this study we have examined the simultaneous operation of these emergency core cooling systems with the suppression/ flooding system to ensure that the ability to handle the accident is not compromised. As shown in Figure 31, the suppression/flooding system performance is relatively unaffected by simultaneous operation of the HPCI. The effect of the $\mathrm{HPCI}$ is to improve slightly the time to reflood the core due to the additional water added by the HPCI pump.

As discussed above, the automatic blowdown system has the same effect as prompt opening of the reactor vessèl vent valves. Actuated on low-low water level, functioning of the automatic blowdown system would simply preempt the vessel vent valves and thereby shorten the time to reflood the core. The core spray and low pressure injection systems are prevented from operating before the reactor vessel has blown down by virtue of 


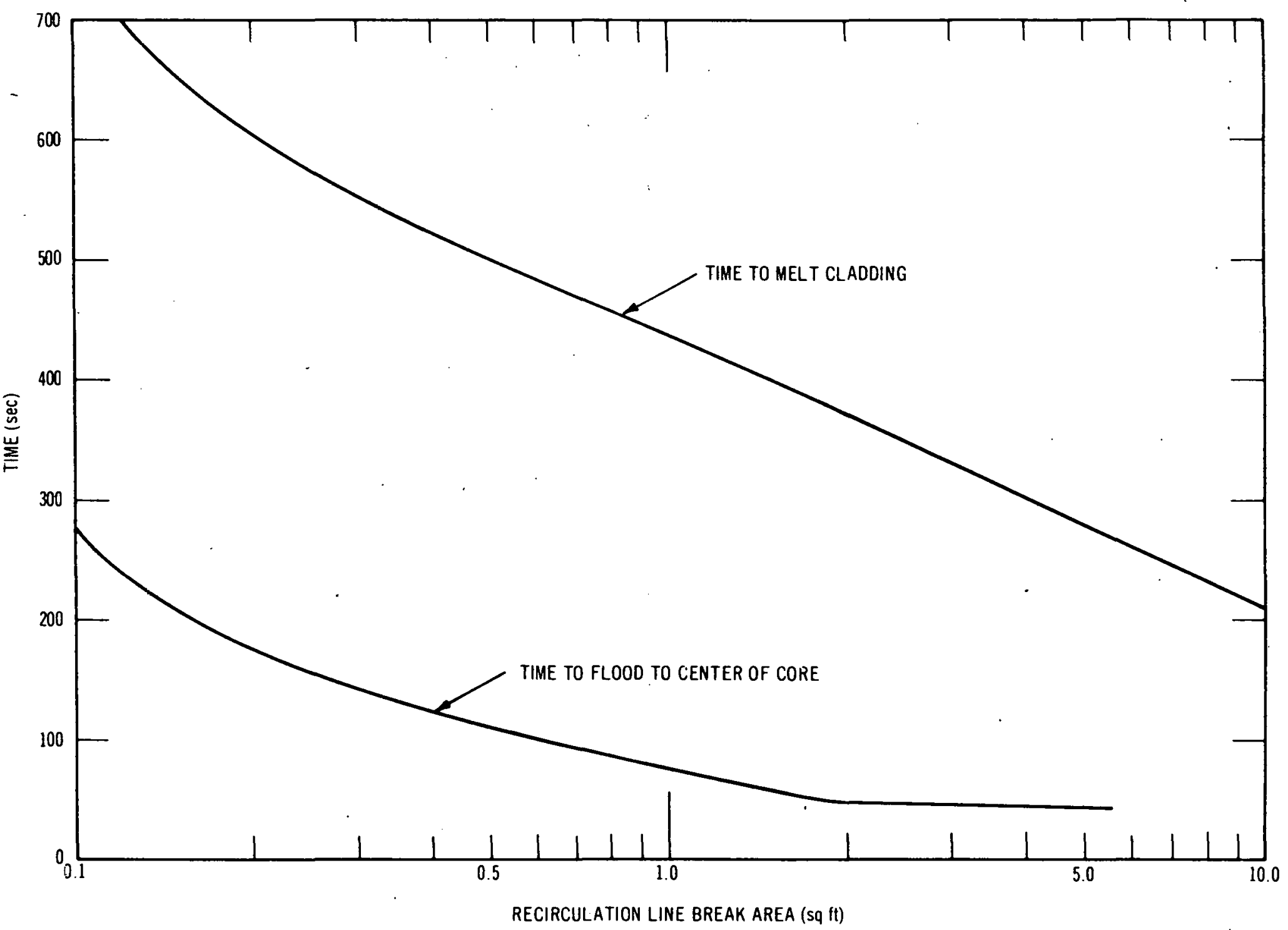




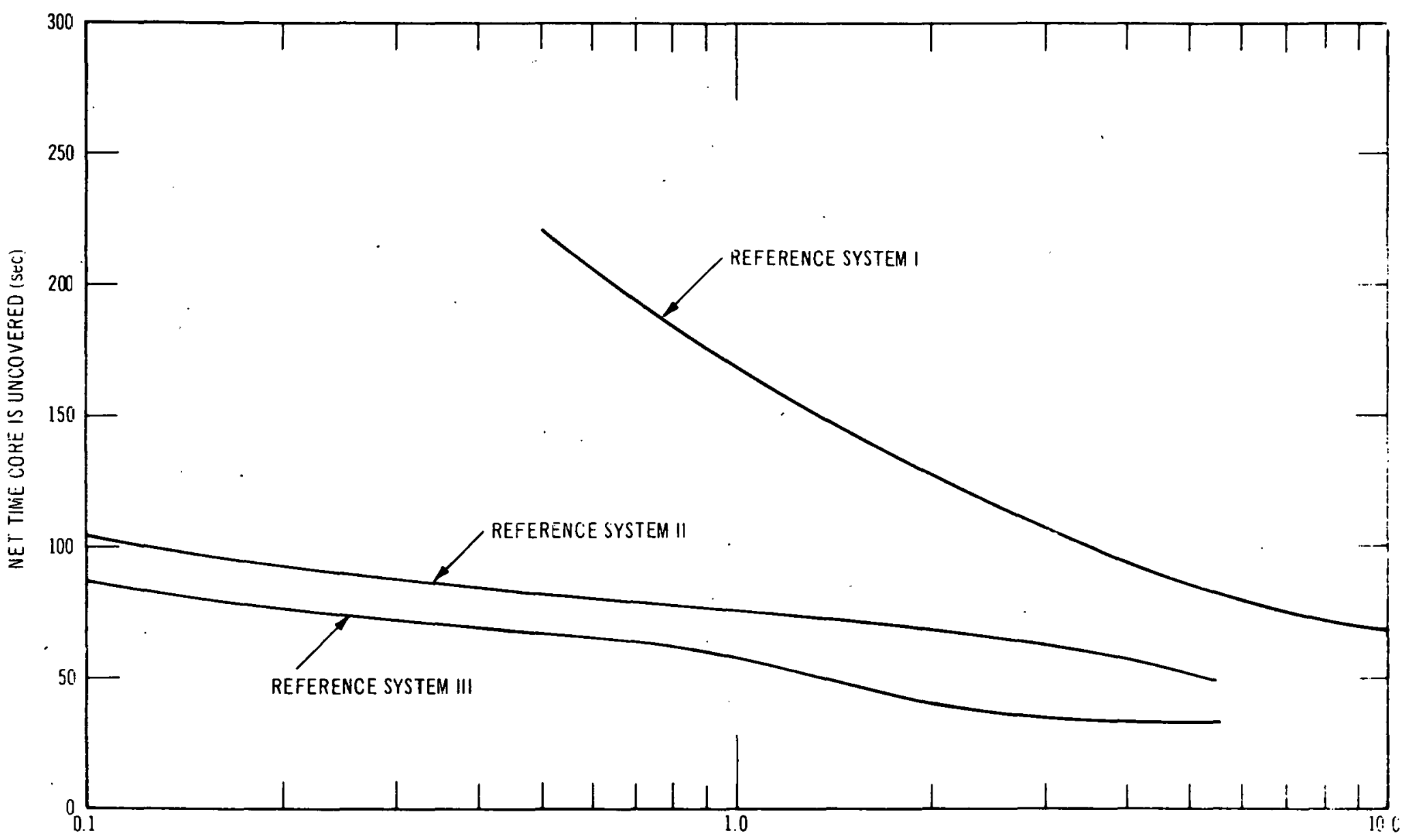

RECIRCULATION LINE BREAK AREA (sq ft)

FIGURE 30. NET TIME CORE IS UNCOVERED VERSUS RECIRCULATION LINE BREAK AREACOMPARISON OF REFERENCE SYSTEMS I, II, AND III 


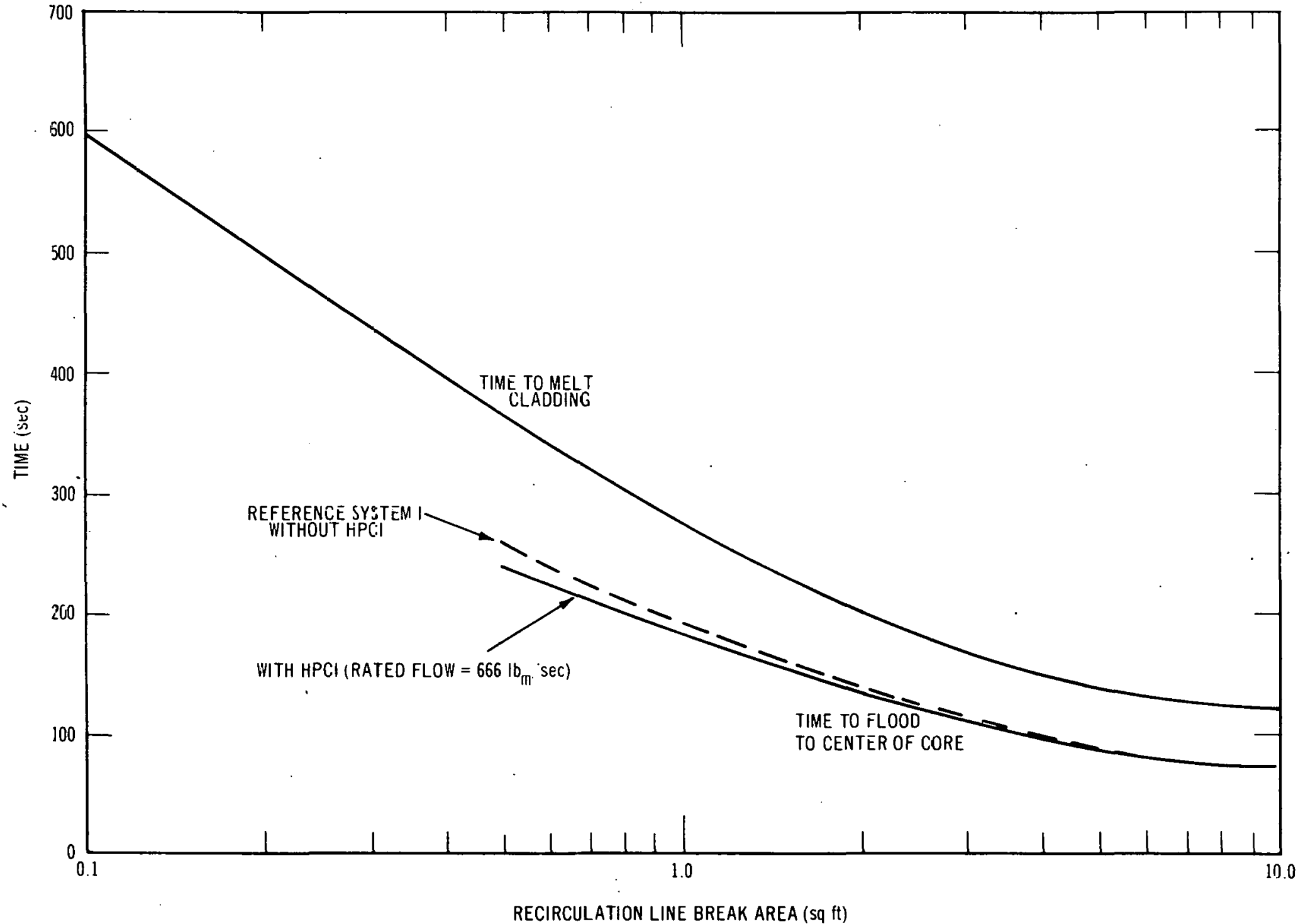


their relatively low delivery pressure. Consequently, they can not affect the initial stages of the transient, but after the reactor is at lower pressures they provide core cooling and inventory makeup in the vessel. Here again, the net result is to improve slightly the system's performance.

\subsection{VIABILITY ANALYSIS}

The response of a pressure suppression/ gravity flooding containment system consists of the following sequence of events:

1. A pipe break in the primary system initiates the loss-of-coolant accident.

2. The primary system blows down, pressurizing the drywell.

3. Air and steam flow through the auxiliary vents to the auxiliary suppression pool.

4. The rupture disks on the drywell vents burst, venting the drywell into the flood pool.

5. Water flows from the flood pool into the drywell.

6. Reactor vessel vents open, and refloodling of the vessel proceeds.

Of these six events, the first three are common to all pressure suppression containment systems and only the last three are unique with the gravity flooding concept. The factors which determine the viability of this system with regard to these three events are:

1. The rupture disks must burst at the proper pressure and open the required flow area for venting and subsequently flooding the drywell.

2. The pressure vessel vent valves must open in order to flood the reactor vessel in the time predicted.
There are two types of rupture disks which can be used in the drywell vent system. One type of disk ruptures by material failure when the applied pressure stresses the disk beyond the yield point. This type of disk is subject to some uncertainty in the set pressure due to the temperature dependence of the yield stress, variation of yield stress from one lot to another, and creep. Disks of this type are the "standard" rupture disk design and are commercially available in a variety of sizes and materials.

A second type of disk ruptures by elastic instability when the applied pressure loads the disk support structure to the point where it buckles. This type of disk is less sensitive to temperature since elastic modulus and Poisson's ratio are the principal properties which control its performance. This disk holds considerable promise for the drywell vent system. An example of a commercially available disk of this type is the Calmec design shown in Figure 32 . In this design a Bellville spring washer provides the element for elastic instability operation. Pressure on the disk loads the washer until it snaps to the right, impaling the disk on a knife edge just beyond the spring, cleanly shearing off the disk.

A relatively simple and common arrangement of double rupture disks can be developed to ensure that all disks burst at the desired pressure. Figure 33 illustrates this rupture disk arrangement. Gas pressure between the disks supports them and prevents them from bursting until the pressure difference across the disks reaches the desired level. At this point, one of the disks will rupture, blowing down the nitrogen charging gas in the other inter-disk spaces, loading all the other disks well beyond their rupture points. The interconnecting pipe lines between the rupture disks can be made redundant by having each inter-disk space connected to two others, virtually eliminating the possibility of a plugged line disrupting the sequence. 


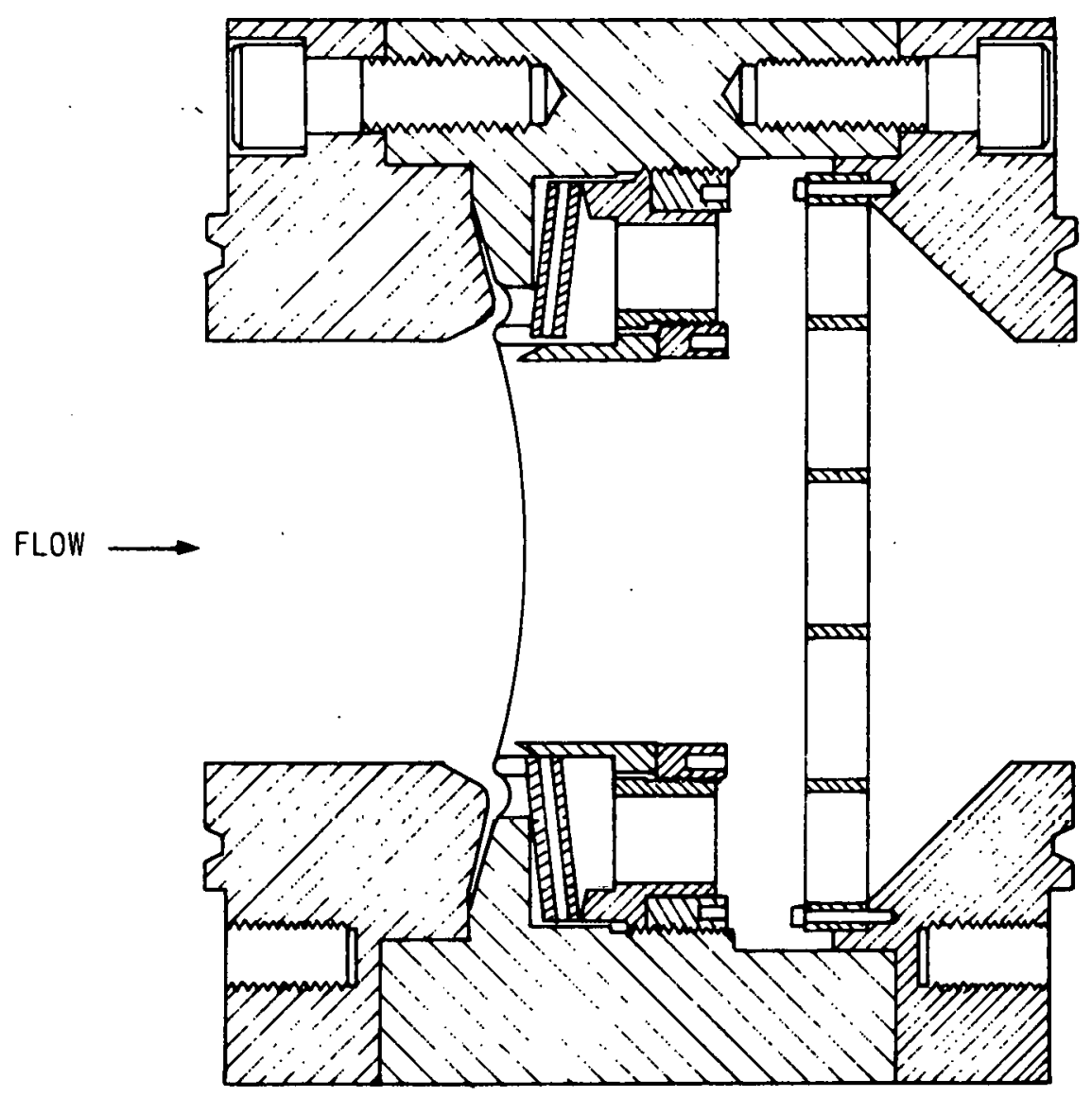

FIGURE 32. RUPTURE DISK DETAIL 


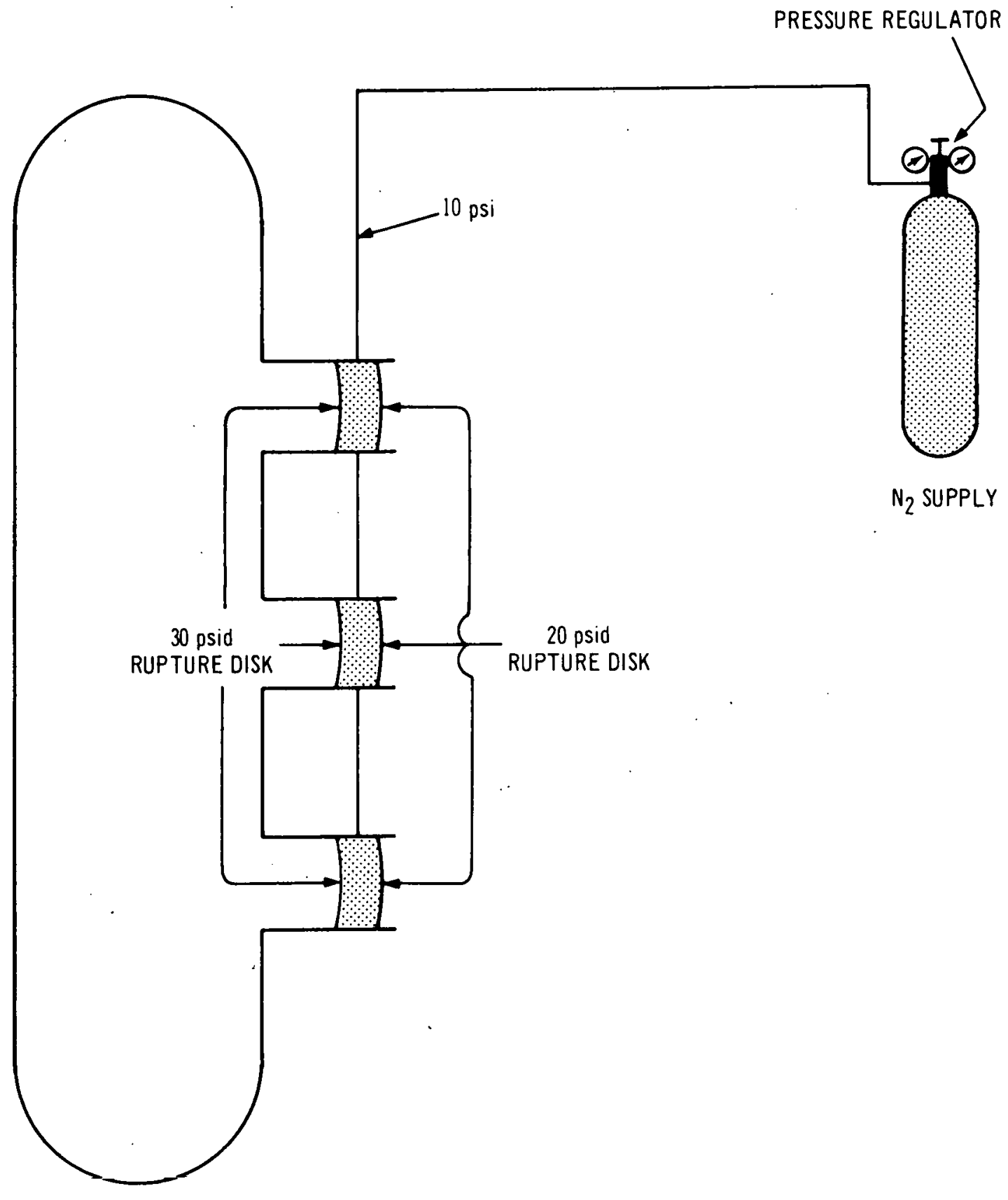


The gas charging supply line will be very small, only large enough to make up for leaks, but not large enough to keep the pressure in the disk plena at the steady-state level.

A system which is important to any flooding scheme is the reactor vessel vent which must open for reflooding the vessel. A completely passive venting system for performing this function would make use of reactor pressure on the valve seat to hold the valve in the closed position, and stored energy in a spring to open the valve when reactor pressure drops off. If the system designer prefers to actuate the reactor vent on low water level rather than low pressure, the techniques used in existing automatic blowdown systems could be used. In either case it is apparent that there will be no particular difficulty in providing the required reactor vessel venting system.

In any reactor safety system, the integrity of the primary containment (i.e., the drywell in this system) is of primary importance. The type of drywell envisioned for the suppression/flooding scheme is a prestressed concrete pressure vessel designed for the internal pressure which would result if there were no pressure suppression at all. The use of prestressed concrete pressure vessels is a proven technique which has been applied to reactor vessels in the nuclear power industry because of their inherent safety (e.g., French reactors EDF-1, EDF-2, and British gas-cooled reactors). In addition, prestressed concrete is currently being used in "standard" type containment structures.

More specifically with regard to this application, the concrete drywell must be able to sustain the consequences of a loss-ofcoolant accident without violating the drywell integrity. The mechanism by which loss of integrity might occur could be either a reaction force of a pipeline or a missile being hurled against the drywell wall. Both of these possibilities are not unique with the suppression/flooding system. The type of accidents being investigated here are indigenous to all nuclear plants and have been investigated for standard emergency cooling systems and containment systems. Hence, the same precautions which are taken to prevent pipe whipping or potentially dangerous missiles in current plant designs must be employed in the suppression/flooding concept as well. The question then reduces to whether the suppression/flooding drywell is as strong or resistant to impact as current plant designs. The drywell of the suppression/flooding safety system will be designed for a higher pressure than is the current practice for both dry and pressure suppression containment systems. It is, therefore, inherently stronger and more impact resistant. In addition to its higher pressure rating, the prestressed concrete construction has considerably more mass and, therefore, has greater ability to absorb impact loads without serious damage.

Another possibility which must be avoided is causing the loss-of-coolant accident by failure of the prestressed concrete drywell. The prestressed concrete structure is basically a very stable structure which can readily be designed to withstand such things as earthquake loads, hurricanes, etc., just as is routinely done with containment structures for the present power plants.

In summary, the viability of the pressure suppression/gravity flooding containment system concept does not appear to present any unique problems. The drywell venting system, which is envisioned as using rupture disks, is an application of current techniques and equipment. The reactor vessel venting system will use valves of a type that is not uncommon in current practice. The development program in Phase II will investigate the operating characteristics of these systems to provide the containment system designer the information needed to build reliable 
systems. Other points can be raised concerning containment system malperformance. but these questions apply to all containment system designs and are being resolved with existing design methods.

SECTION III

\section{CONCLUSIONS}

1. The pressure suppression 'gravity fluoding concept. a unified reactor-containment/emergency-core-cooling system, provides adequate protection over a wide spectrum of reactor loss-of coolant accidents, without the aid of supplementary cooling systems. This concept has been shown to provide a wide margin of safety for preventing reactor core melting over a large range of reactor system parameters, including both BWR and PWR systems.

2. The pressure suppression/gravity flooding system possesses a considerable degree of flexibility in its ability to provide protection for different reactor systems, and in its ability to be adapted to meet different criteria for a given reactor system. This is reflected in the fact that the improvements in core reflooding time made in Reference System I to generate Reference Systems II and III did not require compromise of other desirable features of the system.

3. The pressure suppression/gravity flooding system is capable of providing protection for future water reactors which may have higher power levels, higher core power densities, or higher pressures. Reference System II was shown to be capable of handling power densities and total power levels which were 50 percent greater than the reference power density and total power level. without any modification. Even larger systems could be handled by merely increasing the suppression/ flooding system size (e.g. . larger floodpool, drywell, vents, etc.)

4. Additional design modifications in the suppression;'flooding system are possible to further improve various aspects of its performance, e.g., core réflooding tıme mảy be shortened by increasing the size of the direct reflood vents in Reference System III. Additional flexibility on the minimum pressure to burst the rupture disks may be gained by having a portion of the auxiliary vent area covered by rupture disks which are interconnected with the drywell vent rupture disk actuation system shown in Figure 33. 


\section{SECTION IV}

\section{DESCRIPTION OF ANALYSIS}

The analytical methods used to determine the pressure, temperature, and mass inventory transients in the various compartments of the reactor containment system following a loss-of-coolant accident are described in this section.

\subsection{REACTOR VESSEL BLOWDOWN RESPONSE-G. L. SOZZi}

\subsubsection{General Considerations}

The analytical methods used to calculate the energy and mass release rates issuing from a reactor vessel during blowdown are described in this section. Conservation of mass and energy equations are written for a constant-volume system containing saturated steam and liquid in thermodynamic equilibrium to determine the thermodynamic state in the vessel. Mass flow rates into and out of the vessel are then used to find the rate of change of system pressure and mass inventory.

\subsubsection{Theoretical Development}

The mathematical formulation for the depressurization of the reactor vessel can be derived by considering the conservation of mass and energy in the constant-volume system during blowdown as shown in the control volume sketch below. If the mass now rates are known it is pussible lu develop expressions for the rate of change of mass, energy, and pressure within the system.

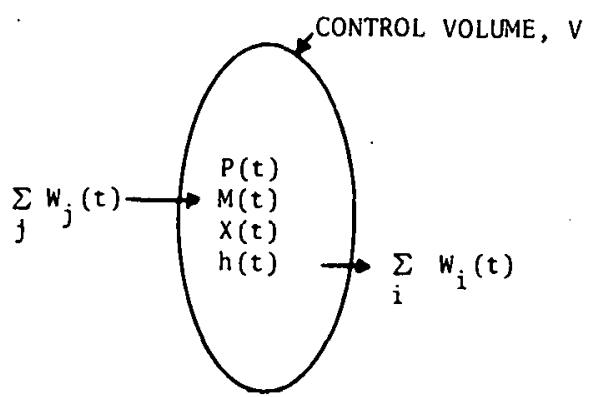

Mass Balance. The volume of the control system is comprised of saturated liquid and saturated vapor in equilibrium:

$$
\mathrm{V}=\mathbf{M}_{\mathbf{f}} \mathbf{v}_{\mathrm{f}}+\mathbf{M}_{\mathrm{g}} \mathbf{v}_{\mathrm{g}}=\text { constant, }
$$

where:

$$
\begin{aligned}
& \mathrm{V}=\text { Total volume of the system } \\
& \text { (i.e., the reactor vessel), } \\
& \mathrm{v} \quad=\text { Specific volume, and } \\
& \mathbf{M}=\text { Mass. }
\end{aligned}
$$

(The subscripts $f$ and $g$ refer to the liquid and vapor phases, respectively.)

Since the total mass in the system is simply

$$
M=M_{f}+M_{g}
$$

then the steam quality, by weight, is given as,

$$
x=\frac{M_{g}}{M} .
$$


Mass Rate of Change in Vessel. From continuity we know that the rate of change of vapor mass in the system is equal to the net inflow of vapor plus the rate at which liquid is flashed to vapor due to depressurization.

Hence,

$$
\frac{d M_{g}}{d t}=\sum_{j} w_{g_{j}}-\sum_{i} w_{g_{i}}+w_{f_{g}}
$$

where

$$
\begin{aligned}
& \mathrm{w}=\text { mass flow rate } \\
& \mathrm{W}_{\mathrm{f}_{\mathrm{g}}}=\text { net nashing rate. }
\end{aligned}
$$

(The subscript $\mathrm{j}$ corresponds to inflow while i refers to the outflow from the vessel evaluated at the thermodynamic conditions within the system.) Similarly, the rate of change of liquid mass in the vessel is

$$
\frac{d M_{f}}{d t}=\sum_{j} w_{f_{j}}-\sum_{i} w_{f_{i}}-w_{f_{g}} .
$$

Rate of Change of Energy in Vessel. The rate of change of energy in the system can be expressed from the First Law of Thermodynamics:

(Net energy inflow) - (net energy outflow) $=$ (rate of change of internal energy)

$$
\begin{aligned}
& \left(\dot{q} \mp \sum_{j} w_{f} h_{f}+\sum_{j} w_{g}^{\prime} h_{g}\right) \\
& -\left(\sum_{i} w_{f} h_{f}+\sum_{i} w_{g} h_{g}\right) \\
& =\frac{d}{d t}\left(M_{f} h_{f}+M_{g} h_{g}-v P,\right)
\end{aligned}
$$

where:

$$
\begin{aligned}
\mathrm{h}= & \text { Enthalpy, } \\
\mathrm{P}= & \begin{array}{l}
\text { Saturated pressure in the sys - } \\
\text { tem, and }
\end{array} \\
\dot{\mathrm{q}}= & \text { Heat transfer rate to the fluid } \\
& \text { from the surroundings (solids). }
\end{aligned}
$$

The right hand side of Equation 4.6 can be expanded, using the chain rule, to yield

$$
\begin{aligned}
& \text { (Rate of change of internal energy) } \\
& =\left[M_{g} \frac{d h_{g}}{d P}+M_{f} \frac{d h_{f}}{d P}\right] \frac{d P}{d t}+h_{g} \frac{d M_{g}}{d t} \\
& +h_{f} \frac{d M_{f}}{d t}-\frac{V d P}{d t} .
\end{aligned}
$$

Flashing Rate in Vessel. After substituting Equations 4.4, 4.5, and 4.6a into Equation 4.6 the expression for the net flashing rate is:

$$
w_{f g}=\frac{1}{h_{f g}}\left\{\dot{q}+\sum_{j} w_{g} h_{g}-\sum_{i} w_{g} h_{g}\right.
$$

$$
\begin{aligned}
& +\sum_{j} w_{f} h_{f}-\sum_{i} w_{f} h_{f}-\left[M_{g} \frac{d h}{d P}\right. \\
& \left.\left.+M_{f} \frac{d h_{f}}{d P}-V\right] \frac{d P}{d t}\right\}
\end{aligned}
$$

Vessel Depressurization Rate. In order to arrive at an expression for depressurization rate we start by differentiating Equation 4.1, realizing that for a fixed total system volume $\dot{V}=0$; then,

$$
\begin{aligned}
& M_{g} \frac{d v_{g}}{d t}+v_{g} \frac{d M_{g}}{d t}+M_{f} \frac{d v_{f}}{d t} \\
& +v_{f} \frac{d M_{f}}{d t}=0 .
\end{aligned}
$$


Now expanding this by means of the chain rule we obtain:

$$
\begin{aligned}
& v_{g} \frac{d M_{g}}{d t}+v_{f} \frac{d M_{f}}{d t}+\left(M_{f} \frac{d v_{f}}{d P}\right. \\
& \left.+M_{g} \frac{d v_{g}}{d P}\right) \frac{d P}{d t}=0 .
\end{aligned}
$$

With expressions for $d M_{g} / d t$ and $d M_{f} / d t$ as given by Equations 4.4 and 4.5, Equation 4.9 can be written:

$$
\begin{aligned}
& v_{g}\left[\sum_{j} w_{g}-\sum_{i} w_{g}+w_{f_{g}}\right] \\
& +v_{f}\left[\sum_{j} w_{f}-\sum_{i} w_{f}-w_{f g}\right] \\
& +\left[M_{f} \frac{d v_{f}}{d P}+M_{g} \frac{d v_{g}}{d P}\right] \frac{d P}{d t}=0 .
\end{aligned}
$$

After substituting Equation 4.7 into Equation 4.10 and rearranging, we obtain the following expression for depressurization rate:

$$
\frac{d P}{d t}=-\left[\frac{f_{1}(P)+f_{2}(P)}{f_{3}(P)}\right],
$$

where:

$$
\begin{aligned}
f_{1}(P)= & {\left[v_{f}-l_{f} \frac{v_{f}}{h_{f_{g}}}\right] \sum_{j} w_{f} } \\
& +\left[v_{g}-h_{g} \frac{v_{f_{g}}}{h_{f_{g}}}\right] \sum_{j} w_{g}
\end{aligned}
$$

$$
\begin{aligned}
f_{2}(P)= & \frac{v_{f_{g}}}{h_{f_{g}}}\left[\dot{q}+\sum_{j} w_{f} h_{f}-\sum_{i} w_{f} h_{f}\right. \\
& \left.+\sum_{j} w_{g} i_{g}-\sum_{i} w_{g} h_{g}\right] \\
f_{3}(P)= & M_{g}\left[\frac{d v_{g}}{d P}-\left(\frac{v_{f_{g}}}{h_{f_{g}}}\right) \frac{d h_{g}}{d p}\right] \\
& +M_{f}\left[\frac{d v_{f}}{d P}-\left(\frac{v_{f}}{h_{f_{g}}}\right) \frac{d h_{f}}{d P}\right] \\
& +\left(\frac{v_{f g}}{h_{f}} \frac{v}{J} .\right.
\end{aligned}
$$

Mass Flow Rates. The mass flow rates entering the reactor vessel during the blowdown are treated as functions of time and are independent of the internal thermodynamic conditions in the vessel. These flow rates may be liquid or vapor or some combination of the two. The outlet flow rate may also be independent variables calculated from one of two flow models: critical flow as a function of the control volume stagnation properties $P_{0}$ and $h_{0}$, or subcritical flow as a function of the pressure difference $P_{0}-P_{\text {sink }}$ (sink refers to the pressure outside the vessel).

Critical flow is flow which is "choked" at some point in the blowdown line where the Mach number is unity. Critical or maximum flow (both single-phase and two-phase) will persist when the ratio of driving pressure (vessel pressure) to sink pressure (drywell) 
is greater than approximately two. The critical flow analysis of F. J. Moody ${ }^{(1)}$ is used to determine the flow rate for critical flow conditions. The results of his analysis are shown in Figures 34 through 38 for various friction coefficients ( $\bar{f} \mathrm{~L} / \mathrm{d})$.

For the instantaneous values of pressure, $P$, enthalpy, $h$, and friction coefficient, $\overline{\mathrm{fL}} / \mathrm{d}$, a three-variable interpolation is performed using Moody's results to find the critical mass velocity:

$$
G_{c}=G(P, h, \bar{f} L / d) .
$$

The mass flow rate is now calculated from

$$
w_{c}=A G_{c} \text {, }
$$

where

A = minimum flow area in the line.

Subcritical flow will exist prior to the formation of bubbles in a liquid flow and establishment of two-phase critical flow, or when the source pressure is low so that the ratio of $\mathrm{P}_{0} / \mathrm{P}_{\text {sink }}<2$.

Subcritical mass velocity is calculated from:

$$
G_{s c}=\sqrt{\frac{2 g\left(P_{0}-P_{s i n k}\right)}{v_{f}(1.4+\bar{f} L / d) \phi^{2}}},
$$

where:

$$
\begin{aligned}
\phi \cdot= & \text { Martinelli-Nelson two-phase } \\
& \text { multiplier. }
\end{aligned}
$$

The mass fluw rate is:

$$
w_{s c}=A G_{s c} .
$$

\subsubsection{Numerical Solution}

If a function of time and its time derivatives are known at time $t_{1}$, the value of the function at time $t_{1}+\Delta t$ can be obtained from a Taylor series expansiül. The first three terms of the series are

$$
\begin{aligned}
f\left(t_{1}+\Delta t\right)= & f\left(t_{1}\right)+\frac{\Delta t}{1 !} f^{\prime}\left(t_{1}\right) \\
& +\frac{\Delta t^{2}}{2 !} f^{\prime \prime}\left(t_{1}\right)+\ldots,(
\end{aligned}
$$

where:

$$
\begin{aligned}
& f^{\prime}\left(t_{1}\right)=\frac{d f}{d t} \text { at } t=t_{1}, \\
& f^{\prime \prime}\left(t_{1}\right)=\frac{d^{2} f}{d t^{2}} \text { at } t=t_{1} \text {, and } \\
& \Delta t \quad=\text { Size of time step. }
\end{aligned}
$$

Integration. If the term involving the second derivative is negligible, the Euler forward integration method is obtained:

$$
f\left(t_{1} \Delta t\right)=f\left(t_{1}\right)+\Delta t f^{\prime}\left(t_{1}\right)
$$

Time Step. A variable time step based on an accuracy criterion has been used in the integration method. The error made in one extrapolation of the Euler method can be approximated by the third term of Taylor's series given by Equation 4.16 ; i.e.,

$$
e=\frac{\Delta t^{2}}{2 !} r^{\prime \prime}\left(t_{1}\right)
$$

An exact equation for the second time derivative can be approximated by the rate of change of the first derivative, i.e.

$$
f^{\prime \prime}\left(t_{1}\right)-\frac{f^{\prime}\left(t_{1}+\Delta t\right)-f^{\prime}\left(t_{1}\right)}{\Delta t} .
$$



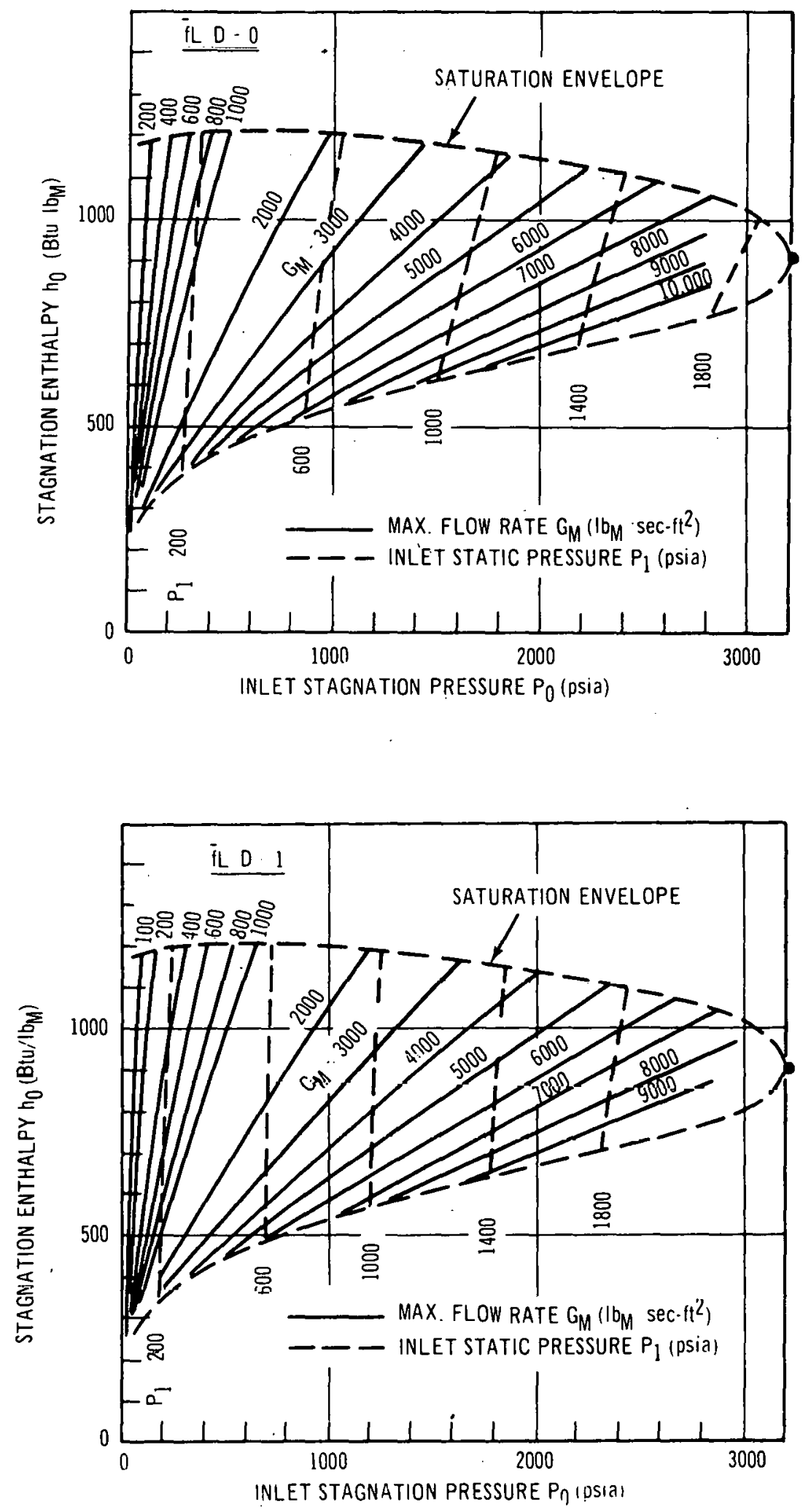

FIGURE 34. PIPE MAXIMUM STEAM.'WATER DISCHARGE RATE 

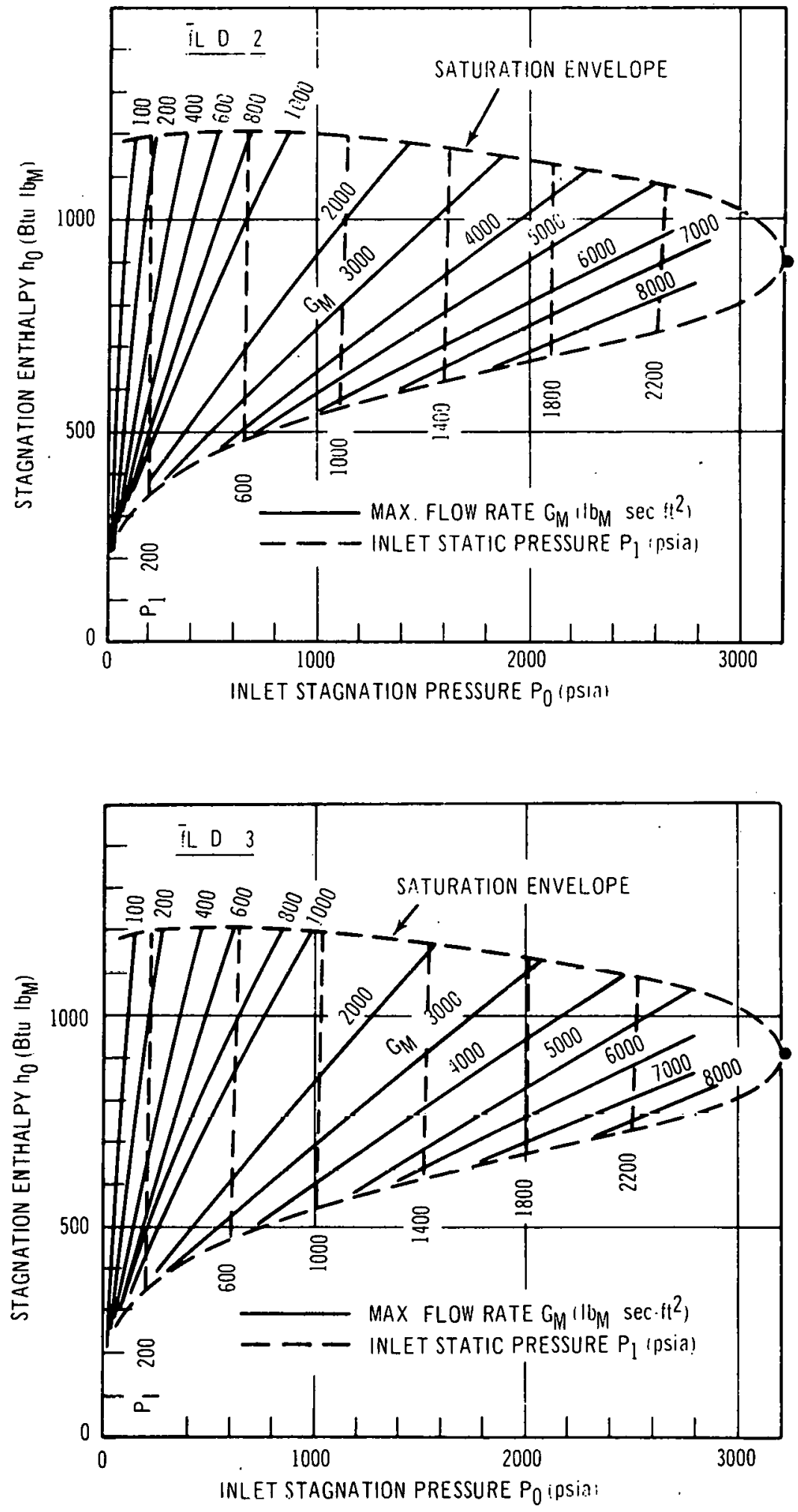

FIGURE 35. PIPE MAXIMUM STEAM. WATER DISCHARGE RATE 

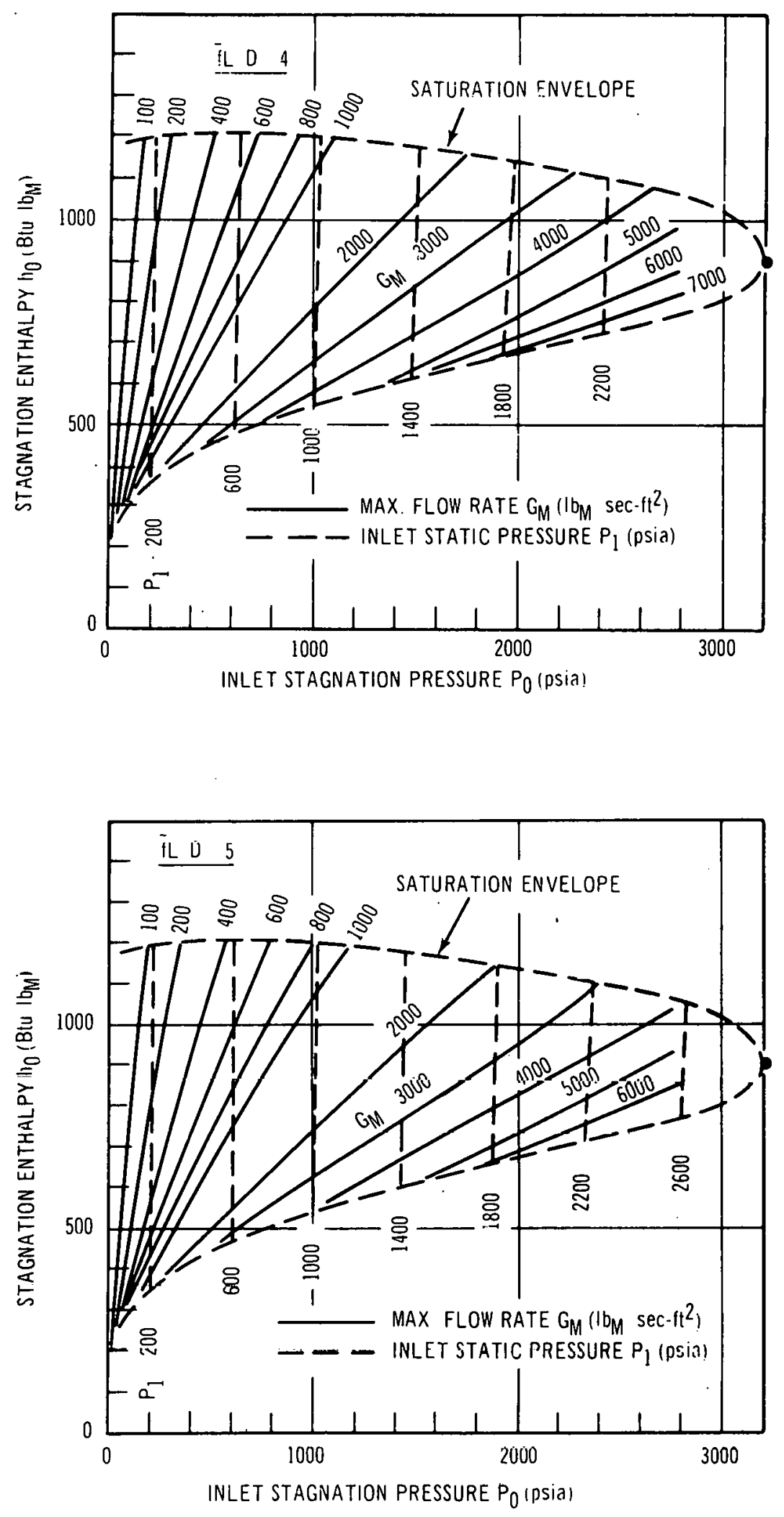

FIGURE 36. PIPE MAXIMUM STEAM/WATER DISCHARGE RATE 

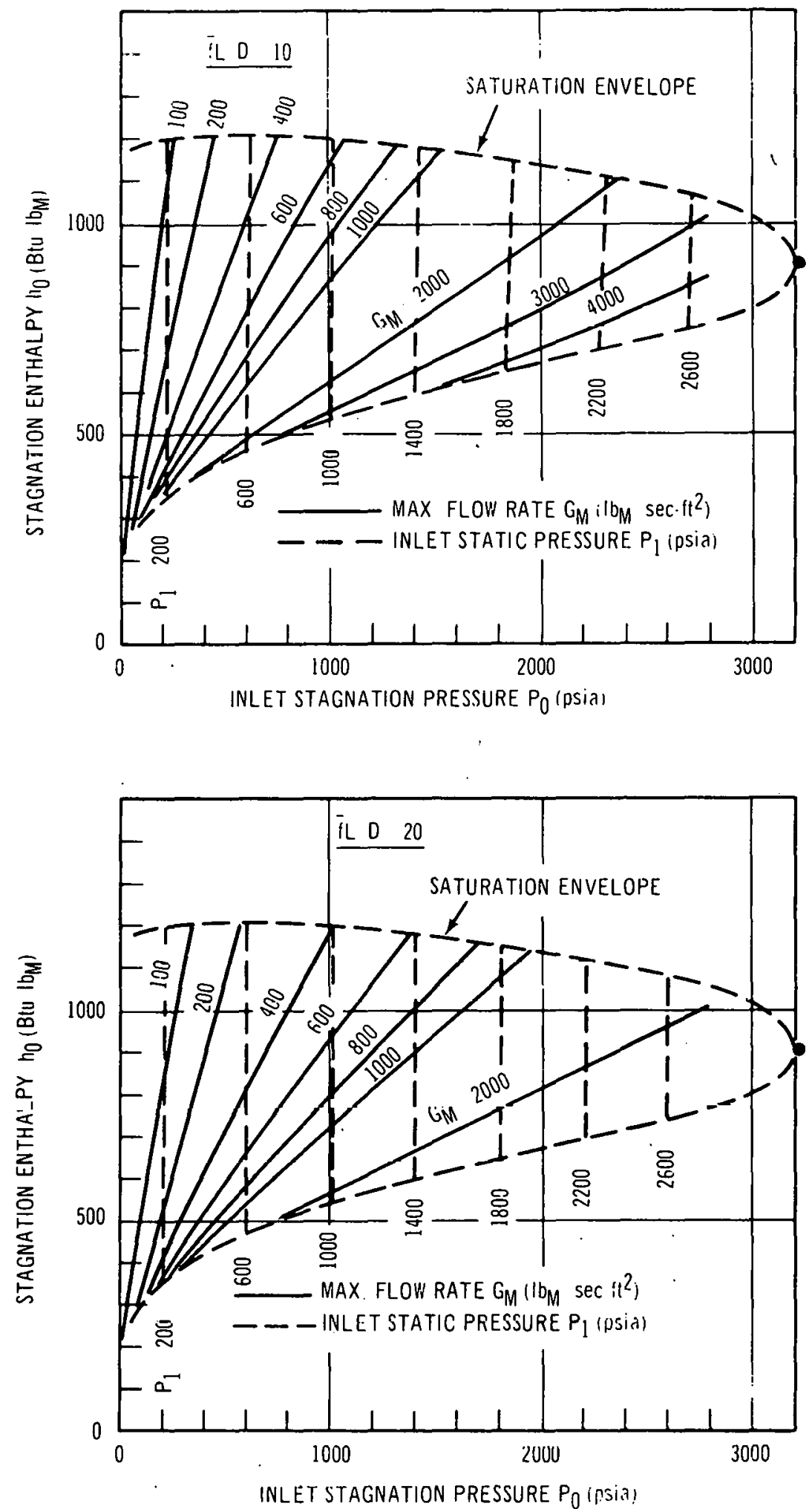

FIGURE 37. PIPE MAXIMUM STEAM/WATER DISCHARGE RATE 

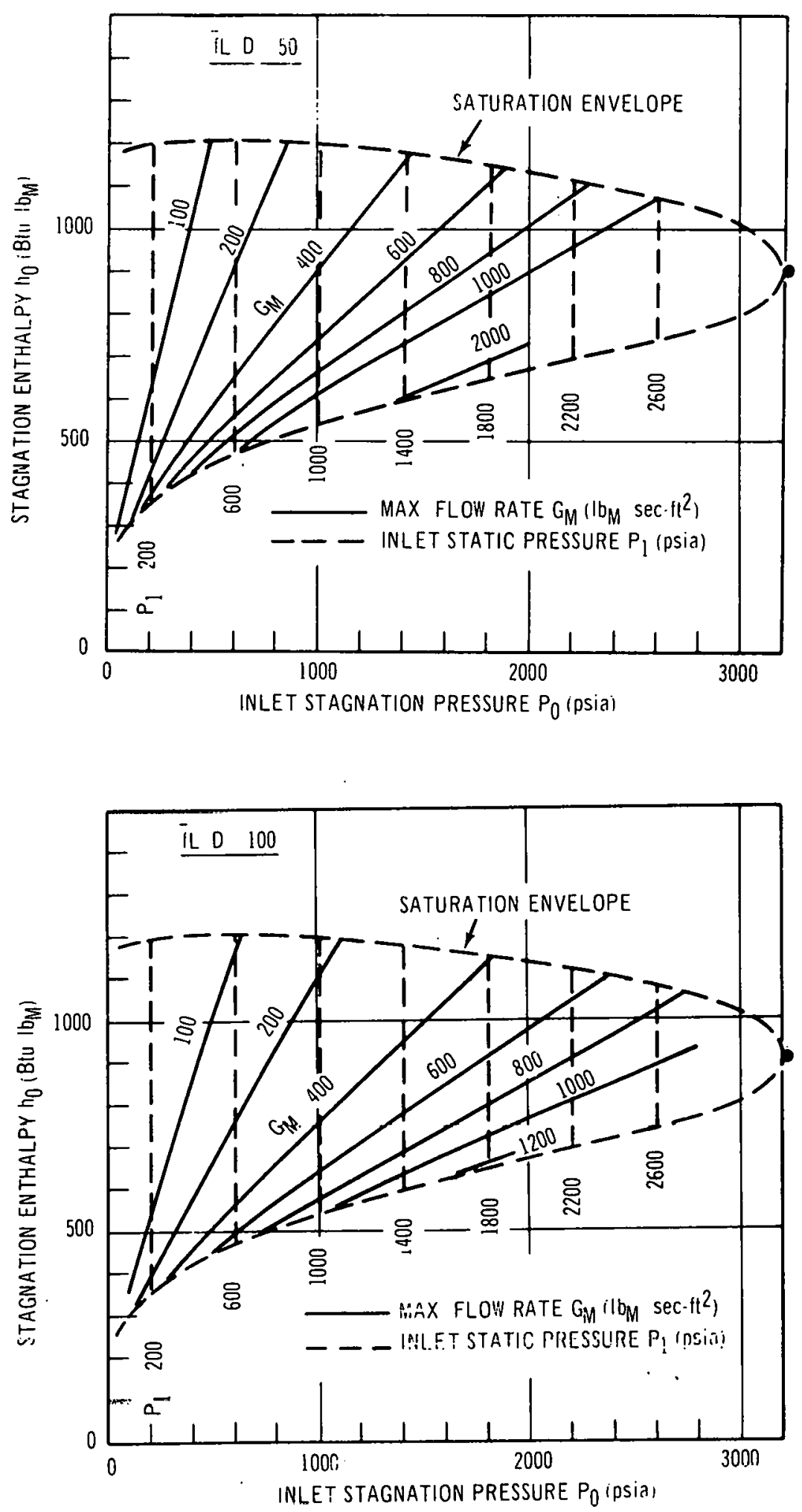
After substituting Equation 4.19 into 4.18 , an approximation of the error made in one time step can be calculated:

$$
e \approx \frac{\Delta t}{2}\left[f^{\prime}\left(t_{1}+\Delta t\right)-f^{\prime}\left(t_{1}\right)\right]
$$

If the magnitude of this error is within the error criterion, $\epsilon$, then the time step is doubled for the next calculation. If $|c| \therefore c$, then the time step is halved and the previous calculations are repeated.

Calculations. Equations 4.4, 4.5, and 4.11 were programmed for machine calculation using the numerical methods described above.

\subsection{DRYWELL RESPONSE AND PRESSURE SUPPRESSION- -J. A. Woolley}

\subsubsection{General Consideration}

This section describes the analytical model used to study the pressure suppression part of the loss-of-coolant accident. The system to be analyzed is diagrammed in the sketch. It consists of a drywell which has mass and energy flowing into it from the reactor vessel. The drywell has two vents: the auxiliary vent and the drywell vent. The auxiliary vent, which may be partially filled with water, is directed into a small pool. The drywell vent has rupture disks at its exit into the flood pool. Once the disks have ruptured, the flood pool is combined with the auxiliary pool, creating one pressure suppression pool for all future time. The secondary containment building makes up the common air space above the auxiliary and flood pools.

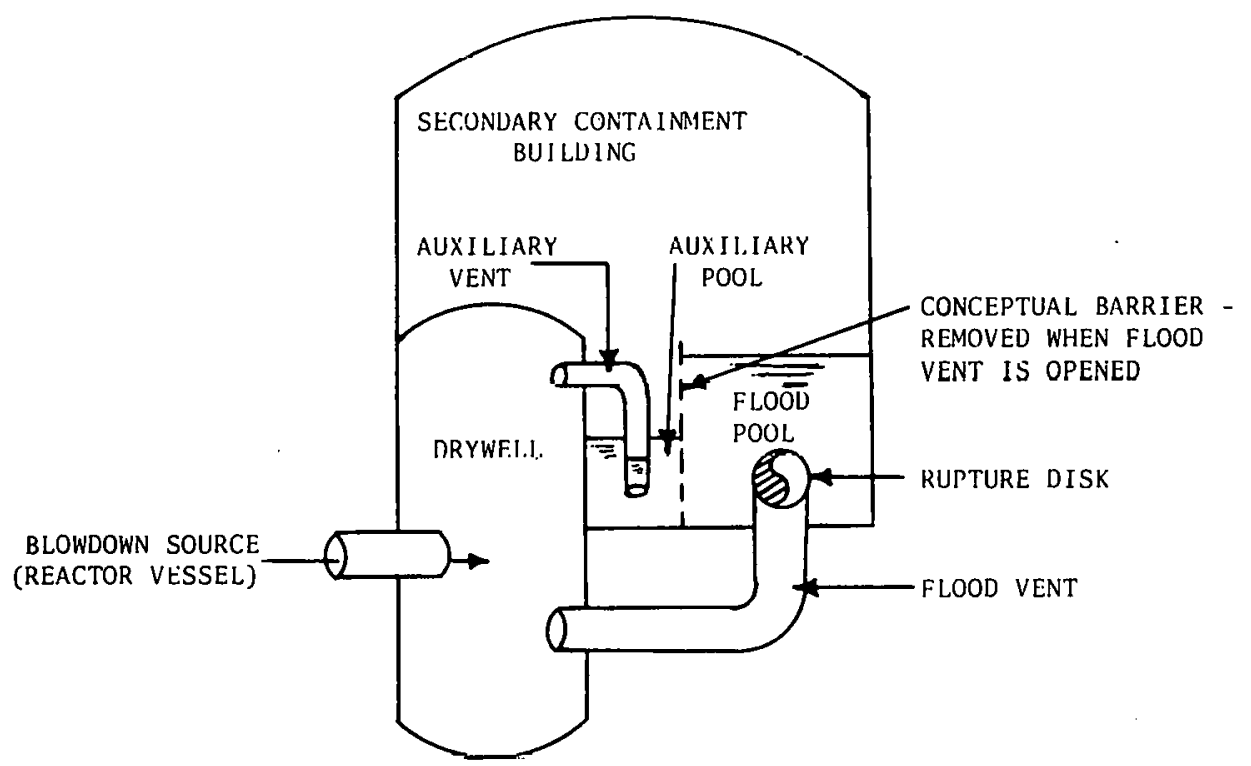

The chain of events occurring during the pressure-suppression phase of an accident is as follows:

1. Mass and energy enter the drywell from the blowdown source, i.e., from the reactor vessel.
2. Drywell temperature and pressure increase.

3. The increased pressure acts to clear water from the auxiliary vent line and presses against the main vent rupture disks. 
4. When the auxiliary vent is cleared, air and steam flow through the vent and into the auxiliary pool. The steam is condensed by the pool, increasing the pool temperature. The air passes through the pool and enters the secondary containment building, causing temperature and pressure in that building to rise.

5. When the drywell pressure causes the rupture disks to burst, air and steam flow through the main vent into the flood pool. Auxiliary and flood pools are now lumped together forming a single suppression pool to simplify the analysis. Flow from both vents is directed to this pool; steam is condensed and air bubbles through as in number 4 .

6. As the transient proceeds, energy inflow from the blowdown source decreases, because of reduced reactor pressure, while vent flow continues. The result is reduced drywell pressure.

7. Vent flow decreases with decreasing drywell pressure.

8. Eventually, air-steam flow out the main vent is no longer sufficient to hold back water flow from the flood tank to the drywell. At this point drywell flooding begins, and the pressure suppression phase of the accident is complete.

\subsubsection{Theoretical Development}

Drywell Conditions. The total energy, $\mathrm{E}_{\mathrm{D}^{\prime}}$ air mass, $\mathrm{M}_{\mathrm{a}_{\mathrm{D}}}$, and water mass, $\mathrm{M}_{\mathrm{w}_{\mathrm{D}}}$ (liquid plus vapor), in the drywell at any time are known by numerical integration of the appropriate rate equations, Equations 4.44, 4.45 , and 4.46 ; which are developed by taking mass and energy balances on the drywell.
An independent expression for total drywell energy is

$$
\begin{aligned}
E_{D}= & M_{f_{D}} u_{f}+M_{g_{D}} u_{g} \\
& +M_{a_{D}} C_{v} T_{D}
\end{aligned}
$$

where:

$$
\begin{aligned}
\mathbf{M}_{f_{D}} & =\left(1-\chi_{D}\right) M_{w_{D}} \\
M_{g_{D}} & =x_{D} M_{w_{D}} \\
x_{D} & =\frac{v-v_{f}}{v_{g}-v_{f}} \\
v & =\frac{v_{D}}{M_{w_{D}}}
\end{aligned}
$$

and all thermodynamic properties arè evaluated at $\mathrm{T}_{D}$, the equilibrium temperature of the air-steam-liquid mixture within the drywell. Numerical solution of Equation 4.21 gives $T_{D}$. The vapor partial pressure, $P_{g}$ ' is obtained from property tables if saturated conditions exist, or by iteration if the drywell conditions are superheated.

With $\mathrm{T}_{\mathrm{D}}, \mathrm{P}_{\mathrm{g}_{\mathrm{D}}}$, and all thermodynamic properties known, the total drywell pressure is

$$
P_{\cdot D}=P_{g_{D}}+P_{a_{D}}
$$

where:

$$
\begin{aligned}
& \mathrm{P}_{\mathrm{a}_{\mathrm{D}}}=\frac{\mathrm{M}_{\mathrm{a}_{\mathrm{D}}} \mathrm{R}_{\mathrm{a}} \mathrm{T}_{\mathrm{D}}}{\mathrm{v}_{\mathrm{a}_{\mathrm{D}}}} \text { and } \\
& \mathrm{v}_{\mathrm{a}_{\mathrm{D}}}=\mathrm{v}_{\mathrm{D}}-\mathrm{v}_{\mathrm{f}} \mathrm{M}_{\mathrm{f}_{\mathrm{D}}}
\end{aligned}
$$


Clearing the Auxiliary Vent. As indicated in the sketch of the system, the auxiliary vent may be partially filled with water. This water slug must be cleared before flow may yass from the drywell to the auxiliary pool. Applying Newton's Law,

$$
\mathbf{F}=\mathbf{M a},
$$

where $F$ is the net force on the slug, $M$ is its equivalent mass, and $a$, its acceleration, is given by

$$
a=-\ddot{L},
$$

where $L$ is the length of vent still containing water. The equivalent mass of the water slug is

$$
\mathrm{M}=\mathrm{L}_{\mathrm{e}} \frac{\mathrm{A}}{\mathrm{v}} \text {, }
$$

where $A$ is the cross-sectional area of the vent, $v$ is the specific volume of the water, and

$$
\mathrm{L}_{\mathrm{e}}=\mathrm{L}+\mathrm{L}^{\prime}
$$

$L^{\prime}$ being the equivalent length of water outside the vent which must be accelerated. The net force on the slug is

$$
F=\left[P_{D}-\left(P_{S}+P_{H_{S}}\right)\right] A
$$

where $\mathbf{P}_{\mathbf{S}}$ is the pressure in the secondary containment building and $\mathrm{P}_{\mathrm{H}_{\mathrm{S}}}$ is the water head above the auxiliary vent exit. By using Equations 4.20 through 4.33 in Equation 4.29 and applying the gravitational constant, $g_{c}$. we find

$$
\ddot{L}=-g_{c} \dot{v}\left[\frac{P_{D}-P_{S}-P_{H_{S}}}{L+L^{\prime}}\right] .
$$

By integrating this equation twice, the length of vent still containing water is obtained.
Flow may not pass from the drywell to the auxiliary pool until the auxiliary vent is cleared, i.e. $\mathrm{L}=0$.

Opening the Flood Pool Vents (Rupture Disks). When the drywell pressure reaches the value

$$
P_{D}=P_{R}+P_{S}+P_{H_{L}},
$$

where $P_{R}$ is the rupture disk set pressure (differential) and $\mathrm{P}_{\mathrm{H}_{\mathrm{L}}}$ is the water head above the flood vent exit, then the rupture disks are said to burst. At this point the flood vent is open, allowing steam and air to flow from the drywell. The flood pool is combined with the auxiliary pool, and an energy balance calculation gives the temperature of this lumped suppression pool. For all future time, reference to the suppression pool is to this single, lumped pool.

Flow Rate Through Vents. For the total mass flow rate through vent $j$, the compress ible flow equation is

$$
\begin{aligned}
& w_{T_{j}}=A_{j} \sqrt{\frac{k g_{c} P_{D}}{v_{M}}} \\
& x \frac{M_{j}}{\frac{k+1}{2(k-1)}}, \\
& \left(1+\frac{k-1}{2} M_{j}^{2}\right)^{\overline{2(k-1)}}
\end{aligned}
$$

where

$$
k=\frac{C_{P}}{C_{v}}
$$

and $\mathrm{M}_{\mathrm{j}}$ is the Mach number at the vent entrance, which is a function of vent loss coefficient $K_{j}$ and the ratio of entrance pressure to exit pressure, i.e.

$$
M_{j}=f\left(K_{j}, \frac{P_{D}}{P_{s}+P_{{ }_{L}}}\right) .
$$


The specific volume in the vent, assuming an air-steam mixture, is given by

$$
\mathrm{v}_{\mathrm{M}}=\frac{\mathrm{v}_{\mathrm{a}_{\mathrm{D}}}}{\mathrm{M}_{\mathrm{a}_{\mathrm{D}}}+\mathrm{M}_{\mathrm{g}_{\mathrm{D}}}} .
$$

To determine the vent flow rate of each constituent, we have

$$
\begin{aligned}
& w_{g_{j}}=\frac{M_{g_{D}}}{M_{a_{D}}+M_{g_{D}}} w_{T_{j}} \text { and } \\
& w_{a_{j}}=\frac{M_{a_{D}}}{M_{a_{D}}+M_{g_{D}}} w_{T_{j}} .
\end{aligned}
$$

The total flow rate out of the drywell is the sum of the flow out each vent,

$$
\begin{aligned}
& w_{g_{2}}=\sum w_{g_{j}} \\
& w_{a_{2}}=\sum w_{a_{j}}
\end{aligned}
$$

where the subscript 2 represents flow from drywell to suppression chamber.

Drywell Time Derivatives. To get the rate of change of mass in the drywell, a mass balance gives

$$
\begin{aligned}
& \dot{\mathrm{M}}_{\mathrm{w}_{\mathrm{D}}}=\mathrm{w}_{\mathrm{g}_{1}}+\mathrm{w}_{\mathrm{f}_{1}}-\mathrm{w}_{\mathrm{g}_{2}} \text { and } \\
& \dot{\mathrm{M}}_{\mathrm{a}_{\mathrm{D}}}=-\mathrm{w}_{\mathrm{a}_{2}},
\end{aligned}
$$

where the subscript 1 represents the source flow into the drywell. The rate of change of energy in the drywell, assuming no heat loss, is

$$
\begin{aligned}
\dot{E}_{D}= & h_{g_{1}} w_{g_{1}}+h_{f_{1}} w_{f_{1}}-h_{g_{2}} w_{g_{2}} \\
& -C_{p} T_{D} w_{a_{2}} .
\end{aligned}
$$

Suppression Chamber Time Derivatives. An energy balance on the air in the secondary containment building, assuming no noncondensables remain in the pool and neglecting heat losses and pool evaporation, gives

$$
\begin{aligned}
& w_{a_{2}} C_{p} T_{a}^{\prime}=\frac{d}{d t}\left[\begin{array}{lll}
M_{a_{s}} & C_{v} & T_{a_{s}}
\end{array}\right] \\
& =\mathrm{C}_{\mathrm{v}} \mathrm{T}_{\mathrm{a}_{\mathrm{s}}} \dot{\mathrm{M}}_{\mathrm{a}_{\mathrm{s}}} \\
& +C_{v} M_{a_{s}} \dot{T}_{a_{s}}
\end{aligned}
$$

where $T_{a}^{\prime}$ is the temperature of the air entering the building after bubbling through the pool, $\mathrm{M}_{\mathrm{a}_{\mathrm{S}}}$ is the mass of air in the building, and $\mathrm{T}_{\mathrm{a}_{\mathrm{S}}}$ is the temperature of the air in the building. From a mass balance, we have

$$
\dot{\mathrm{M}}_{\mathrm{a}_{\mathrm{s}}}=\mathrm{w}_{\mathrm{a}_{2}}=-\dot{\mathrm{M}}_{\mathrm{a}_{\mathrm{D}}}
$$

therefore,

$$
\dot{\mathrm{T}}_{\mathrm{a}_{\mathrm{s}}}=-\frac{\dot{\mathrm{M}}_{\mathrm{a}_{\mathrm{D}}}}{\mathrm{M}_{\mathrm{a}_{\mathrm{s}}}}\left(\mathrm{lc} \mathrm{T}_{\mathrm{a}}^{\prime}-\mathrm{T}_{\mathrm{a}_{\mathrm{s}}}\right) .
$$

An energy balance on the lumped suppression pool, assuming complete condensation of the steam entering the pool and neglecting heat losses and evaporation, gives

$$
\begin{aligned}
& h_{g_{2}} w_{g_{2}}+C_{p}\left(T_{D}-T_{a}^{\prime}\right) w_{a_{2}} \\
& =\frac{d}{d t}\left[M_{w_{s}} h\right] .
\end{aligned}
$$


where $M_{w}$ is the pool mass and $h$ is the enthalpy of the pool. After expanding, the right hand side of Equation 4.50 becomes:

$$
\begin{aligned}
\frac{d}{d t}\left[M_{w_{s}} h\right]= & h \dot{M}_{w_{s}}+M_{w_{s}}\left(\frac{\partial h}{\partial T}\right)_{p} \dot{T}_{s} \\
& +M_{w_{s}}\left(\frac{\partial h}{\partial P}\right)_{T} \dot{P}_{s}(4.51)
\end{aligned}
$$

For nearly saturated liquid water, $h$ is given approximately by the linear equation $\mathrm{h} \cong \mathrm{C}_{\mathrm{p}}(\mathrm{T}-492) ;$ thus, $(\partial \mathrm{h} / \partial \mathrm{T})_{\mathrm{p}} \cong 1.0$, $(\partial \mathrm{h} / \partial \mathrm{P})_{\mathrm{T}} \cong 0.0$, and we have

$$
\dot{\mathrm{T}}_{\mathrm{s}}=\frac{\mathrm{h}_{f_{2}} \mathrm{w}_{\mathrm{f}_{2}}+\mathrm{h}_{\mathrm{g}_{2}} \mathrm{w}_{\mathrm{g}_{2}}+\mathrm{C}_{\mathrm{p}}\left(\mathrm{T}_{\mathrm{D}}-\mathrm{T}_{\mathrm{a}}^{\prime}\right) \mathrm{w}_{\mathrm{a}_{2}}{ }^{-\mathrm{h} \dot{\mathrm{M}}_{\mathrm{w}_{\mathrm{s}}}}}{\mathrm{M}_{\mathrm{w}_{\mathrm{s}}}}
$$

A mass balance gives

$$
\dot{\mathrm{M}}_{w_{s}}=w_{f_{2}}+w_{g_{2}} .
$$

Assuming that in bubbling through the pool the air reaches the pool temperature, we have

$$
\mathrm{T}_{\mathrm{a}}^{\prime}=\mathrm{T}_{\mathrm{s}}
$$

Also, knowing $\mathrm{T}_{\mathbf{s}}$ from the integral of Equation 4.52 , we can determine $P_{g_{S}}$, the partial pressure of vapor in the secondary containment building. Thus,

$$
\mathbf{P}_{\mathbf{s}}=\mathbf{P}_{\mathbf{g}_{\mathbf{s}}}+\frac{\mathrm{M}_{\mathbf{s}} \mathrm{R}_{\mathrm{a}} \mathrm{T}_{\mathbf{s}}}{\mathrm{v}_{\mathrm{a}_{\mathbf{s}}}}
$$

where:

$$
\begin{aligned}
v_{a_{s}}= & v_{s}-v M_{w_{s}} \text {, and } \\
v \quad= & \text { The specific volume of the pool } \\
& \text { water. }
\end{aligned}
$$

Solution. The equations described above were programmed for computer solution. Time derivatives a re integrated using the numerical method described in Section 4.1. Thermodynamic properties in the drywell are found using algorithms which employ both curve fits and fifth-order interpolation routines. A step-and-interpolate iteration is used to determine the drywell temperature, the vapor pressure for superheated conditions being found from a nested iteration using a perfect gas approximation. The conditions in the secondary containment building must be saturated, with properties found from table look-up and interpolation. The blowdown source is input as a table of mass flow rate and enthalpy versus time, the entries being obtained from the reactor vessel blowdown analysis.

\subsection{GRAVITY FLOODING RESPONSE} -G. L. Sozzi

\subsubsection{General Considerations}

The analytical methods used to investigate the gravity flooding of the drywell and reflooding of the reactor vessel following blowdown of the primary system and bursting of the main rupture disks are discussed in this section. The system for this analysis consists of four interconnected control volumes: flood tank, auxiliary pool, drywell, and reactor vessel. The arrangement of these volumes is shown in Figure 39.

Conservation of mass and energy equations are written for the drywell and reactor vessel; a mass balance alone is applied to the flood tank. The initial conditions in each control volume are derived from the mass and energy remaining in the $m$ at the time gravity flooding of the drywell begins. The pressure suppression response of the drywell containment causes most, if not all, of the air in the drywell to be exhausted to the secondary containment before flooding begins. Therefore, the initial mass in each control system consists of saturated liquid and vapor only. 
0

GEAP-5536

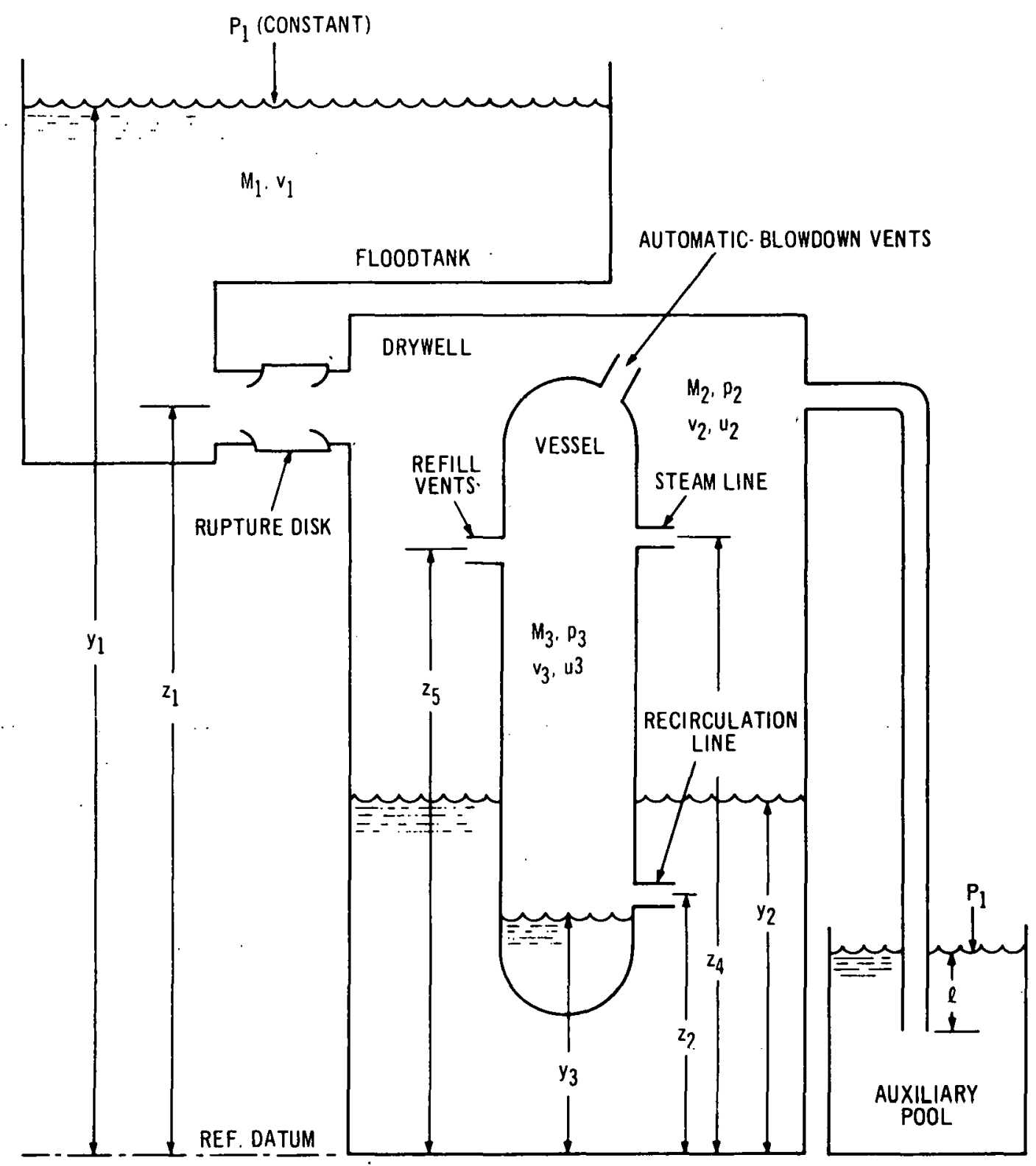


The mass and energy exchange between control systems is evaluated using the saturated properties within each volume.

\subsubsection{Theoretical Development}

The arrangement of control volumes is shown in Figure 39. The elevations, Z, of the various penetrations (breaks, vents, valves, etc.) in each control volume together with the liquid levels, $y$, are shown referenced to the bottom of the drywell.

Mass Balance. Consider the single control volume sketched below.

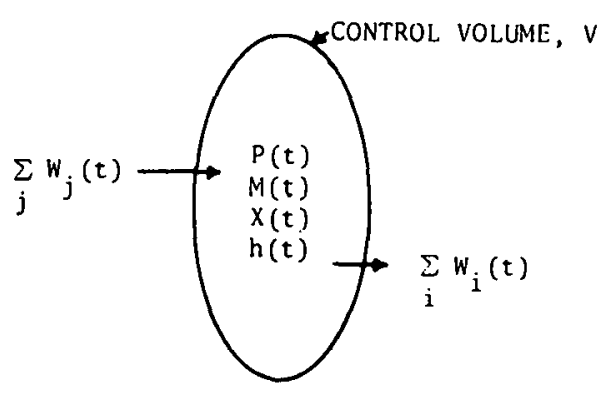

The total water mass, $M$, for the control volume is given as

$$
\mathbf{M}=\mathbf{M}_{\mathrm{f}}+\mathbf{M}_{\mathrm{g}}
$$

where the subscripts, $f$ and $g$, refer to liquid and vapor, respectively. The steam quality (by weight) is given as

$$
\chi=\frac{\mathrm{M}_{\mathrm{g}}}{\mathrm{M}} .
$$

The mass rate of chatige is made up of the net mass flow crossing the boundaries of the control system:

$$
\frac{d \mathrm{M}}{\mathrm{dt}}=\sum_{j} \mathrm{w}_{j}-\sum_{\mathrm{i}} \mathrm{w}_{\mathrm{i}} .
$$

where $w=$ mass flow rate
(The subscripts. $j$ and $i$, refer to inflow and outllow, rèspèctively.)

Energy Balance. The total energy within the control volume is made up of the energy associated with the steam and liquid:

$$
E=M_{g} u_{g}+M_{f} u_{f}=u M
$$

where $u$ is the internal energy of the liquidvapor mixture.

For a constant volume process with no work being performed by the system, the time rate of change of energy can be expressed, from the first Law of Thermodynamics, as follows:

$$
\frac{d E}{d t}=\dot{q}+\sum_{j} w_{j} h_{j}-\sum_{i} w_{i} h_{i} \text {, }
$$

where:

$\dot{\mathrm{q}}=$ Heat transfer rate to the control volume from the surroundings.

$$
\begin{aligned}
& h_{j}=\begin{array}{l}
\text { Enthalpy of the entering fluid, } \\
\text { and }
\end{array} \\
& \mathrm{h}_{\mathrm{i}}=\text { Enthalpy in the control volume. }
\end{aligned}
$$

State Properties. The specific internal - energy of the saturated mixture in each control volume is obtained from Equation 4.60:

$$
u=\frac{E}{M} .
$$

The specific volume of the mixture, by definition. is

$$
v-\frac{V}{M}
$$

With the (wo state properties $v$ and u known. an incration morecture. using satarated 
properties from the steam tables, ${ }^{(3)}$ gives the saturated pressure of the mixture:

$$
P=P(v, u) .
$$

Liquid Water Level. The specific volume of fluid in each control volume is determined from the saturation pressure

$$
v_{f}=v_{f}(P) .
$$

The volume occupied by this liquid is given as

$$
\mathrm{v}_{\mathrm{f}}=\mathrm{M}_{\mathrm{f}} \mathrm{v}_{\mathrm{f}}
$$

If the cumulative volume of the control system is known as a function of elevation, then the level of the liquid is

$$
\dot{y}_{f}=y\left(V_{f}\right) \text {. }
$$

Mass Flow Rates. If the water level and saturated pressure within each control system are known, it is possible to determine the net mass exchange between corresponding control volumes. The direction of the flow is obtained from the magnitude of the total static pressure head above the flow passage between adjacent control volumes. Consider the typical case illustrated in the sketch below.
For this situation the total static head above the flow passage in $\mathrm{CV}_{\mathrm{i}}$ ( $\mathrm{CV}$ denotes control volume) is

$$
H_{i}=P_{i}+\left(\frac{y_{i}-1}{v_{f i}}\right) \frac{g}{g_{c}},
$$

where:

$$
\begin{aligned}
\mathrm{H}= & \text { Total head, } \\
\mathrm{l}= & \text { Elevation of flow passage, } \\
\mathrm{g}= & \begin{array}{l}
\text { Acceleration of gravity } \\
\left(32.2 \mathrm{ft} / \mathrm{sec}^{2}\right), \text { and }
\end{array} \\
\mathrm{g}_{\mathrm{c}}= & \begin{array}{l}
\text { Conversion factor } \\
\left(32.2 \mathrm{lb} \mathrm{m}^{-\mathrm{ft} /} / \mathrm{lb}_{\mathrm{f}}-\sec ^{2}\right)
\end{array}
\end{aligned}
$$

Similarly, the static head for $\mathrm{CV}_{\mathrm{j}}$ is

$$
H_{j}=P_{j}+\left(\frac{y_{j}-1}{v f_{j}}\right) \frac{g}{g_{c}} .
$$

The flow direction is determined by the larger of $\mathrm{H}_{\mathrm{i}}$ and $\mathrm{H}_{j}$, while the flow rate is proportional to the square-root of the difference between the two. Assume, for example, that $H_{i}>H_{j}$. For this case, the flow rate is from $\mathrm{CV}_{\mathrm{i}}$ to $\mathrm{CV}_{\mathrm{j}}$ with specific volume $\mathrm{v}_{\mathrm{fi}}$. The

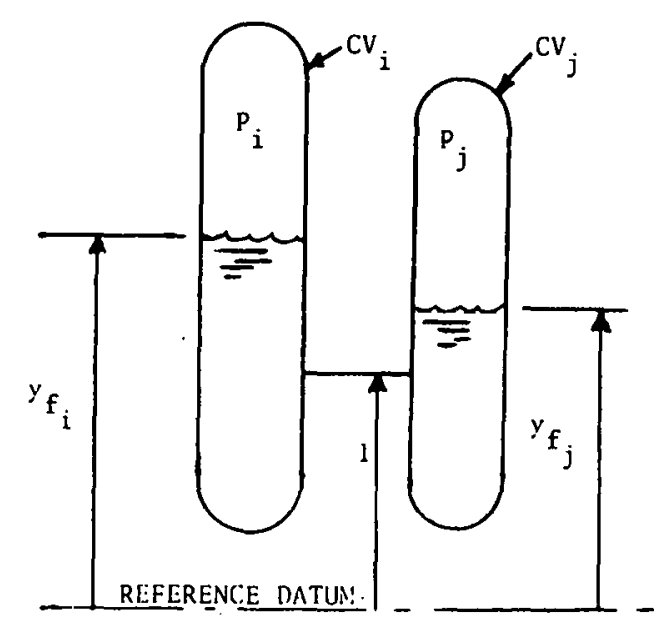


incompressible mass velocity is calculated from the following equation:

$$
G_{i j}=\sqrt{\frac{2 g\left(H_{i}-H_{j}\right)}{v_{f i} K}},
$$

where $K$ is a loss coefficient. If the area of the flow passage is $A$, then the mass flow rate is

$$
w_{i j}=A \cdot G_{i j} \text {. }
$$

As a second example, consider the following:

$$
\begin{aligned}
& y_{f i}<1 \\
& y_{f j}<1 \\
& P_{i}>P_{j} .
\end{aligned}
$$

Again the mass exchange is from $i$ to $\mathrm{j}$ : however, the flow will be steam with the saturated property $\mathbf{v}_{\mathrm{gi}}$. The same incompressible flow equation is used but the static fluid heads are not included. The mass velocity is

$$
G_{i j}=\sqrt{\frac{2{ }_{g}\left(P_{i}-P_{j}\right)}{v_{g i} K}},
$$

and the mass flow rate can again be found from Equation 4.71. In general when gas flow persists the pressure difference is only a small fraction of the absolute pressure of the gas. The initial values of saturation pressure used in this analysis are usually below 100 psia with pressure differences on the order of about 10 to 20 psi. Within this range, the incompressible flow equation can be used to approximate the gas flow rate; these calculated flow rates are, at most, 10 percent higher than if approximated by using a compressible flow equation.

\subsubsection{Numerical Solution}

The differential equations written for the mass and energy balance, i.e., Equations 4.59 and 4.61 were programmed for machine calculations using the numerical integration techniques uiscussed in Section 4.1.

\subsection{REACTOR CORE HEATUP ANALYSIS -M. J. May}

\subsubsection{General Considerations}

The analytical method used to calculate the reactor core thermal transient following a loss-of-coolant accident is described in this section. The fuel temperature, cladding temperature, channel temperature, and amount of metal-water reaction are calculated as functions of time from the start of the accident. In this analysis the power of decaying fission products, the chemical energy released by metal-water reactions, and the stored heat in the fuel, cladding, and other metal in the core are included as heat sources.

The fuel rods are classified such that those with similar power levels and fuel bundle locations are analyzed as a group. A one-dimensional heat balance is then written for cach type of fuel rod. Heat is transferred from the surface of the fuel rods by convection to the water, steam or hydrogen formed in the metal-water reaction. In addition, thermal radiation between fuel rods and from the rods to the channel is accounted for in the over-all heat balance.

\subsubsection{Theoretical Development}

A typical fuel rod consists of uranium dioxide fuel with a Zircaloy cladding. A fuel bundle consists of 36,49 , or 64 fuel rods, grouped together to form a square array which is surrounded by a metal channel. The fuel rods are divided into three radial temperature zones for the numerical calculations 
as shown in Figure 40. The cladding, on the other hand, is described by the average cladding temperature, with an outer surface temperature computed from the average temperature. The channel (Figure 41) is considered to be at a uniform temperature radially. The fuel rods within the channel are divided into four representative zones to describe the spatial variation of power generation. The entire reactor core is made up of several nundred fuel bundles and channels. To describe the radial variation of power generation, the core is divided into five radial zones. The fuel rods and channels are divided into five axial regions. Axial conduction between regions is neglected. Each channel is considered to be isolated from the rest of the core so that interactions between adjacent channels is neglected.

Heat Sources. The energy generated by delayed neutrons and decaying fission products is assumed to be unifor $m$ within a fuel rod and to have the same radial and axial variation within the core as the steady-state power distribution. The chemical energy released by the metal-water reaction is described by the parabolic rate law given by Baker, ${ }^{(4)}$ where the rate of change of the metal oxide thickness is written as

$$
\frac{\mathrm{d} \delta}{\mathrm{dt}}=\frac{\mathrm{Ke}}{\delta}{ }^{-\mathrm{D} / \mathrm{T}_{\mathrm{c}}}
$$

where:

$$
\begin{aligned}
& \mathbf{K} \quad=\text { Rate coefficient, } \\
& \mathbf{T}_{\mathbf{C}} \quad=\text { Cladding temperature, } \\
& \mathbf{D} \quad=\text { Activation coefficient, and } \\
& \delta \quad=\text { Oxide thickness. }
\end{aligned}
$$

The heat generation rate and hydrogen release rate are proportional to the rate of change of oxide generated. The chemical heat liberated is given as follows:

$$
\frac{\mathrm{dQ}}{\mathrm{dt}}=\frac{\mathrm{d} \delta}{\mathrm{dt}} \Delta \mathrm{H} \rho_{\mathrm{c}} \mathrm{A}_{\mathrm{s}},
$$

where:

$$
\begin{aligned}
& \Delta H \quad=\text { Heat of reaction, } \\
& \rho_{c} \quad=\text { Density of metal, and } \\
& A_{S} \quad=\text { Exposed surface area of oxide. }
\end{aligned}
$$

The mass rate of hydrogen generated is

$$
\frac{\mathrm{dW}_{\mathrm{H}}}{\mathrm{dt}}=2 \frac{\mathrm{d} \delta}{\mathrm{dt}} \rho_{\mathrm{c}} \mathrm{A}_{\mathrm{s}} \frac{\mathrm{N}_{\mathrm{H}_{2}}}{\mathrm{~N}_{\text {METAL }}}
$$

where:

$$
\begin{aligned}
& \mathrm{W}_{\mathrm{H}}=\text { Mass of hydrogen generated, } \\
& \mathrm{N}=\text { Molecular weight. }
\end{aligned}
$$

The above reaction rate considers that there is an unlimited source of saturated steam available for the reaction. The empirical reaction constants, $K$ and $D$, are based upon experimental data obtained under conditions where the metal and water are at the same temperature. Therefore, for Equation 4.73 to be correct the water must be heated to the cladding temperature. The energy required to heat this water is deducted from the total chemical energy added to the system.

Steam Cooling During Blowdown. During the blowdown large quantities of water are flashed into steam, which, if free to flow upward 


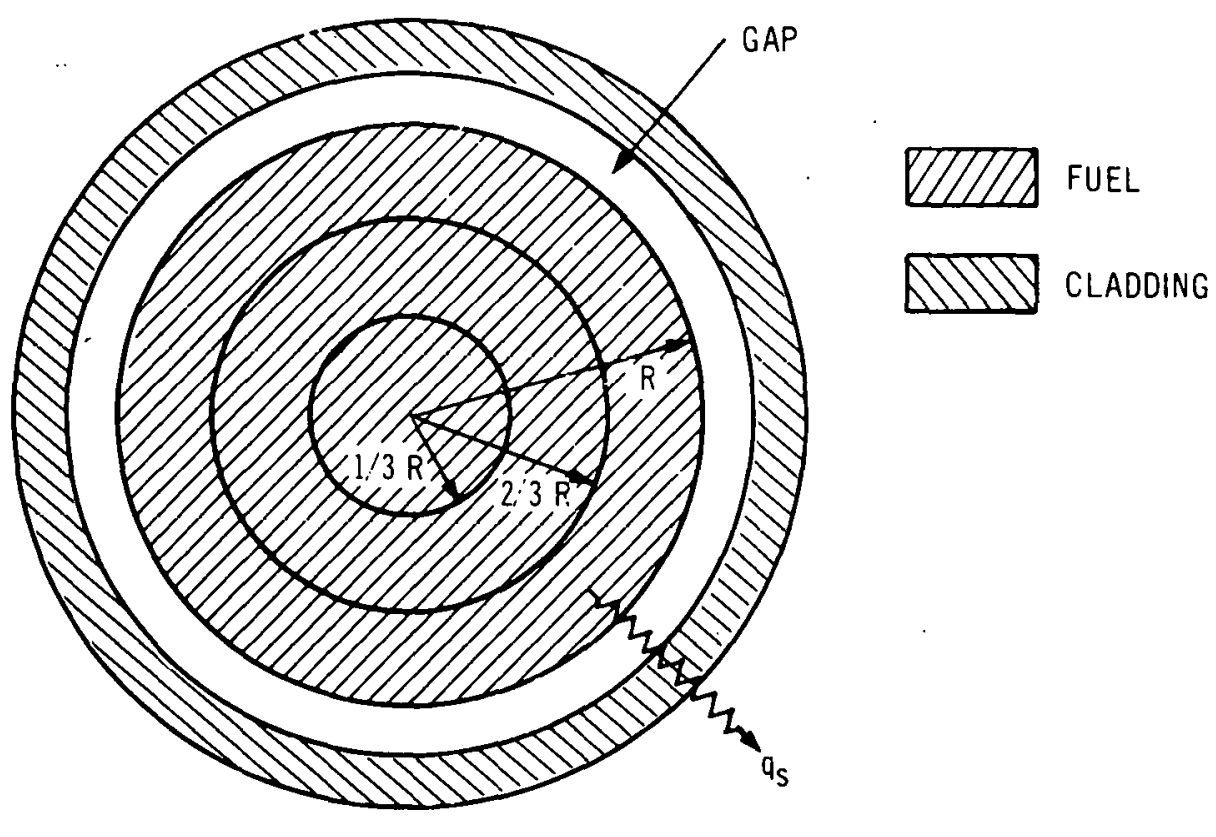

FIGURE 40. FUEL ROD DETAIL

CHANNEL CROSS SECTION

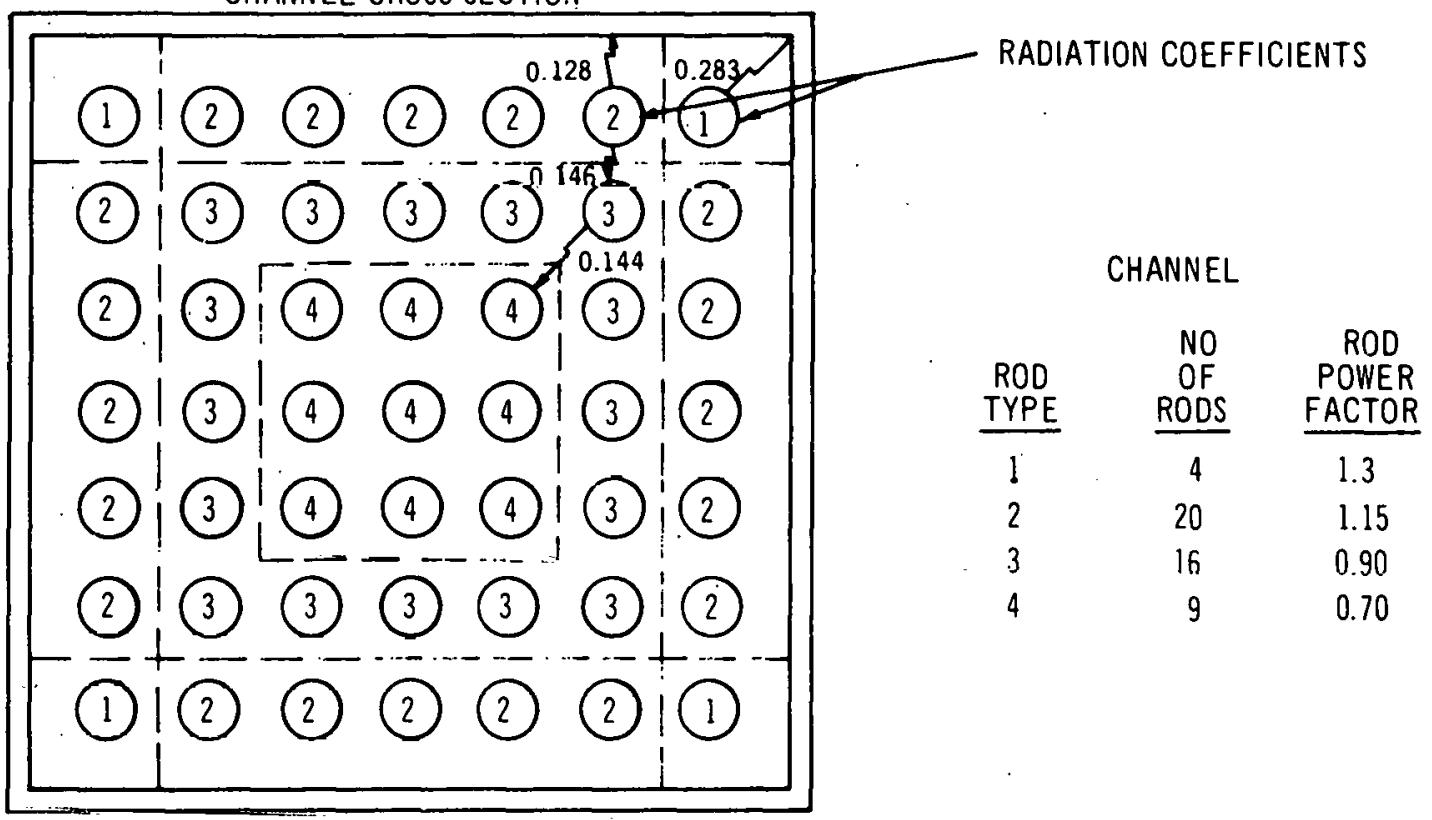

FIGURE 41. FUEL BUNDLE DETAIL 
through the core, can remove a considerable amount of heat. The heat transfer coefficient for flowing steam is obtained from the Dittus Boelter correlation, ${ }^{(5)}$ where the Nusselt number for turbulent flow is given by

$$
\mathrm{Nu}=0.0243(\mathrm{Re})^{0.8}(\mathrm{Pr})^{0.4},
$$

where:

$$
\begin{aligned}
& \text { Re } \quad=\text { Reynolds number, and } \\
& \mathrm{Pr} \quad=\text { Prandtl number } .
\end{aligned}
$$

The heat transfer coefficient is then obtained from the relationship

$$
\mathrm{h}=\frac{\mathrm{Nu} \mathrm{D}_{\mathrm{H}}}{\mathrm{k}} \text {, }
$$

where:

$$
\begin{aligned}
& \mathbf{k} \quad=\text { conductivity, and } \\
& \mathrm{D}_{\mathrm{H}} \quad=\text { Hydraulic diameter } .
\end{aligned}
$$

The steam cooling is considered only when there is an opening above the core for the steam to freely escape, such as a steam line break or open automatic blowdown vent. Steam cooling for flashing rates less than 1000 pounds of steam per second are ignored.

Conduction Heat Transfer. The heatup analysis considers only radial conduction of heat from the fuel to the cladding surface. Axial conduction along the fuel rods or to support structures is neglected. Resistance to heat flow through the fuel-cladding gap is taken into account.

Convection Heat Transfer. Heat is transferred from the cladding and channel to the surrounding fluid by thermal radiation and convection. During the blowdown a convection heat transfer coefficient must be calculated. The water level is calculated from the mass inventory in the reactor vessel during the blowdown. If the core is more than one-half covered with water, the heat transfer coefficient is obtained from the Jens-Lottes correlation for boiling heat transfer:

$$
h=\frac{e^{P / 900}}{1.829}\left(Q_{s}\right)^{0.75}
$$

where:

$$
\begin{aligned}
& \mathbf{P} \quad=\text { Reactor pressure, and } \\
& \mathbf{Q}_{\mathbf{S}} \quad=\text { Surface heat flux. }
\end{aligned}
$$

From experimental work previously performed at General Electric, it has been demonstrated that the full length of a fuel bundle is adequately cooled if the water level is as high as the core midpoint, or even less. To make use of this fact, Equation 4.77 is used to describe the heat transfer coefficient if the calculated water level is above the core midpoint. When water level drops below the core midpoint, the core is treated as being completely uncovered and the heat transfer rate diminishes to zero. For large breaks in the steam or recirculation line, the heatup analysis uses the dryout correlation for the heat transfer coefficient. The dryout correlation, based on experimental work done at General Electric shows that boiling water heat transfer according to Equation 4.77 exists up to the "dryout time" for large breaks. After this, the heat transfer coefficient diminishes inversely proportional to the time after dryout. The dryout times are a function of the initial thermal-hydraulic conditions existing in each bundle at the start of the accident and are usually of the order of 1 to 3 seconds. The heatup analysis uses the dryout correlation if the calculated core uncovery time is of the same magnitude as the calculated dryout time, such that more heat is transferred using the dryout correlation; i.e., the dryout model represents the worst case for heat transfer with the largest 
breaks. The dryout correlation can be expressed analytically as

$$
\begin{aligned}
& \frac{\mathrm{h}}{\mathrm{h}_{\mathrm{B}}}=1, \quad \mathrm{t} \leq \theta, \text { or } \\
& \frac{\mathrm{h}}{\mathrm{h}_{\mathrm{B}}}=\mathrm{f}(\mathrm{t}), \quad \theta \leq \mathrm{t},
\end{aligned}
$$

where:

$$
\theta \quad=\text { Dryout time. }
$$

Details of the dryout time, $\theta$, and the decaying function, $f(t)$, can be found in Reference 6 .

Radiation. Thermal radiation between fuel rods and the fuel channel box is permitted if they are not covered with water. To simplify calculations, the fuel rods are grouped into four groups. Figure 41 shows the channel configuration. Group 1 rods exchange radiation with the channel only. Group 2 rods exchange radiation with the channel and Group 3 rods. Group 3 rods exchange radiation with Group 2 rods and Group 4 rods only. Finaliy, Group 4 rods exchange radiation only with Group 3 rods. View factors are also calculated for each group of rods.

Figure 41 illustrates typical radiation factors and rod powers.

Method of Solution. The fuel, cladding, and channel temperature are calculated at each time step by considering the aforementioned energy consideration. All temperatures are integrated using a simple Euler forward difference method:

$$
\Phi(t+\Delta t)=\Phi(t)+\frac{d \Phi(t)}{d t} \Delta t
$$

All physical properties are considered constant with temperature and time. The model utilizes the calculated histories of pressure, water level, and heat transfer coefficients. The sink temperature for all convective heat transfer calculations is determined by the saturation temperature at the given pressure.

Comparison With Work of Others. A direct comparison between this core heatup analysis and that of other investigators will provide a basis for evaluation of the conclusions reached as a result of this analysis.

Morrison, et al. (7) ${ }^{(7)}$ port results obtained at Battelle Memorial Institute from analysis of a loss-of-coolant accident for a $50.7 \mathrm{~kW} / 1,1000 \mathrm{MWe}$ BWR using the NURLOC computer code. The results were compared with the 5.5-sq-ft recirculation line break for Reference System II with $50.7 \mathrm{~kW} / \mathrm{l}$ power density. The comparison is shown in Figures 42 and 43 .

As is apparent from Figure 42, the cladding temperature results are quite similar for the first 150 seconds. However, after 150 seconds, this analysis shows a rapid increase in cladding temperature which results in cladding melting $\left(3370^{\circ} \mathrm{F}\right)$ at about 210 seconds. In contrast, the NURLOC analysis indicates that the cladding melting: temperature is not reached until 350 seconds. This significant difference in elapsed time before melting of the fuel cladding appears to be a direct result of the fact that NURLOC uses a more sophisticated description of the metal-water reaction. As indicated by Walters and Genco. ${ }^{(8)}$ the effect of hydrogen blanketing of the fuel rod during the metalwater reaction is accounted for by NURLOC: that is, the amount of steam in contact with zirconium is limited by formation of a hydrogen layer on the surface of the fuel rod. In this analysis, the conservative assumption is made that there is unlimited steam available for the metal-water reaction. The result is that our analysis predicts a much higher metal-water reaction rate and, therefore, higher tomperatures in the cladding. 


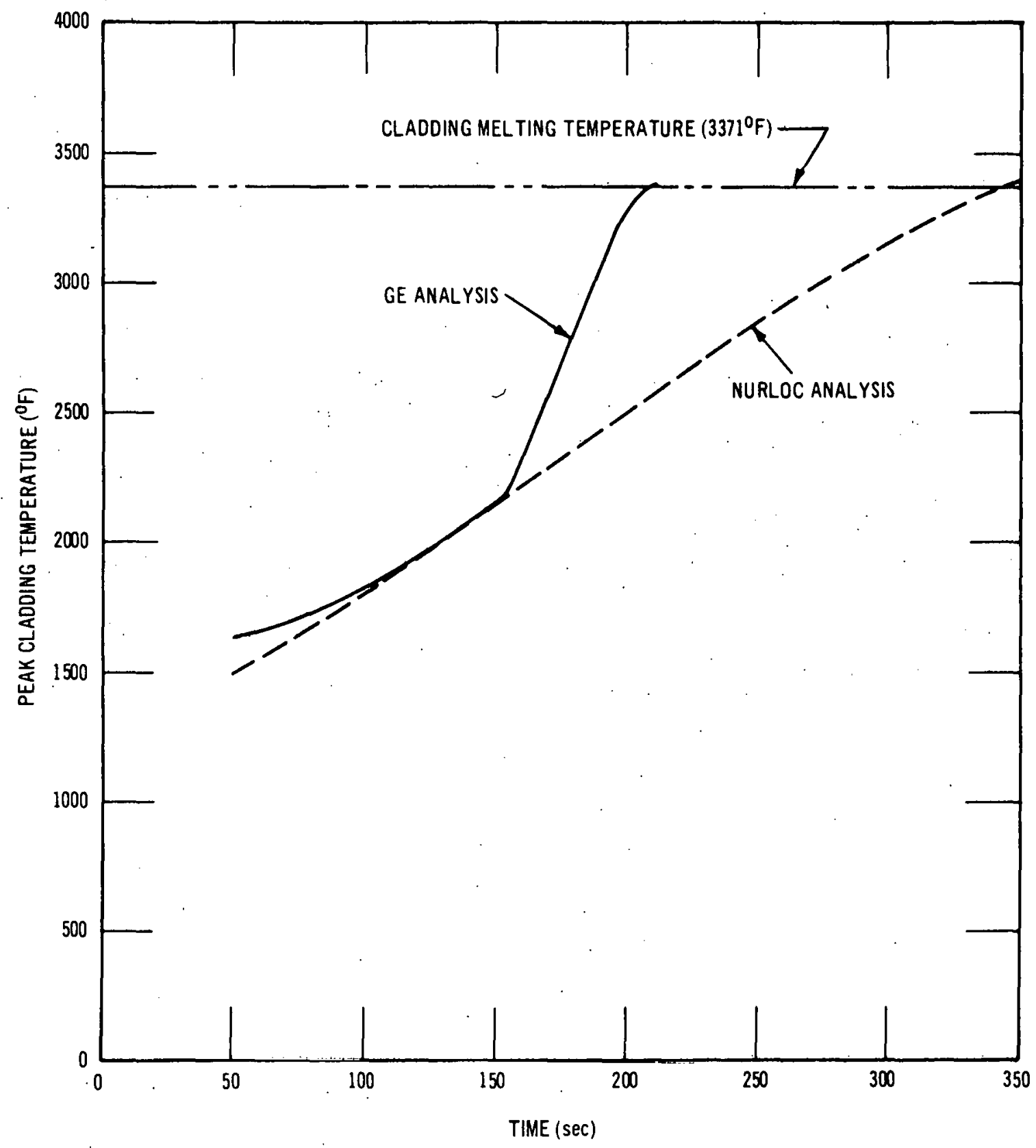




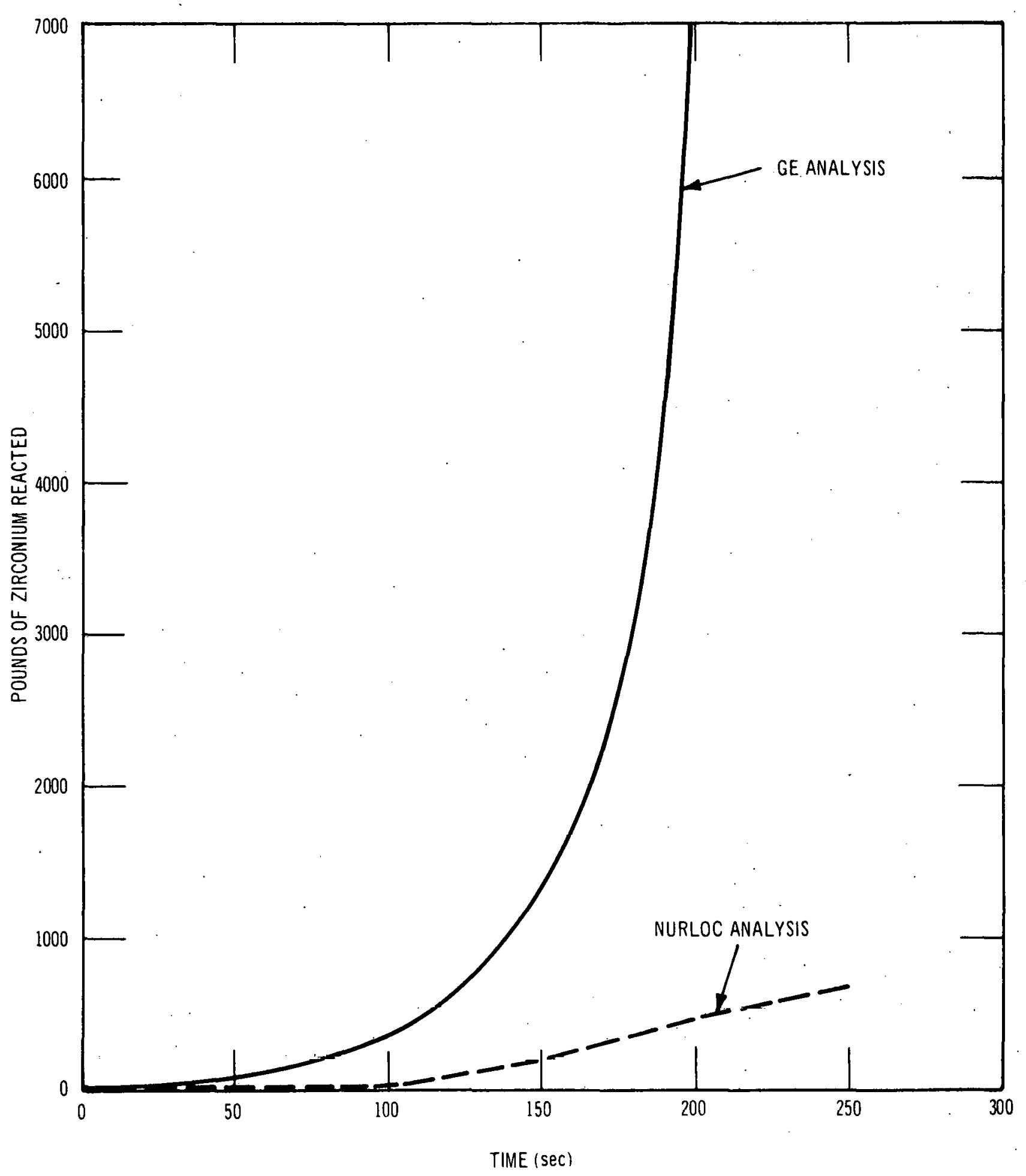

FIGURE 43. POUNDS OF ZIRCONIUM REACTED VERSUS TIME-COMPARISON OF GE ANALYSIS WITH NURLOC ANALYSIS 
This result is indicated by the curves in Figure 43 .

In Reference 8 , Figure 20, page 65, there is a plot of temperature versus time for a LOFT top-break accident showing the effect of metal-water reaction with unlimited steam compared to that with limited steam due to hydrogen blanketing. The fact that this plot is very similar to that of Figure 42 supports the conclusion that the major difference between the NURLOC analysis and this analysis is in the treatment of steamzirconium contact for the metal-water reaction.

An additional comparison of core heatup analyses has been made with the analytical results obtained at Argonne National Laboratory, reported in ANL-7342. ${ }^{(9)}$ The loss-ofcoolant accident which they investigated using a digital computer program entitled CHEMLOC-II has been taken to be a "maximum credible accident" of a $2255 \mathrm{MWt}$ BWR. The CHEMLOC-II core heatup results have been compared with the results for the 5.5-sq-ft recirculation line break for Reference System I. The maximum cladding temperature and the amount of metal-water reaction versus time for both analyses are shown in Figures 44 and 45 . Figure 44 illus-. trates that results again show a more rapid increase in cladding temperatures: initiation of cladding melting occurs at about $135 \mathrm{sec}-$ onds as opposed to 500 seconds in the CHEMLOC-II analysis. The difference may be attributed to the greater sophistication of the CHEMLOC analysis. This difference in elapsed time is better explained by the comparison shown in Figure 45. As discussed earlier, the General Electric analysis assumes that there is an unlimited steam supply avail able for metal-water reaction. CHEMLOC considers hydrogen-blanketing of the rods with a limited amount of steam flow past these rods and, consequently, results in much less metal-water reaction. It follows that with more metal-water reaction, the cladding temperature will increase more rapidly.

It should be pointed out that for prediction of time to initiate cladding melting, our analysis is conservative; that is, the assumption of unlimited steam for metal-water reaction tends to produce higher core temperatures with the result that the cladding melting temperature is observed sooner after initiation of the loss-of-coolant accident. 


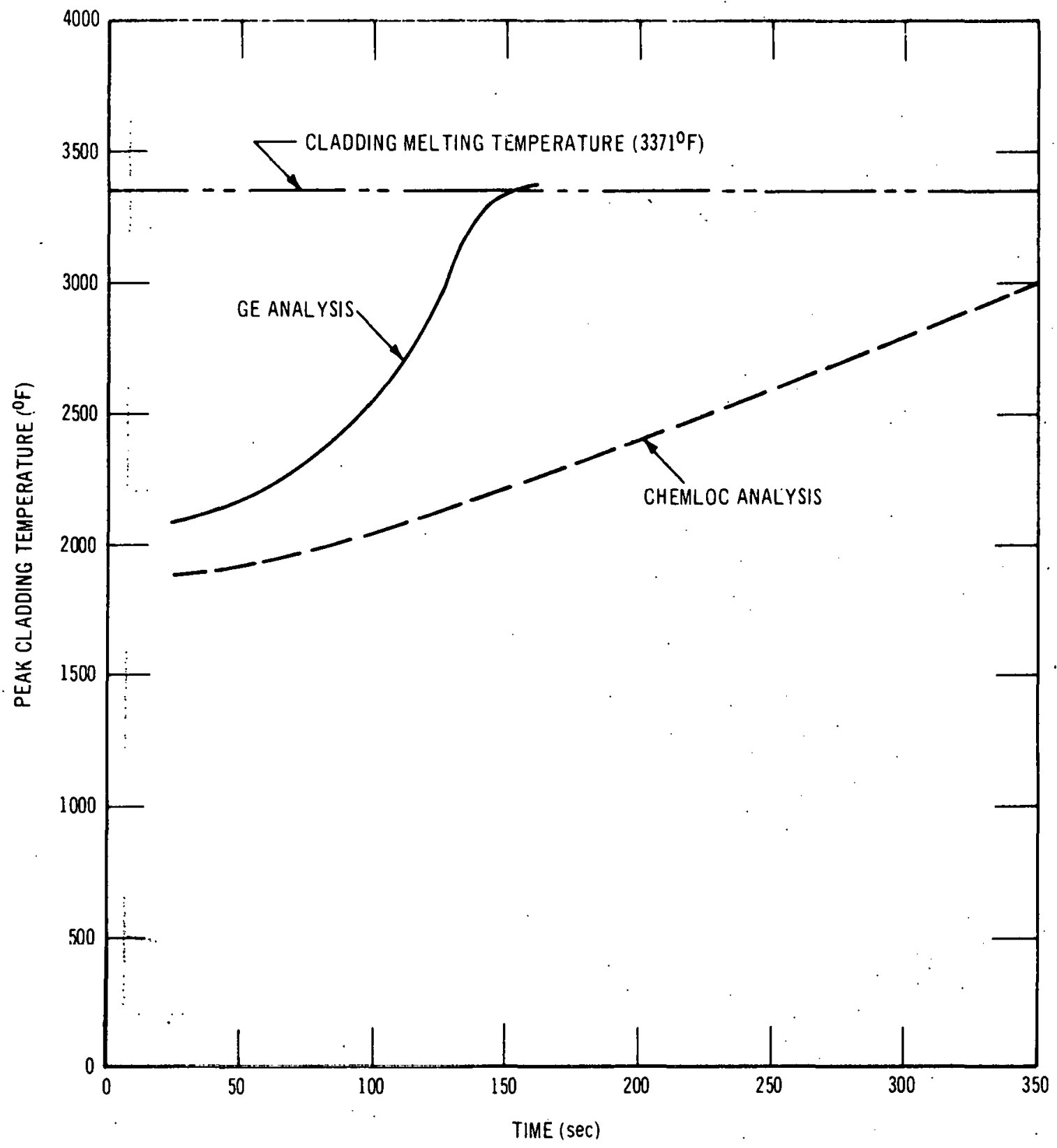




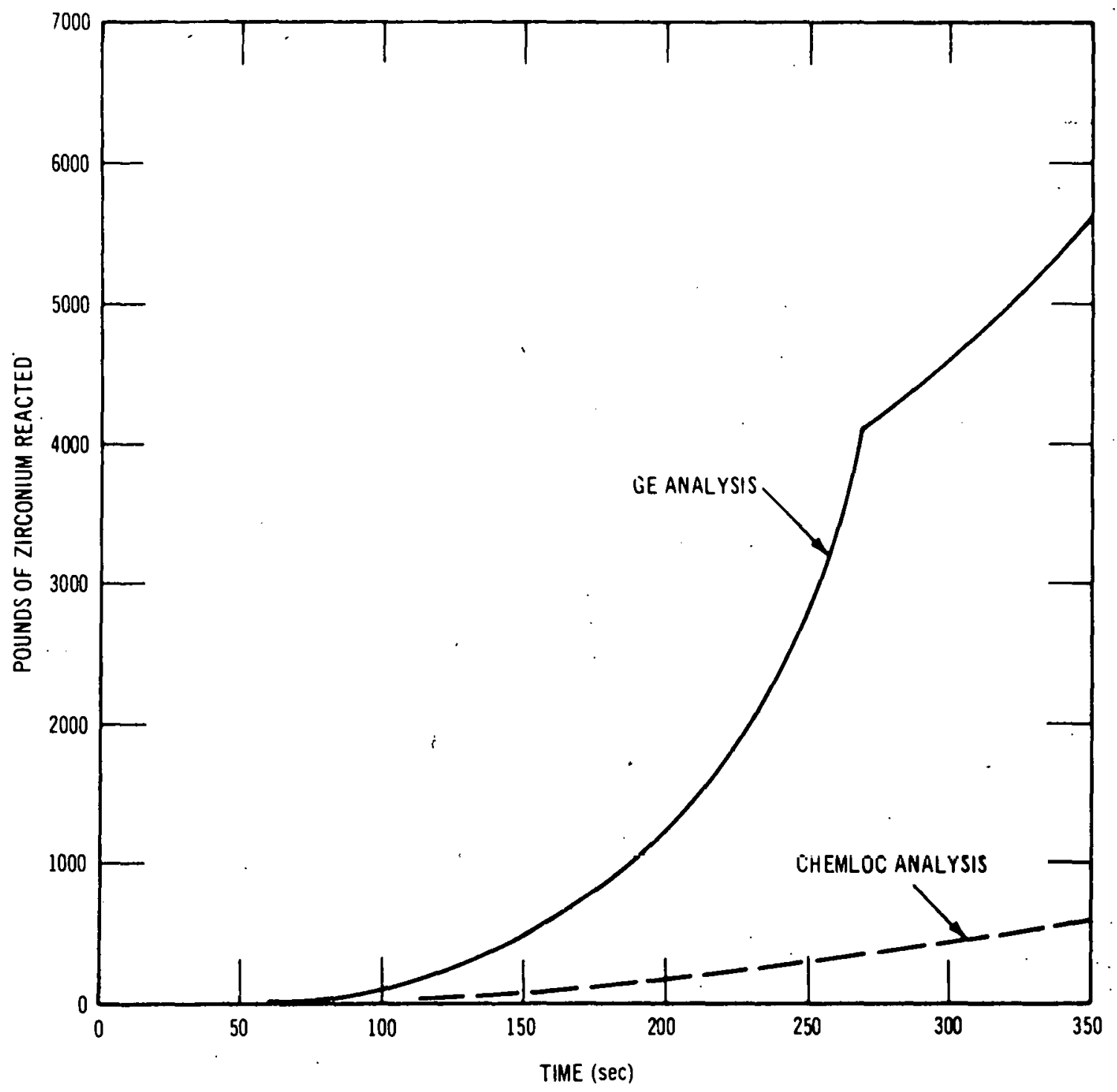




\section{NOMENCLATURE}

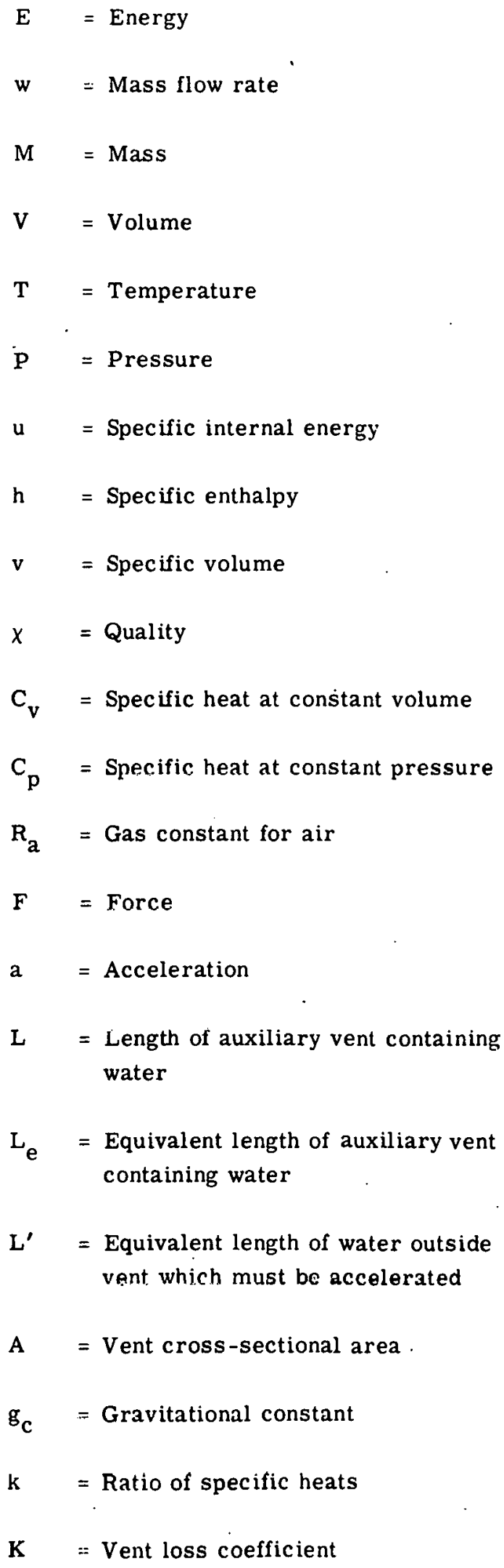

$\mathrm{E} \quad=$ Energy

$\mathrm{w} \quad=$ Mass flow rate

$\mathrm{M} \quad=$ Mass

$\mathrm{V}=$ Volume

$\mathrm{T}=$ Temperature

p $=$ Pressure

$\mathbf{u} \quad=$ Specific internal energy

$\mathrm{h} \quad=$ Specific enthalpy

$\mathrm{v} \quad=$ Specific volume

$x=$ Quality

$C_{v}=$ Specific heat at constant volume

$C_{p}=$ Specific heat at constant pressure

$R_{a}=$ Gas constant for air

$F \quad=$ Force

a $\quad$ Acceleration

$\mathrm{L}=$ Length of auxiliary vent containing water

$\mathrm{L}_{\mathrm{e}} \quad=$ Equivalent length of auxiliary vent containing water

$L^{\prime} \quad=$ Equivalent length of water outside vent which must be accelerated

A = Vent cross-sectional area.

$\mathrm{g}_{\mathbf{c}}=$ Gravitational constant

$\mathbf{k} \quad=$ Ratio of specific heats

K = Vent loss coefficient

$\mathrm{T}_{\mathrm{a}}=$ Temperature of air after bubbling through pool

A $=$ Flow area

$y \quad=$ Liquid level

$\mathrm{H}=$ Total static pressure head for gravity flooding analysis

$\mathrm{z} \quad=$ Elevation of penetration

$\rho \quad=$ Density

\section{Subscripts}

D = Drywell

$\mathrm{S} \quad=$ Suppression chamber

L $\quad=$ Floodpool

w $\quad=$ Water (vapor plus liquid)

$\mathrm{a} \quad=.4 \mathrm{ir}$

f. $\quad=$ Liquid

g $=$ Vapor

$\mathrm{H}=$ Static pressure head due to water

R - Rupture disk

$\mathrm{T} \quad-$ Total

1 = Flow into drywell

$2=$ Flow out of drywell

j ' = Flow into control volume

i $=$ Flow out of control volume 


\section{REFERENCES}

1. Moody, F. J., "Maximum Two-Phase Vessel Blowdown From Pipes," APED-4827 (April 1965).

2. Martinelli, R. C., and Nelson, D. B., "Prediction of Pressure Drop During Forced Circulation Boiling of Water," Trans. ASME, Aug. 1948, p 695.

3. Keenan, J. H., and Keyes, F. G., Thermodynamic Properties of Steam, John Wiley and Son, Inc., New York, N. Y., 5th Edition (1945).

4. Baker, L. J., and Ivins, R. O., "Analyzing the Effects of a ZirconiumWater Reaction, " Nucleonics, 23 (7), 70-74 (July 1965).

5. Eckert, E.R.G. and Drake, R. M., Jr. Heat \& Mass Transfer, p 211, McGrawHill (1957).
6. Dresden Nuclear Power Station, Unit No. 2, Facility Description \& Safety Analysis Report, Amendment 5, Commonwealth Edison Co.

7. Morrison, D. L., et al., "An, Evaluation of the Applicability of Existing Data to the Analytical Description of a Nuclear Reactor Accident," BMI-1797 (April 1, 1967).

8. Walters, C. J., and Genco, J. M., "NURLOC-1.0: A Digital Computer Program for Thermal Analysis of a Nuclear-Reactor Loss-of-Coolant Accident," BMI-1807 (July 6, 1967).

9. 'Reactor Development Program Progress Report, " Argonne National Laboratory, ANL-7342, (May 1967).

\section{EXT ERNAL DISTRIBUTION}

Mr. Milton Shaw, Director Division of Reactor Development and Technology, U.S. Atomic Energy Commission

Washington, D.C. 20545

Dr. J. A. Liberman, Assistant Director for Nuclear Safety Division of Reactor Development and Technology, U.S. Atomic Energy Commissinn Washington, D.C. 20545

Mr. D. E. Williams, Director for Reactor Safety, Idaho Operations Office, U.S. Atomic Energy Commission Idaho Falls, Idahu 83401
Mr. N. K. Sowards, Manager Plant Applications and Engineering Test Branch, Atomic Energy Division Phillips Petroleum Co. P. O. Box 2067 GDF 613 Idaho Falls, Idaho 83401 